\title{
Learning from preclinical patient contacts
}

Citation for published version (APA):

Diemers, A. D. (2014). Learning from preclinical patient contacts. [Doctoral Thesis, Maastricht University]. Maastricht University. https://doi.org/10.26481/dis.20141003ad

Document status and date:

Published: 01/01/2014

DOI:

10.26481/dis.20141003ad

Document Version:

Publisher's PDF, also known as Version of record

\section{Please check the document version of this publication:}

- A submitted manuscript is the version of the article upon submission and before peer-review. There can be important differences between the submitted version and the official published version of record.

People interested in the research are advised to contact the author for the final version of the publication, or visit the DOI to the publisher's website.

- The final author version and the galley proof are versions of the publication after peer review.

- The final published version features the final layout of the paper including the volume, issue and page numbers.

Link to publication

\footnotetext{
General rights rights.

- You may freely distribute the URL identifying the publication in the public portal. please follow below link for the End User Agreement:

www.umlib.nl/taverne-license

Take down policy

If you believe that this document breaches copyright please contact us at:

repository@maastrichtuniversity.nl

providing details and we will investigate your claim.
}

Copyright and moral rights for the publications made accessible in the public portal are retained by the authors and/or other copyright owners and it is a condition of accessing publications that users recognise and abide by the legal requirements associated with these

- Users may download and print one copy of any publication from the public portal for the purpose of private study or research.

- You may not further distribute the material or use it for any profit-making activity or commercial gain

If the publication is distributed under the terms of Article $25 \mathrm{fa}$ of the Dutch Copyright Act, indicated by the "Taverne" license above, 


\section{LEARNING FROM PRECLINICAL PATIENT CONTACTS}

Agnes Dorothy Diemers 
The research reported here was carried out at Maastricht University in Learning!

in the School of Health Professions Education

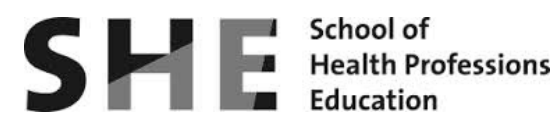

ISBN: 9789090284392

Design and lay out: Marleen Zoon, Groningen 2014

Print: Ten Brink, Meppel 2014

Copyright (C) Agnes D. Diemers, Maastricht 2014. All rights reserved. 


\title{
LEARNING FROM PRECLINICAL PATIENT CONTACTS
}

\author{
PROEFSCHRIFT \\ ter verkrijging van de graad van doctor aan de Universiteit Maastricht, \\ op gezag van de Rector Magnificus, Prof. Dr. L.L.G. Soete, \\ volgens het besluit van het College van Decanen, \\ in het openbaar te verdedigen op \\ vrijdag 3 oktober 2014 om 14:00 uur \\ door \\ Agnes Dorothy Diemers
}




\section{Promotoren}

Prof. dr. D.H.J.M. Dolmans

Prof. dr. A.J.J.A. Scherpbier

\section{Copromotor}

Dr. M.W.J. van de Wiel

\section{Beoordelingscommissie}

Prof. dr. M.G.A. Oude Egbrink (voorzitter)

Prof. dr. H.P.A. Boshuizen (Open Universiteit Heerlen)

Prof. dr. A.D.C. Jaarsma (Universitair Medisch Centrum Groningen)

Prof. dr. R.P. Koopmans

Dr. R.E. Stalmeijer 


\section{TABLE OF CONTENTS}

Chapter 1 General introduction 7

Chapter 2 Students' perceptions about the transition to the clinical phase of a medical curriculum with preclinical patient contacts;

a focus group study

BMC Medical Education 2010; 10: 28

Chapter 3 Students' perceptions of early patient encounters in a PBL curriculum: a first evaluation of the Maastricht experience Medical Teacher 2007; 29: 135-14

Chapter 4 Students' opinions about the effects of preclinical patient contacts on their learning Advances in Health Sciences Education 2008; 13: 633-647

Chapter 5 Preclinical patient contacts and the application of biomedical and clinical knowledge

Medical Education 2011; 45: 280-288

Chapter 6 Effects of problem-based tutorials with real patients on the development of students' diagnostic reasoning and underlying knowledge

Submitted

Chapter 7 General discussion

Chapter 8 Summary

Samenvatting (Summary in Dutch)

Dankwoord (Acknowledgements)

Curriculum Vitae

SHE dissertations series 


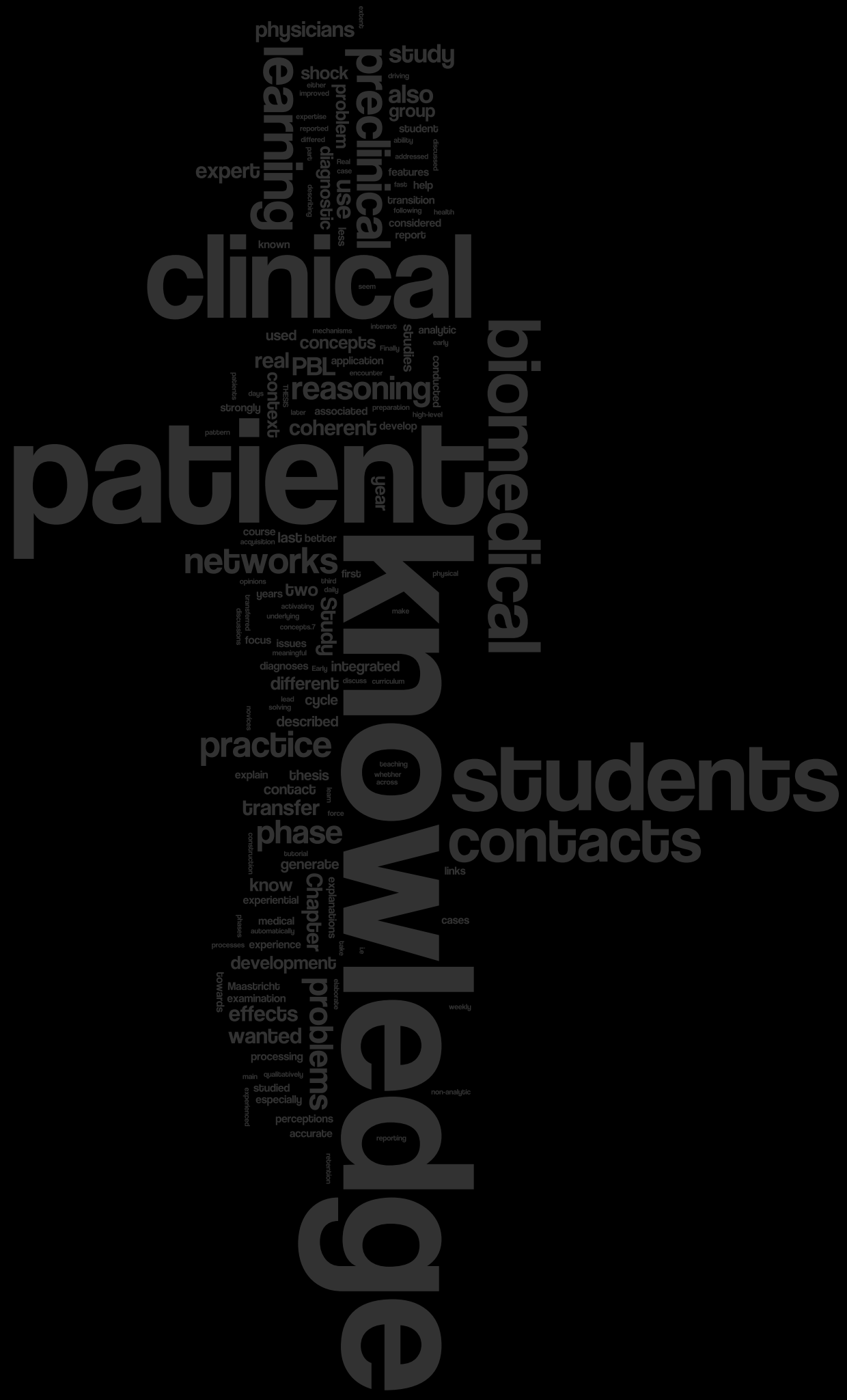


CHAPTER 1

General introduction

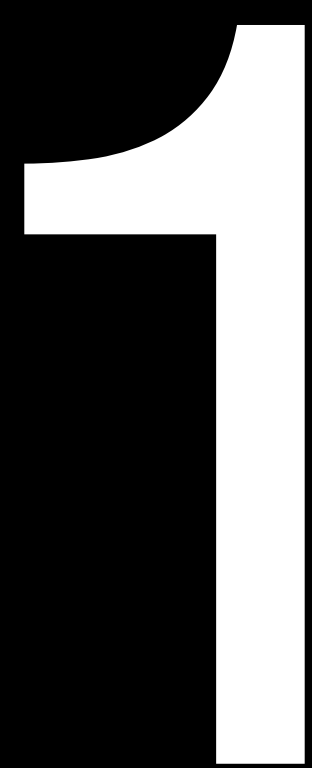




\section{THEORETICAL BACKGROUND}

Until recently most medical curricula were characterized by a sharp distinction between the preclinical years and the clinical phase. During the preclinical years students predominantly study biomedical and clinical knowledge, whereas during the clinical phase they mainly learn in the clinical context of teaching hospitals and health communities. This resulted in students experiencing the transition from the preclinical to the clinical phase known as 'thrown in at the deep end', also described as 'the shock of practice'. ${ }^{1-4}$ When students enter the clinical workplace they show a temporary decrease in their ability to adequately use biomedical knowledge in clinical reasoning. ${ }^{2}$ It was thought that the implementation of Problem Based Learning (PBL) would alleviate this 'shock of practice', by enhancing the ability to link theoretical knowledge to clinical knowledge. ${ }^{5}$ However, it was reported that despite the use of PBL, students still experience difficulties in identifying meaningful links between theory and practice and in transferring biomedical knowledge to clinical problems., ${ }^{4,6}$

Research on medical expertise has shown that expert physicians have access to elaborate and integrated coherent knowledge networks, which enable them to generate more accurate diagnoses in a shorter time. ${ }^{7,8}$ Additionally, when solving patient problems they use less biomedical knowledge and generate qualitatively better explanations of patient features that are less elaborate than those of novices and intermediates. ${ }^{7,9,10}$ When students, being novices, are encouraged to develop more integrated and coherent knowledge networks, they also generate more accurate diagnoses and show a better retention and recall of knowledge like expert physicians do..$^{11,12}$ It is therefore important that students, in their growth towards expertise, develop integrated and coherent knowledge networks. The knowledge networks of expert physicians consist of biomedical, clinical and experiential knowledge that closely interact when activated during clinical reasoning processes., ${ }^{7,13}$ Biomedical knowledge is all knowledge describing the functioning and malfunctioning of the human body (i.e. knowledge about anatomy, physiology, biochemistry, pathophysiology and pharmacology) and is used to link and explain clinical features. ${ }^{7,11,12}$ Clinical knowledge comprises formal and informal clinical knowledge.

Formal clinical knowledge is knowledge about the manifestations and courses 
of diseases, predictive test values, and methods for examination and treatment strategies. ${ }^{7,14,16}$ Informal knowledge, also known as experiential knowledge, refers to the episodic memories of previously encountered patients. ${ }^{14}$

Since experienced physicians hardly seem to use any biomedical knowledge in daily practice, the role of biomedical knowledge in the knowledge networks of expert physicians has been investigated. ${ }^{10,17,18}$ Through repeated application of knowledge and practice with real patients, biomedical knowledge is considered to be encapsulated into high-level clinical concepts. ${ }^{7,9}$ With increasing experience, the links between high-level concepts and other clinical concepts in the knowledge networks become much stronger than the links between clinical and biomedical concepts. ${ }^{7,19}$ So, although biomedical knowledge is activated alongside clinical knowledge during diagnostic reasoning ${ }^{20}$, the activation level of the biomedical concepts is not strong enough to be part of the mental representation of the patient problem, especially when case processing is fast.

Case processing is fast when expert physicians are solving routine noncomplex problems. They quickly arrive at accurate diagnoses, unconsciously and automatically activating strongly associated clinical knowledge. This nonanalytic reasoning process is also interpreted as pattern recognition. ${ }^{16,21,22}$ When faced with non-routine cases though, such as difficult or rare and complex problems, expert clinicians do not automatically form a coherent representation of the patient problem and case processing takes more time. They then return to analytic reasoning processes, consciously and deliberately activating not only strongly associated clinical concepts, but also less strongly associated biomedical concepts, used to explain the patient feature. ${ }^{7,13,21}$ Although analytic and non-analytic reasoning are described as two different processes both are considered to interact continuously during daily practice. The type of patient problem and the familiarity of the physician with the problem at hand determine if the process either moves more towards pattern recognition or towards analytic reasoning. ${ }^{23,24}$

To help students to integrate biomedical knowledge into knowledge networks that can be applied in and transferred to different patient problems and to overcome the 'shock of practice, various authors have proposed exposing students to varied and real patient problems early in their medical education..$^{3,4,25,26}$ Early experience is defined by Dornan et al. as pre-clerkship experiences with authentic patient 
contacts in a clinical context that enhances learning'. ${ }^{26}$ Additionally, experiential learning is 'situated' in a context relevant to learners' own future careers, which gives an opportunity for transfer of knowledge. ${ }^{27}$ Real patient contacts have several beneficial effects. They motivate students to learn, have positive effects on professional socialization, make students feel more comfortable performing physical examination and make students more aware of the impact of illness on patients. ${ }^{1,3,26,28-30}$ They also help students to align themselves with patient and community perspectives on health care provision and to focus on patientcentered communication. ${ }^{31}$ Moreover, they are regarded as a powerful driving force for meaningful and profound learning. ${ }^{1,3,5,32,33}$ Real patient contacts seem to lead to improved acquisition and retention of knowledge, to contextualization of basic science knowledge, to promoting the formation of coherent and integrated knowledge networks, and to making learning more relevant. ${ }^{1,3,28,33-36}$

Early patient contacts and PBL are assumed to help students develop coherent knowledge networks, including biomedical mechanisms, which can be applied in and transferred to different patient problems.

\section{RATIONALE FOR THESIS AND RESEARCH QUESTIONS}

It is not clear if a PBL-based curriculum with preclinical patient contacts does overcome the 'shock of practice'. Nor is it known how students perceive such contacts in regard to their learning and knowledge construction. Furthermore, no research has been done into the acquisition of biomedical and clinical knowledge and the development of knowledge networks when students are exposed to preclinical patient contacts as a starting point for learning. Do preclinical patient contacts indeed lead to improved diagnostic reasoning, qualitatively better explanations of patient features and transfer of knowledge within and across patient problems? So the main question addressed in this thesis is: What is the effect of preclinical real patient contacts that act as a starting point for learning, on student learning?

We first wanted to know students' perceptions about the effects of preclinical patient contacts on their transition to the clinical context and on their learning. Secondly we wanted to know what the effects of preclinical patient contacts are on the development and transfer of knowledge, especially on the use and 
application of biomedical and clinical knowledge and on students' diagnostic reasoning and the underlying knowledge.

\section{CONTEXT}

The studies described in this thesis were conducted in the third year, i.e. the last preclinical year, of the problem-based, 6-year curriculum at Maastricht Medical School. In this year, the paper patient problems as used in the first two years are replaced by real patient contacts. Students prepare for and report on the patient contacts in weekly tutorial group meetings, consisting of 10 students and a tutor. The PBL cycle in year three has four phases. The patient contacts are prepared for prior to the encounter, using short vignettes describing the patient problem the students will face (preparation phase). One to two days later they see the patient, in pairs, at the teaching outpatient clinics at Maastricht University Hospital. Each student pair sees a different patient and they take the patients' history and perform a physical examination (patient contact phase). The students discuss the encounter afterwards with their clinical supervisor (patient contact phase) to generate learning issues to be studied during the following days (study phase). During the following tutorial meeting, one week later, they present their patient and they discuss their studied learning issues (reporting phase). The weekly tutorials take about 4 hours. The first 3 hours are dedicated to the reporting of the patient problems and the studied learning issues, and the last hour is devoted to the preparation on the next patient contact.

\section{OUTLINE OF THE THESIS}

To seek students' perceptions about the effects of preclinical patient contacts on the transition from preclinical to clinical training and on their learning we performed three studies. Chapter 2 describes Study 1, a focus group study, in which we sought students' opinions about how they experienced the so called 'shock of practice' when they entered the clinical context and their views on how these early patient contacts prepared them for clinical practice. In Chapter 3 we report on Study 2, which was a questionnaire survey to study students' perceptions of their learning organized around the PBL cycle, with the real patient 
contact as a driving force for student learning. Whereas Study 2 focuses on student-learning around the PBL cycle, in Study 3, described in Chapter 4, focus group interviews were conducted to reveal students' opinions about the effects of preclinical real patient contacts on their learning, especially on their knowledge construction and the development of clinical reasoning.

The last two studies of this thesis were conducted to gain more insights in the development and transfer of knowledge. In Chapter 5 we report on an observational study (Study 4) regarding the use and application of biomedical and clinical knowledge during group discussions in two phases of the PBL cycle. We wanted to know the extent to which different kinds of knowledge were addressed and whether this differed per phase. We also wanted to investigate which part of the biomedical knowledge is used to explain underlying mechanisms of diseases and the patient's signs and symptoms and whether connections were made between biomedical and clinical knowledge. Finally we wanted to know to what extent the interactions during the group discussions were led by either students or tutors. In the last study, Study 5, we explored the development and transfer of knowledge by a pre-post intervention study among students who followed a 10-week course in the third year of the Maastricht Medical School. We wanted to know if the course led to a change in diagnostic reasoning and the use of clinical and biomedical knowledge during diagnostic reasoning, if the quality of pathophysiological explanations of patient features increased and if this differed between cases discussed during the course versus transfer cases. This is reported in Chapter 6.

Finally, in Chapter 7 the main findings of the studies in this thesis are summarized and discussed, and the valorization of the results is considered.

Note: Chapters 2-6 are submitted and published journal papers on the same related topic. This means repetitions between and overlap across chapters is inevitable. 


\section{REFERENCES}

1. Dornan T, Bundy C. What can experience add to early medical education? Consensus survey. British Medical Journal 2004;329:834-837.

2. Boshuizen HPA. The shock of practice: Effects on clinical reasoning. In: Paper presented at the Annual Meeting of the American educational Research Association; 8-14 april; New York 1996.

3. Prince $\mathrm{KJAH}$, van de Wiel M, Scherpbier AJJA, van der Vleuten CPM, Boshuizen HPA. A qualitative analysis of the transition from theory to practice in undergraduate training in a pbl-medical school. Advances in Health Sciences Education 2000;5:105 - 116.

4. Prince KJAH, Boshuizen HPA, van der Vleuten CPM, Scherpbier A.J.J.A. Students' opinions about their preparation for clinical practice. Medical Education 2005;39:704-712.

5. Norman GR, Schmidt HG. The psychological basis of problem-based learning: a review of the evidence. Academic Medicine 1992;67:557-565.

6. van de Wiel MWJ, Schaper NC, Scherpbier AJJA, van der Vleuten PM, Boshuizen HPA. Students' experiences with real-patient tutorials in a problem-based curriculum. Teaching and Learning in Medicine 1999;11(1):1220.

7. van de Wiel M, Boshuizen HP, Schmidt HG. Knowledge restructuring in expertise development: evidence from pathophysiological representations of clinical cases by students and physicians. European Journal of Cognitive Psychology 2000;12:323-355.

8. Woods NN, Howey EHA, Brooks LR, Norman GR. Speed skills? Speed, accuracy, encapsulations and causal understanding. Medical Education 2006;40:973-979.

9. Schmidt HG, Boshuizen HPA. On the origin of intermediate effects in clinical case recall. Memory and Cognition 1993;21:338-351.

10. Boshuizen HPA. Cognitive effects of practical experience in high- and lowachieving medical students. Learning and Instruction 1994;4:313-329.

11. Woods NN, Brooks LR, Norman GR The value of basic science in clinical diagnosis: creating coherence among signs and symptoms. Medical Education 2005;39:107-112. 
12. Woods NN. Science is fundamental: the role of biomedical knowledge in clinical reasoning. Medical Education 2007;41:1173-1177.

13. Norman GR, Trott AD, Brooks LR, Smith EK. Cognitive differences in clinical reasoning related to postgraduate training. Teaching and Learning in Medicine 1994;6:114-120.

14. Norman G. Research in clinical reasoning: past history and current trends. Medical Education 2005;39:418-427.

15. Norman G. Building on experience - the development of clinical reasoning. New England Journal of Medicine 2006;355(21):2251-2252.

16. Norman G, Eva K, Brooks L, Hamstra S. Expertise in medicine and surgery. In: Anders Ericsson K, Charness N, Feltovich P, Hoffman R, eds. The Cambridge handbook of expertise and expert performance. Cambridge University Press, New York 2006;339-353.

17. Boshuizen HPA, Schmidt HG. On the role of biomedical knowledge in clinical reasoning by experts, intermediates and novices. Cognitive Science 1992;16:153-184

18. Patel VL, Groen GJ. Knowledge based solution strategies in medical reasoning. Cognitive Science 1986;10:91-116.

19. van de Wiel M. Knowledge encapsulation. Studies on the development of medical expertise. Dissertation, Maastricht University, Maastricht 1997.

20. Rikers RMJP, Loyens S, te Winkel W, Schmidt HG, Sins PHM. The role of biomedical knowledge in clinical reasoning: a lexical decision study. Academic Medicine 2005;80(10):945-949.

21. Eva KW. What every teacher needs to know about clinical reasoning. Medical Education 2005; 39:98-106.

22. Elstein AS, Schwarz A. Clinical problem solving and diagnostic decision making: selective review of the cognitive literature. British Medical Journal 2002;324:729-732.

23. Stolper E, van de Wiel M, van Royen $P$, van Bokhoven $M$, van der Weijden $T$, Dinant GJ. Gut feelings as a third track in general practitioners' diagnostic reasoning. Journal of General Internal Medicine 2011;26(2):197-203.

24. Custers EJFM. Medical and Cognitive Continuum Theory: An alternative perspective on medical problem solving and clinical reasoning. Academic Medicine 2013;88(8):1-7. 
25. Brynhildsen J. Attitudes among students and teachers on vertical integration between clinical medicine and basic science within a problem-based undergraduate medical curriculum. Medical Teacher 2002;24:286-288.

26. Dornan T, Littlewood S, Margolis SA, Scherpbier A, Spencer J, Ypinazar Y. How can experience in clinical and community settings contribute to early medical education? A BEME systematic review. Medical Teacher 2006;28(1):3-18.

27. Yardley S, Teunissen PW, Dornan T. Experiential learning: Transforming theory into practice. Medical Teacher 2012;34:161-164

28. O'Brien-Gonzales A, Blavo C, Barley G, Steinkohl DC, Loeser H. What did we learn about early clinical experience? Academic Medicine 2001;76:S4954.

29. Cooper HC, Gibbs TJ, Brown L. Community-orientated medical education: extending the boundaries. Medical Teacher 2001;23(3):295-299.

30. Frank D, Handfield-Jones R, Dawson DJ, Russel R, Steinert Y, Boillat M, Yaffe M, Guzder J, Keyserlingk E. An integrated curriculum for teaching preparatory clinical skills at a traditional medical school. Teaching and Learning in Medicine 1996;8(1):4-9.

31. Yardley S, Littlewood S, Margolis SA, Scherpbier A, Spencer J, Ypinazar V, Dornan T. What has changed in the evidence for early experience? Update of a BEME systematic review. Medical Teacher 2010;32:740-746

32. Parsell G, Bligh J. Recent perspectives on clinical teaching. Medical Education 2001;35:409-414.

33. Littlewood S, Ypinazar V, Margolis SA, Scherpbier A, Spencer J, Dornan T. Early practical experience and the social responsiveness of clinical education: Systematic review. British Medical Journal 2005;331:387-391.

34. Seabrook M. Clinical students' initial reports of the educational climate in a single medical school. Medical Education 2004;38(6):659-669.

35. Mann M.P. A light at the end of the tunnel: the impact of early clinical experiences on medical students. Annual Meeting of the American Educational Research Association. New Orleans, LA 1994.

36. Schmidt HG, Rikers RMJP. How expertise develops in medicine: knowledge encapsulation and illness script formation. Medical Education 2007,41:11331139. 


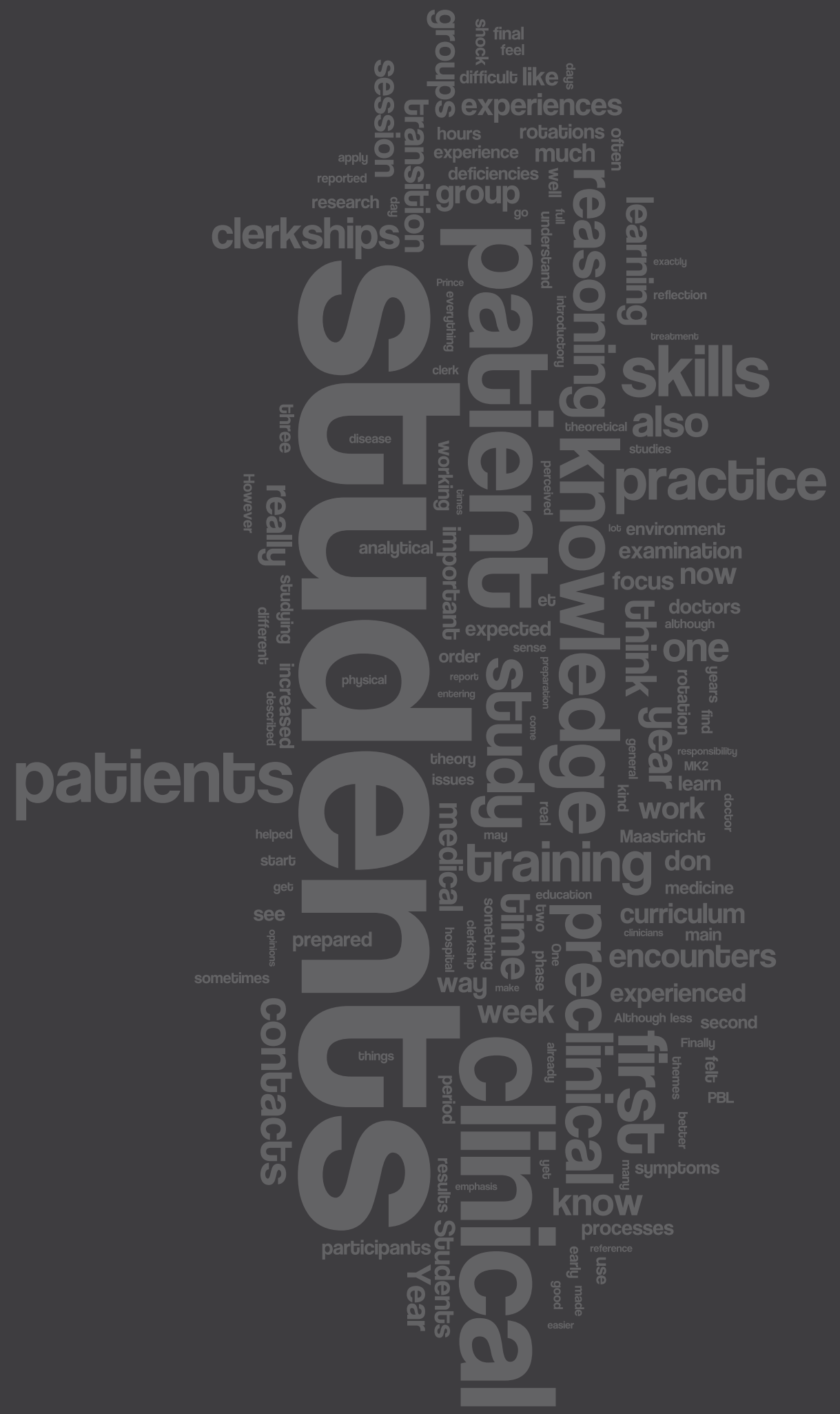




\section{CHAPTER 2}

Students' perceptions about the transition to the clinical phase of a medical curriculum with preclinical patient contacts; a focus group study.

Merijn B Godefrooij, Agnes D Diemers,

Albert JJA Scherpbier

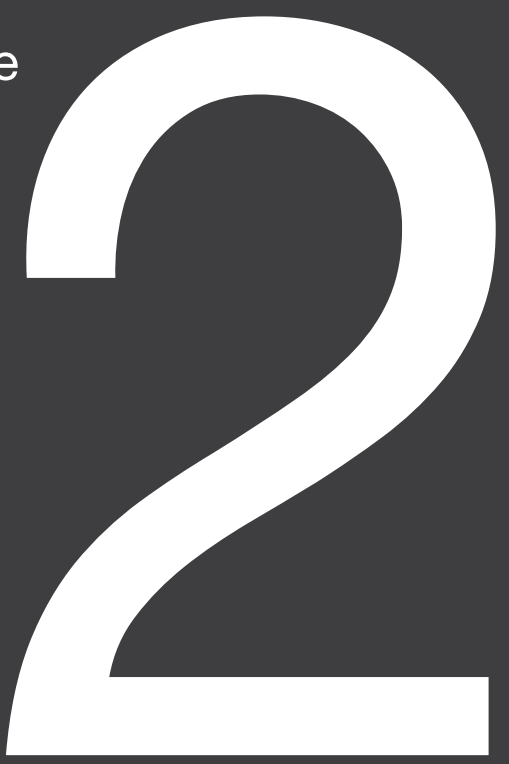

Published in BMC Medical Education 2010; 10: 28 


\section{ABSTRACT}

\section{Background}

Studies have shown that medical students experience the transition between preclinical and clinical training as a stressful period. They are generally frustrated by their inability to apply their knowledge to solve clinical problems in practice. Preclinical patient contacts may offer a solution to this 'shock of practice.' We studied how students who have had preclinical patient contacts perceive the transition from preclinical to clinical training and, more specifically, how they value these early patient contacts as preparation for learning in clinical practice.

\section{Methods}

A purposive sample of 21 students participated in three focus groups which met twice during their first weeks of clinical clerkships. The interviews were recorded and transcribed literally. Qualitative content analysis of the transcriptions was performed.

\section{Results}

According to the students, working in clinical practice was enjoyable, motivated them to study and helped them to develop non-analytical reasoning skills. The students experienced stress due to increased working hours and work load, uncertainty as to what was expected of them and self-perceived lack of knowledge. They did not experience a major gap between the preclinical and clinical phase and felt well prepared for the clerkships. The preclinical patient contacts were considered to be instrumental in this.

\section{Conclusions}

Early patient contacts seem to ameliorate the shock of practice and prepare students for clinical work. The problems mentioned by the students in this study are mainly related to the socialisation process. The results of this study have to be validated by quantitative research. 


\section{BACKGROUND}

The transition between the theoretical and the clinical phase of undergraduate medical education has often been characterised as the most stressful period of undergraduate medical education. ${ }^{1-3}$ The first clinical year has been described as a period where medical students go through intense emotional experiences and students have described entering the clinical arena as though they were being "thrown in at the deep end". ${ }^{4,5}$ Boshuizen ${ }^{6}$ highlighted that the "shock of practice", a crisis experienced by many medical students on first entering the clinical workplace, is marked by a temporary decrease in their ability to properly use biomedical knowledge in clinical reasoning.

The ability to use theoretical knowledge to solve clinical problems is claimed to be enhanced by Problem-Based Learning (PBL). ${ }^{7}$ It has been suggested that the transition from theory to practice is less problematic for students in a PBL curriculum. However, both Van de Wiel et al. ${ }^{8}$ and Prince et al..$^{9}$ discovered that, despite the use of PBL, students from a PBL-based medical school experienced difficulties that were similar to those reported by students from more traditional curricula. Early patient contacts are advocated as a way to improve students' preparedness for clerkships and hence overcome the "shock of practice". .12 $^{-12}$ As yet there is not much evidence of the effects of these contacts.

An opportunity to examine such evidence was presented by the introduction of preclinical patient contacts in the Maastricht PBL curriculum. We explored the following research question: how do students who have had preclinical patient contacts perceive the transition from preclinical to clinical training and, more specifically, how do they value these early patient contacts as preparation for learning in clinical practice?

\section{METHODS}

\section{Research method}

We explored students' perceptions of the transition from the preclinical to the clinical phase through focus group interviews. Focus groups are widely used in exploratory and qualitative education research to gain insight into participants' perceptions, opinions and the processes underlying them. ${ }^{13}$ Focus groups can 
elucidate both what participants think and why participants think as they do. Participants are encouraged to react to one another's views and generate new ideas from different perspectives, something that is not possible in one-on-one interviews. ${ }^{14}$

\section{Context of the study}

Since the foundation of the Maastricht Faculty of Medicine in 1974, PBL has been the predominant educational approach. In 2001, a curriculum renovation was implemented to further the integration of theory and practice by a gradual increase of practice-based activities and a concomitant decrease in theorybased activities from year 1-6. Additionally, early contacts with real patients were introduced in Year 3, while time for basic sciences and reflection on clinical experiences was included in the clerkships in Years 4 and 5.

Currently, the first two years of the curriculum consist mainly of six- to tenweek thematic units during which students work in tutorial groups with paper patients as the starting point for their learning. During those first two years students only occasionally see real patients during lectures, or on videos during tutorial group meetings. In Year 3, the paper patients are replaced by weekly encounters with real patients. Students prepare for these by discussing relevant vignettes, describing the problem of the patient, in small groups one or two days before seeing a patient in the outpatient teaching clinic of Maastricht University Hospital. Student couples are observed by the patient's attending physician while taking a history and performing a physical examination. After the encounter the physician discusses the patient contact with the students, provides feedback on their performance and guides them in deriving learning issues. The attending physician remains responsible for the treatment and management of the patients' disease. The derived learning issues direct students' self-study activities, which are supported by other educational activities, such as lectures, lab work and skills training, including communication skills training with simulated patients. One week after the patient contact, the students present their patient and discuss the results of their self-study in the next group session.

An extensive description of Year 3 of the Maastricht curriculum can be found elsewhere. ${ }^{15}$

Although the order differs per student, clerkship rotations in Year 4 are in 
dermatology, ear-nose-throat (ENT), ophthalmology, internal medicine and surgery plus an elective clerkship, followed in Year 5 by paediatrics, obstetrics and gynaecology, community medicine, neurology, psychiatry and general practice. During the rotations in dermatology, ENT and ophthalmology days in the hospital alternate with days devoted to teaching and reflection in order to ensure that the main subjects of these disciplines are taught alongside workplace experiences. Most of the other rotations are preceded by an introductory week where prior knowledge and skills are activated and conclude with a final week for reflection, reporting and assessment. Clerkships are offered in Maastricht University Hospital and affiliated teaching hospitals. The sixth and final year of undergraduate training is divided into an eighteen-week research project and eighteen weeks of participation in patient care as a junior doctor.

During the above described curriculum, students follow a longitudinal skills training programme in the skills laboratory from year 1-5. During the programme they practise skills (including communication skills) on models, manikins, each other and simulated patients.

\section{Participants}

At the start of the academic year 2006-2007 all 294 fourth-year students were invited by email to voluntarily participate in focus groups. A reminder was sent by email after one week. Of the 32 students who responded, seven were excluded because they did not meet the condition of having completed at least one full week of their first rotation at the time of the first session. The remaining 25 students were assigned to one of three focus groups according to availability and rotation. In order to achieve maximal variation in disciplines and teaching hospitals, we set the maximum number of students in the same rotation per group at three. This resulted in the exclusion of two students. Because two other students, for different reasons, withdrew their participation, the final three focus groups consisted of six, eight and seven students, respectively. One student of group 2 was unable to attend the second focus group session of group 2, and participated in the second session of group 3 instead. One student of group 3 was unable to attend the first session.

The participants were on rotations in all the disciplines of Year 4 (Table 1). Of the participants $67 \%(n=14)$ were female, which reflects the gender distribution 
of this Year 4 cohort. Clerkship experience of the students ranged from one to three weeks at the time of the first focus group and by the second session some students had finished their first rotation and moved to a different discipline. The students received a financial incentive of 30 euros for participation and for critically commenting on the summary of the first interview and the final report. They were assured that the results would be reported anonymously.

\begin{tabular}{|l|l|l|l|l|l|l|}
\hline CLERKSHIP & Group 1 & & Group 2 & & Group 3 & \\
\hline Dermatology & $\mathbf{1}^{\text {st }}$ & $\mathbf{2}^{\text {nd }}$ & $\mathbf{1}^{\text {st }}$ & $2^{\text {nd }}$ & $\mathbf{1}^{\text {st }}$ & $2^{\text {nd }}$ \\
\hline ENT & 1 & 0 & 2 & 1 & 1 & 1 \\
\hline Ophthalmology & 3 & 3 & 1 & 2 & 1 & 1 \\
\hline Internal medicine & 1 & 1 & 3 & 1 & 2 & 1 \\
\hline Surgery & 0 & 0 & 1 & 1 & 2 & 3 \\
\hline No current clerkship & 0 & 1 & 0 & 0 & 0 & 2 \\
\hline
\end{tabular}

Table 1 An overview of the participants in each group at the time of the 1st and 2nd interview

\section{Procedure}

The focus groups met twice, with a one-month interval, between September and November 2006. After the second session saturation was deemed to have been reached, so no third session was organised. The meetings were scheduled for 1.5 hours after working hours to avoid interference with students' clinical work. The discussions were guided and stimulated by the first moderator (AS), who is familiar with the curriculum and a highly experienced moderator of focus groups. The assistant moderator (MG) took notes and made sure the sessions were audio taped. Occasionally, he asked the participants to clarify statements.

\section{Instruments}

For the first session a set of open-ended questions was prepared relating to the following topics: 
1. Students' experiences during their first clerkship week.

2. Perceived differences between preclinical and clinical training.

3. The role of the preclinical patient encounters in the students' overall preparation for clinical training.

4. Recommendations to further ease the transition from preclinical to clinical training.

During the second session the findings of the first session were verified and clarified and the participants were asked to comment on a written report of the first session, that was send to them in advance of the second session. Additionally, the role of Year 3 as preparation on the clinical phase was elaborated upon.

\section{Data collection and analysis}

All focus group sessions were audio taped and transcribed literally by MG. Using the software program ATLAS.ti, coding of text fragments based on content was done through multiple coding by three researchers (MG, AD and AS) independently. ${ }^{16,17}$ They then compared the coded text fragments and adjusted their coding until consensus was reached. Subsequently, the codes were reorganised and grouped, main themes and sub-themes were identified and illustrative quotations selected. The final report was sent to all participating students for approval. All the students responded and approved the summary of the first interview and the final report, without any comments or modifications.

\section{Ethical approval}

At the time of the study, educational research studies reporting students' opinions did not require approval from the ethics committee in the Netherlands. However, relevant ethical issues were carefully considered by the Chair of the Department of Educational Development and Research at Maastricht University.

\section{RESULTS}

Guided by the open-ended questions, the three groups discussed almost identical topics. We present the main themes and the sub-themes (Table 2) with illustrative quotations. Differences of opinion in the groups are reported. 


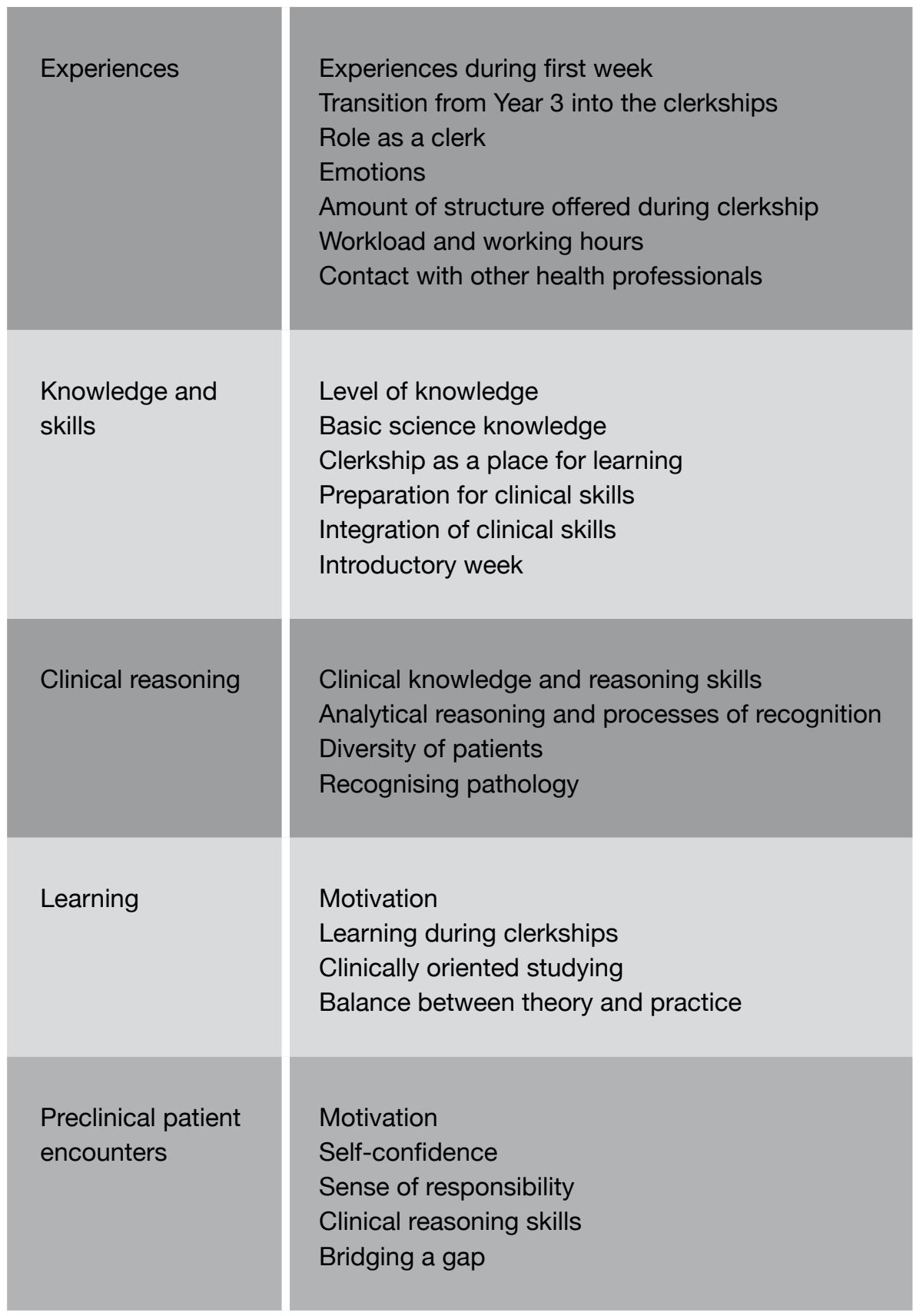

Table 2 Main themes and corresponding sub-themes discussed during interviews 


\section{Experiences}

The students' experiences during the first week of clinical training varied but the prevailing view was that they thoroughly enjoyed the experience.

"Working as a clerk is better than expected" (FK1)

"I did not look forward to the clerkships, but now that I'm in it:

it really is one of the best experiences I have ever had." (JR3)

One of the most dramatic differences with preclinical training was the huge increase in working hours, although students in each group also said this was to be expected on moving from preclinical to clinical training.

"Yes, all that busyness. All at once your days are full. Now, during the winter period, I feel like some kind of caveman: you go to work in the dark and you come home in the dark. That really is a change for me." (FK1)

"If you do any other study there would also come a point where you'd have to start gaining work experience (...) and you start working, so it's just all in the game." (KN2)

Not only the hours but also the intensity of work increased for most of the students. The work pace in the hospital was high, which meant less time for individual patients, studying and homework assignments. Some of the students whose first rotation was in a rotation with alternate clinical and reflection days (dermatology, ophthalmology and ENT) did not yet experience a great difference in workload, but they anticipated this would happen when they moved to other rotations, like internal medicine or surgery.

A challenge reported by most students was getting to grips with their role and position in the clinical department: how were they supposed to behave and act? Occasionally, it was difficult for them to understand what staff expected from them. In most hospital settings there seemed to be a set of unwritten rules for clerks. 
"What I find difficult to sense is, you know, when it is okay to speak up and when you had better keep quiet." (MB1)

"I think what we mean here is this: you are put on a ward, which is challenging, but you don't know the rules. You don't know which person is nice and which person is not, and sometimes even how you should dress (...)." (CS2)

Students indicated that it would be easier for them to find their place in a department when clerkships were more structured. They were eager to understand where they were expected to be and at what time. However, this uncertainty was not experienced as negative by all the students. Some students appreciated their freedom to determine their own schedule.

"No, I do not have a problem with being thrown in at the deep end, but structure... so that you know what's being expected of you, that I would appreciate." (RS2)

"(...) Apparently there are these meetings going on everywhere in the hospital, but where do I have to run to, and at what time?" (MK2)

"When there are moments when it's very quiet I actively start looking for something to do. (...) Now I have the chance to see those patients, so I just go in search of them." (CB2)

Students pointed to the emotional impact of having to deal with many patients with serious illnesses as well as their increased sense of responsibility for patients. They admitted they had to learn to cope with these - at times very intense emotions.

"What I find a bit heavy of the clerkships is how many impressions you get. You see so many sick people in such a short period of time. And that does affect you at first, so that sometimes you think: wow, these are more people than I expected, it's all a bit worse than I expected, and that makes you think." (MK2) 


\section{Knowledge and skills}

Upon entering the clinical environment, students are confronted with their own very limited knowledge compared to that of clinicians:

"You enter this environment with these medical doctors and professors, and you feel they know everything. And quite possibly you actually know quite a lot, but because of this environment with all these doctors (...), you can get that feeling." (MG2)

"I haven't even finished my second week as a clerk yet. I'm currently going through the absolute depression of ignorance." (MK2)

Many students experienced deficiencies in basic science knowledge and in their ability to apply it. Deficiencies in anatomy, pharmacology, physiology, endocrinology and the interpretation of lab results were mentioned and confirmed by the majority of the students.

"Anatomy is the very worst" (FK1)

"It is important that you have some kind of basis, and we don't have that." (CS2)

"There's a lot you don't know yet. I find it very frustrating when I am asked a question and again and again l'm not able to give the correct answer." (KN3)

These reactions were qualified, however. For instance, students acknowledged that clerkships are for learning, implying that it is normal for them not to know everything yet. Students also observed that although the use of pharmaceutical brand names was difficult, they did understand most of the mechanisms of the drugs prescribed by doctors. Furthermore, some anatomical knowledge proved to be easier learnt from real patients than from textbooks:

“I'm a clerk in order to learn, if I knew everything already then I wouldn't be here" (KN2) 
"On my first day I didn't know exactly what veins and arteries looked like. But within one day that knowledge was drilled into me, and then I knew exactly what they looked like. You only need to see two blood vessel operations in order to know exactly how all these veins run through the human body. And then you also understand their relation with other structures, which I find difficult to learn from textbooks." (JR3)

The confrontation with deficiencies in knowledge was a powerful drive for the students to study and they thought deficiencies could be interpreted as learning issues to guide their studies.

In general students felt well prepared with regard to clinical skills, communication skills in particular. However, it was confusing for the students when different doctors had different notions of the correct way to perform a physical examination:

"But you can never do it right, because each doctor has his own method and says: no, you have to do it this way. And next time, when you do it like that, another doctor will tell you: no, you should do it this way." (KN3)

Another challenge in respect of clinical skills was to integrate skills students had learned as separate entities into a smooth physical examination. However, this was easily remedied thanks to an extra training session during the introductory week of some rotations.

"The only disadvantage is that we learn everything in packages, you know: examination of the heart, examination of the lungs... And in internal medicine you need to do all these examinations in one and the same patient. And when you first do a full cardiologic examination and then a full pulmonary examination, your patient has to turn over six or seven times." (MG1)

"I think we've had enough practice [with regard to clinical skills]. I thought it was really good that a full physical examination was demonstrated during the introductory week of internal medicine." (JB3) 
Finally, the students valued the introductory weeks of most rotations, which helped them refresh and integrate their prior knowledge and skills and fill the most important gaps in their knowledge, thereby improving their preparedness for the rotation. Nevertheless the students also noted a need for improvement in the educational quality of the introductory week in some rotations.

"You are really stimulated to refresh your knowledge, for instance in cardiology and other subjects... That is really good." (CB2)

"I don't think lectures are the ideal way to teach students for eight hours a day." (JG3)

\section{Clinical reasoning}

The students perceived a shift of emphasis from theoretical knowledge in the preclinical years to clinically oriented knowledge and reasoning in the hospital. The emphasis moved from understanding underlying mechanisms of disease to recognising clinical signs and symptoms and making treatment decisions.

"Last year treatment was not our main goal, you know, but now the emphasis is more on management strategies. That's why it's more important now to be up-to-date. Before you would say: you can either operate or you can laser it, but now the question is: how exactly do you operate or laser it?" (FM3)

"I think, from now on, all we will be doing during our clerkships is work on those differential diagnoses." (FK1)

The students said that pattern recognition became increasingly important, sometimes at the expense of analytical reasoning. They also said that most doctors did not encourage them to fully understand the underlying mechanisms of a disease, and that often they were not given enough time to fully exploit their analytical reasoning skills. 
"Because you are so much busier during the clerkships, you are already pleased when you recognise something. And I think that will become more and more important, because in the outpatient clinic doctors never ask you to explain symptoms. If you recognise symptoms, they are usually quite pleased with you already, and often they themselves don't understand the exact underlying mechanisms." (JP1)

The number of patient encounters was much higher than during the preclinical years. Students appreciated the diversity of patients they saw, because it enabled them to compare symptoms and diseases and expand their reference base for recognition processes.

"And now you just see more patients in one day, and you can compare patients: one patient deals with his problem like this, the other patient like that. And: this one has this much inconvenience, and that one that much. Which symptoms coincide, and which differ enormously?" (JP1)

"But I also find it easier, because you have seen patients and you can make connections, and then you recognise things faster - that is a great advantage." (SP1)

The students said that patient encounters provided a frame of reference for identifying physiological and pathological processes, although it was sometimes difficult for them to recognise pathology.

"It's very useful that you get these frames of reference about what's normal and what's not, especially with auscultation. Sometimes you think you hear something abnormal and then you think: hey, l've found something! Then you go to the doctor and then: no, that's nothing. But then you know the next time, that it's nothing, so that's useful." (JR3)

\section{Learning}

There was general agreement that motivation to study increased during clerkships. Studying was more fun. The main motivators were patients and doctors. Students enjoyed being able to apply their knowledge in practice. 
"It is so cool and you learn so much, and there's so much that you can do yourself." (MB1)

"When those doctors ask you questions then you don't want to make a fool of yourself. So yes, that motivated me to really study some subjectmatter." (LW1)

"Your learning improves: the fact that you have a patient contact makes you want to know things better." (JW3)

"It's also more fun to notice that you can apply the things you learn." (FM3)

However, it was also remarked that in-depth studying was discouraged if clinicians had low expectations of students:

"It is true that your attitude becomes more lax, [if these people are so easily satisfied], so you think: I don't really have to study that chapter because they won't pick me up on it anyway tomorrow, so I will go and have another beer now." (FM3)

The students experienced an increase in the speed and ease of learning. They saw more patients and more diseases than before and this repetition made it easier for them to memorise knowledge about various diseases.

"It sticks in your mind more easily when you are working with a patient" (KN3)

"You see 10 times as many patients, so it just goes much faster" (MB1)

According to the students, learning issues were less broad and more specific. The increased patient load meant less time to study for each case. Some students perceived this more specific way of studying as detrimental to in-depth studying. 
"As far as knowledge goes, I think I learn less from [each patient now]. Because at the end of the day I have a list of at least 10 things that I could look up but very often I don't even get to that anymore" (MG2)

"And much more specific (...) I often look for one specific thing (...) Specifically for the use of that particular drug when I run into that. I don't study in the way I used to: an entire disease with its epidemiology and then symptoms, diagnosis, treatment, no longer in that order." (MG1)

The students agreed that learning - like their knowledge - was more clinically oriented now. They hardly ever opened a physiology textbook and the importance of keeping up with recent literature and publications had increased.

"Yes, a lot more articles. When I read those books, I come in and think: oh, that's a good thing to mention. But then they say: that is so out-dated." (JR3)

Most students were happy with the combination of theory and practice and preferred practice, although they agreed that it was also important to have sufficient time for studying and reflection.

"The combination of theory and seeing patients, to be able to apply it all, that's a lot of fun." (MK2)

\section{Early patient encounters}

Students generally felt better prepared for clinical training as a result of the patient encounters in Year 3, which had given them more self-confidence in dealing with patients and helped them to develop interview and physical examination skills in a safe environment.

"Because you have already done it a couple of times (...) then [at the beginning of the clerkships] you feel: I'm ready for it. I also felt like I wanted to see patients because it's fun and because l'm not nervous about meeting them at all. And the more you do it, the better it goes and so you notice your confidence increases and your uncertainty disappears." (JW3) 
"The thing that's really good about year 3 is those [early patient contacts]. Because now we have entered clinical practice it's so different from last year. Then there was so much calmness, you were really given the time and space you needed with your patient, and you were really well guided." (CS2)

The preclinical patient encounters had also been a strong motivation for students to study and taken them closer to their final goal: working as a medical professional. Students remarked that being more actively involved in their learning had made the preclinical patient contacts very enjoyable.

"Finally it's beginning to get professional. Finally it's moving toward being a doctor." (JP1)

"It really stimulated me to start studying, when you would see a patient and think: whoops..." (CS2)

Some students said that the preclinical patient contacts had triggered the development of a sense of responsibility, which was growing stronger during clerkships.

"Yes, and I think that because of that you already have a sense of responsibility. That in year 3 you really (...) are confronted with a patient." (HL2)

"In year 3, on our first time in the outpatient clinic we had prepared something but not everything. And then you feel: this patient has come here especially for you and you don't even know what to ask. And then you realise that you have a certain obligation towards patients, because they are so kind as to help you, you have to make sure you are well prepared." (FM3) 
The benefit of the preclinical patient encounters that was mentioned most frequently was the development of clinical reasoning skills. The students said they had been challenged to build knowledge structures and experiment with differential diagnosis in a safe environment.

"What I like about year 3 is, and you notice that more and more now: it helps you to create a certain structure in your way of thinking. In year 3 we first made differential diagnoses and that is one of the most important things in medicine." (JB3)

"Year 3 was one of the best, or so to say, and it really helped me to learn to form all these connections into a comprehensive structure in my mind." (JP1)

Finally, there was general agreement that the preclinical patient encounters had eased the transition to clinical training and bridged the gap between the more theoretical orientation of preclinical training and the clinical orientation of the clerkships.

"But what is difficult sometimes is that you have learned to first study a disease and then its symptoms, and now you have to reason the other way around and sometimes that's difficult." (KN3)

"But I think the good thing about year 3 is that it taught us how to deal with that." (JB3)

"Now we make the same kind of patient reports [as we did in year 3], we still have the same kind of learning issues to study, and we still use patients to link our knowledge to." (MK2)

"Year 3 really is a kind of pre-clerkship. Really a year in which you are prepared for clinical training." (MG2) 


\section{DISCUSSION}

In this study we asked students whose preclinical curriculum had included encounters with real patients to talk about how they experienced the transition from the preclinical to the clinical phase of medical training. The general feeling among students was that they enjoyed their clinical experiences, especially the ability to put their knowledge into practice. Students felt well prepared for clinical practice and did not feel daunted by a large gap between preclinical and clinical training.

Negative experiences were related to professional socialisation processes, the increased workload, and perceived knowledge deficiencies. Although these feelings differed somewhat amongst the students, they were largely deemed to be a normal aspect of entering a new work environment.

The most striking result of this study is that the "shock of practice" described by Boshuizen ${ }^{6}$ and Prince et al. ${ }^{12}$ in earlier studies was not reflected in the perceptions of the students in this study. Although the students reported a shift of emphasis from theoretical knowledge to clinical knowledge, they also said this transition was a gradual and natural process and the encounters with real patients in the previous year had enabled them take the first steps in a protected environment. In line with other research, the students thought the early patient contacts had increased their self-confidence, motivated them to study, helped them develop clinical reasoning skills, and inculcated a sense of responsibility. ${ }^{12,18}$ The last preclinical year was literally described as a bridge between preclinical and clinical training. It thus seems that early patient encounters are effective in counteracting at least part of the negative effects of the shock of practice.

Concerning the development of clinical reasoning skills, students noted that nonanalytical reasoning became more prominent during clinical training and was facilitated by the rapid expansion of their 'reference database' as a result of the increasing numbers of patients they saw. Eva ${ }^{19,20}$ has argued that non-analytical processes of reasoning are in no way inferior to more analytical forms of reasoning, but he and $\mathrm{Ark}^{21}$ also contended that the combined use of both reasoning strategies promotes diagnostic accuracy. This suggests that both types of reasoning should receive attention during medical education. 
From this perspective it seems somewhat worrying that the students in our study felt they were not sufficiently guided in developing skills for analytical reasoning. This is the more reason for concern in light of Eva's ${ }^{19}$ and Van de Wiel et al.'s ${ }^{8}$ finding that students do not automatically engage in analytical reasoning of their own accord, but have to be explicitly alerted to links between theory and practice. This is supported by the students of our study, who said that feedback and questions from clinicians can be an important motivator and guide in the development of analytical reasoning and regretted that there often was not enough time for this.

It was also observed in earlier studies that students experience deficiencies in basic and clinical science knowledge when they are confronted with diseases and diagnostic methods that are new to them and with vastly more experienced and knowledgeable clinicians. ${ }^{9}$ Prince et al. ${ }^{22}$ also showed that these perceived deficiencies should not necessarily be interpreted as shortcomings of the curriculum. Although students from the Maastricht PBL curriculum felt they were vastly lacking in anatomical knowledge, Prince et al. ${ }^{22}$ demonstrated that their knowledge was in no way inferior to that of students from other medical schools. Additionally, Van Hell et al..$^{23}$ found that the levels of pre-clinical knowledge and skills did not influence students' performance during the transition period. Although experienced by the students, these deficiencies do not need to be a cause for direct concern. As some of the students acknowledged, clerkships are learning experiences and it is normal that their knowledge is imperfect. Nevertheless, it is important not to dismiss students' feelings in this respect.

One of the limitations of this study is that, although the amount of patient contacts during Years 1-3 is the same for all students, the amount of patient contacts during the start of Year 4 may differ and thus may influence students' experiences with the transition phase.

Another limitation is that the students might have known the main moderator as the head of the Institute for Medical Education. This may have withheld students from fully sharing their ideas and opinions. On the other hand, it may as well have encouraged them to express their feelings and ideas in order to suggest improvements to be made about the curriculum.

Furthermore, it has to be taken into account that the students who reacted on the 
invitation to participate in this study were probably the most enthusiastic ones. Finally, the results of this study are based upon the opinions of a small sample of 21 students. Even though saturation was reached in all three groups and the groups discussed similar themes, it cannot be ruled out that not all relevant themes were appropriately covered. Nevertheless, the purposive sample ensured the inclusion of a wide variety of experiences. How representative the positive results are for the entire student population will have to be investigated by larger, quantitative studies, for example through a questionnaire survey amongst fourthyear students.

\section{Conclusions}

The main conclusions from this study are:

- Early patient contacts seem to alleviate the perceived "shock of practice" during the transition from the pre-clinical into the clinical years of medical education and prepare students for their work as a clerk.

- The negative experiences regarding the transition period that were expressed by the students are mainly related to professional socialisation processes.

- Non-analytical reasoning processes become more important during the clinical years of medical education. Students often did not feel sufficiently challenged by clinicians to fully exploit their analytical reasoning skills.

The results of this study have to be validated by quantitative research. 


\section{REFERENCES}

1. Morrison J, Moffat K. More on medical student stress. Medical Education 2001;35:617-618.

2. Moss F, McManus IC. The anxieties of new clinical students. Medical Education 1992;26:17-20.

3. Radcliffe $\mathrm{C}$, Lester $\mathrm{H}$. Perceived stress during undergraduate medical training: a qualitative study. Medical Education 2003;37:32-38.

4. Pitkala $\mathrm{KH}$, Mantyranta T. Professional socialization revised: medical students' own conceptions related to adoption of the future physician's rolea qualitative study. Medical Teacher 2003;25:155-160.

5. Dornan T, Bundy C. What can experience add to early medical education? Consensus survey. British Medical Journal 2004;329:834-837.

6. Boshuizen HPA. The shock of practice: Effects on clinical reasoning. In Paper presented at the Annual Meeting of the American educational Research Association; 8-14 april; New York 1996

7. Norman GR, Schmidt HG. The psychological basis of problem-based learning: a review of the evidence. Academic Medicine 1992;67:557-565.

8. van de Wiel MWJ, Schaper NC, Scherpbier AJJA, van der Vleuten CPM, Boshuizen HPA. Students' experiences with real-patient tutorials in a problem-based curriculum. Teaching and Learning in Medicine 1999;11:1220.

9. Prince KJAH, Boshuizen HPA, van der Vleuten CPM, Scherpbier AJJA. Students' opinions about their preparation for clinical practice. Medical Education 2005;39:704-712.

10. Brynhildsen J. Attitudes among students and teachers on vertical integration between clinical medicine and basic science within a problem-based undergraduate medical curriculum. Medical Teacher 2002;24:286-288.

11. Dornan T, Littlewood S, Margolis SA, Scherpbier A, Spencer J, Ypinazar Y. How can experience in clinical and community settings contribute to early medical education? A BEME systematic review. Medical Teacher 2006;28:318.

12. Prince $\mathrm{KJAH}$, van de Wiel M, Scherpbier AJJA, van der Vleuten CPM, Boshuizen HPA. A Qualitative Analysis of the Transition from Theory to Practice in Undergraduate Training in a PBL-Medical School. Advances in Health Sciences Education 2000;5:105-116. 
13. Barbour RS. Making sense of focus groups. Medical Education 2005;742750.

14. Kitzinger J. Introducing focus groups. British Medical Journal 1995;299-302.

15. Diemers AD, Dolmans DHJM, van Santen M, van Luijk SJ, Janssen-Noordman AMB, Scherpbier AJJA. Students' perceptions of early patient encounters in a PBL curriculum: A first evaluation of the Maastricht experience. Medical Teacher 2007;29:135-142.

16. Muhr T. ATLAS/ti-Visual qualitative data analysis - management - model building in education, research and business. ATLAS/ti-Visual qualitative data analysis - management - model building in education, research and business. Release 4.1 edition. Scientific Software Development; Berlin 1997.

17. Barbour RS. Checklists for improving rigour in qualitative research: A case of the tail wagging the dog. British Medical Journal 2001;322:1115-1117.

18. Diemers AD, Dolmans DHJM, Verwijnen MGM, Heineman E, Scherpbier AJJA. Students' opinions about the effects of preclinical patient contacts on their learning. Advances in Health Sciences Education 2008;13:633-647.

19. Eva KW. What every teacher needs to know about clinical reasoning. Medical Education 2005;39:98-106.

20. Eva KW, Hatala RM, LeBlanc VR, Brooks LR. Teaching from the clinical reasoning literature: combined reasoning strategies help novice diagnosticians overcome misleading information. Medical Education 2007;41:1152-1158.

21. Ark TK, Brooks LR, Eva KW. The benefits of flexibility: the pedagogical value of instructions to adopt multifaceted diagnostic reasoning strategies. Medical Education 2007;41:281-287.

22. Prince KJAH, van Mameren H, Hylkema N, Drukker J, Scherpbier AJJA, van der Vleuten CPM. Does problem-based learning lead to deficiencies in basic science knowledge? An empirical case on anatomy. Medical Education 2003;37:15-21.

23. van Hell EA, Kuks JBM, Schönrock-Adema J, van Lohuizen M, T., CohenSchotanus J. Transition to clinical training: influence of pre-clinical knowledge and skills, and consequences for clinical performance. Medical Education 2008;42:830-837. 


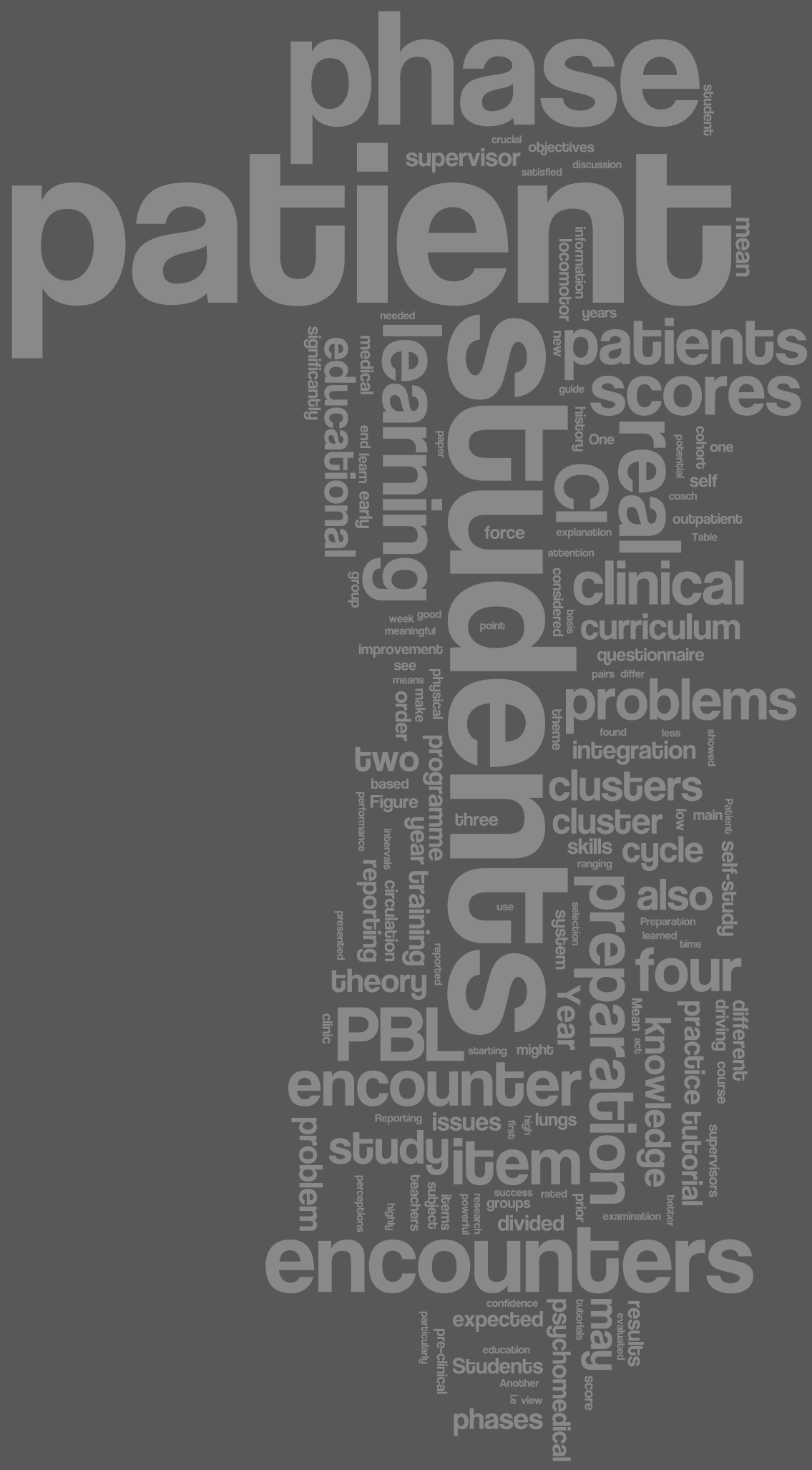




\section{CHAPTER 3}

Students' perceptions of early patient encounters in a PBL curriculum: a first evaluation of the Maastricht experience

Agnes D Diemers, Diana HJM Dolmans,

Marijke van Santen, Scheltus J van Luijk, Ameike MB Janssen-Noordman,

Albert JJA Scherpbier

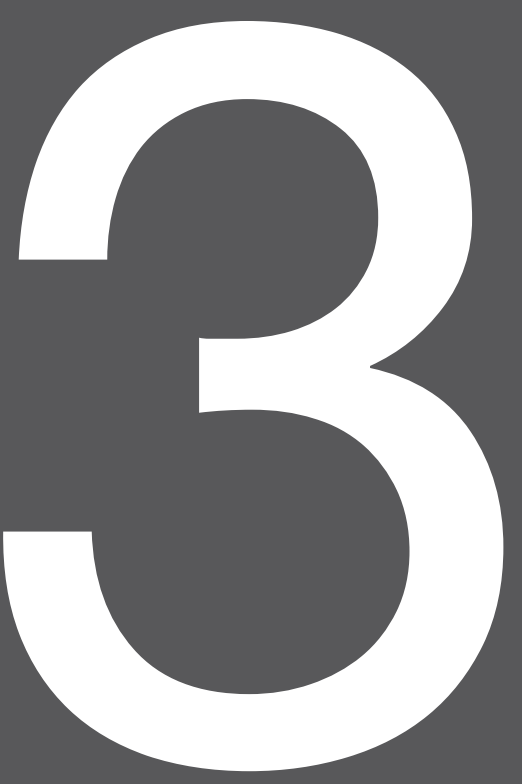

Published in Medical Teacher 2007; 29: 135-142 


\section{ABSTRACT}

\section{Introduction}

Real patient encounters before the clinical phase of undergraduate medical education are recommended to stimulate integration of theory and practice. Such encounters are not easy to integrate into the three phases of the problem-based learning cycle, i.e. preparation, self-study, and reporting. We studied students' perceptions of problem-based learning with real patient encounters as the starting point for learning.

\section{Method}

Students' perceptions of the programme with real patients were evaluated by means of a questionnaire. Mean item scores on a five-point Likert scale and $95 \%$ confidence intervals were calculated.

\section{Results}

Students showed satisfaction with the patient encounters and said they learned a lot from them. Reporting was also highly rated, particularly the integration of theory and practice. Preparation and self study received lower scores.

\section{Discussion}

The findings support the view that real patient encounters can act as a powerful driving force for learning and enhance integration of theory and practice. Student learning might benefit from: better information to students and teachers regarding educational objectives, teacher training and careful selection of patients. In order to gain more insight into learning from patient encounters, further studies should address students' and teachers' views and behaviours in respect of this type of learning. 


\section{INTRODUCTION}

Problem based learning (PBL) is increasingly being used as an educational approach in medical education. It is supposed to "promote the transfer of concepts to new problems and the integration of basic science concepts into clinical problems". ${ }^{1}$ Despite this assumed benefit, students in a PBL curriculum have reported difficulty in applying theoretical knowledge to real patient problems when making the transition from pre-clinical, mainly theoretical courses to clinical training during the clerkships. ${ }^{2,3}$ Contacts with real patients during the pre-clinical phase have been proposed as a solution to this problem. ${ }^{2,3}$

Reports in the literature concerning the use of early patient encounters in PBL have confirmed the beneficial effects of such encounters. ${ }^{4-6}$ New knowledge is better internalized when students can relate it to a real patient. ${ }^{2}$ When students learn theory within the context of real patients, it becomes "more relevant", is "easier to learn" and easier to remember. ${ }^{1,7,8}$ Furthermore, when real patients are used as the starting point for learning, they act as a powerful driving force for meaningful and profound learning. ${ }^{1,2,7-9}$

The actual implementation and integration of patient contacts in medical curricula is an undertaking that should not be embarked upon lightly and success is not to be taken for granted. The main problems reported in the literature are matching patient problems to course themes and expected difficulties in selecting sufficient numbers of suitable cases to ensure coverage of the core curriculum. . $^{4,5,10,11}$ Another potential problem is students having difficulty identifying meaningful links between theory and practice. One study reported that confrontation with real patients in the curriculum did not automatically result in medical students studying the pathophysiology underlying patients' problems. ${ }^{12}$ In that study, students said that they did not make the connection between patients and learning of their own accord and that they needed "... to be shown those links". ${ }^{12}$ Additionally, Eva ${ }^{13}$ argues that students do not spontaneously use analytic reasoning, but should be explicitly instructed to link the problems presented by the patient to basic science and make comparisons across problems.

In order to realize the combined educational potential of early patient encounters and PBL, a way has to be found to effectively integrate real patient encounters into the PBL cycle. The PBL cycle generally comprises three phases: preparation, 
self-study, and reporting. We studied a course in which real patient encounters were incorporated into the PBL cycle immediately after the preparation phase (Figure 1). The aim of our study was to evaluate students' perceptions of their learning organised around this four phased PBL cycle, in which a real patient encounter was introduced as a driving force for student learning.

\section{EDUCATIONAL BACKGROUND}

In 2001, extensive innovations were introduced into the six-year PBL curriculum of Maastricht Medical School, the Netherlands. The 'old' curriculum consisted of two distinct phases: a four-year pre-clinical phase in which PBL tutorials were the predominant educational method and two years of mainly hospital based clinical clerkships. One of the aims of the new curriculum is to offer students experiences with real patients earlier in the curriculum. In Year 3 this is realised by the introduction of frequent real patient encounters. The theme of the new Year 3 is Chronic Diseases. This theme is divided into four subject clusters, i.e. abdominal region, locomotor system, circulation \& lungs and psychomedical problems \& mental health care. Every week students see a patient in the teaching outpatient clinic at University Hospital Maastricht. The patient encounters are the starting point for learning in the PBL cycle. Each cycle lasts a week and comprises one four-hour tutorial attended by ten students and their coach, patient encounters for all students, and self study between the patient encounter and the next tutorial. We divided the original first phase of PBL tutorials into two phases: the "preparation phase" in which students prepare for the patient encounter and activate prior knowledge and the "patient encounter phase" in which students, in pairs, meet a real patient instead of a paper patient. From this encounter students derive learning issues for self study. As a result, four consecutive phases can be discerned in the PBL cycle. The preparation phase takes up the last hour of the tutorial, the patient encounter phase is scheduled one or two days after the tutorial, the self study phase covers the time between the patient encounter and the tutorial in the next week, and the reporting phase takes place during the first three hours of the tutorial. The PBL cycle is the main educational component of Year 3 and is complemented by lectures, skills training and other educational activities. The content of the four phases will now be discussed in some detail. 




Figure 1 PBL cycle with four phases

\section{Preparation phase}

The students are given the GP's letter of referral or a vignette (box 1) describing the problem (or a similar problem) of the patient they will see in the outpatient clinic. The patient problems are elaborated on by the group in order to activate the knowledge gained during the preceding two years of the curriculum. During elaboration, attention is also being paid to history taking and physical examination. The students then generate learning issues and decide what to study in preparation for the patient encounter.

\section{Patient encounter phase}

One or two days after the preparation phase, student pairs go to the outpatient clinic where they take a history and perform a physical examination of a patient. After about 30 minutes, when history and physical are finished, the students consult the patient's attending physician, who acts as their "clinical supervisor". The students and the clinical supervisor then return to the patient to complete 
the consultation. The role of the clinical supervisor is to guide the students in generating learning issues on the basis of the problem presented by the patient and to give the students feedback on their performance.

\section{Self-study phase}

During the self-study phase the students work on the learning issues derived from the patient encounter. They make use of a variety of learning resources, such as books, skills training, lectures and so on. The student pairs prepare a clinical presentation about 'their patient' to present to the group during the reporting phase.

\section{Reporting phase}

This phase is partly devoted to the patient presentations, which consist of a report of history, physical examination, differential diagnosis and management plan. The presentation is followed by a discussion of what the students have learned during the patient encounters and self-study phase. The purpose of this phase is to promote integration of theory and practice. Students apply their newly acquired knowledge to the patient problems.

The coach and the clinical supervisor are both clinical staff members of the disciplines involved in the Year 3 programme. Both have had two hours' training in advance in which it is explained to them how to guide the session as a coach and clinical supervisor.

Example of a vignette used in the abdominal cluster describing a patient problem at the urology outpatient clinic.

A 63 year old woman presents at the urology outpatient clinic with frequency, nocturia and urgency. She has had these complaints for two years and by now she knows every public convenience in town.

BOX 1 Example of a vignette 


\section{METHODS}

\section{Context}

The cohort of Year 3 students is divided into four groups and the academic year is divided into four 10-week periods. The educational content of the year is divided into four subject clusters, which are run four times in the course of the year. The four groups of students attend the clusters in different order (figure 2).

The main feature of the PBL curriculum in the two preceding years is the small group tutorial based on paper cases. Students also follow a longitudinal skills training programme in the skills laboratory where they practise skills (including communication skills) on models, manikins, each other and simulated patients.

\section{YEAR 3: CHRONIC DISEASE}

\section{CLUSTERS}

\begin{tabular}{|c|c|c|c|c|}
\hline Student groups & Weeks $1-10$ & Weeks 11-20 & Weeks 21-30 & Weeks $31-40$ \\
\hline Group 1 & Abdomen & Locomotor & Circulation \& lungs & Psychomedical \\
\hline Group 2 & Locomotor & Circulation \& lungs & Psychomedical & Abdomen \\
\hline Group 3 & Circulation \& lungs & Psychomedical & Abdomen & Locomotor \\
\hline Group 4 & Psychomedical & Abdomen & Locomotor & Circulation \& lungs \\
\hline
\end{tabular}

Figure 2 Logistics of Year 3: four groups of approximately 56 students attend four subject clusters in different order. At the end of the year each group has completed the same programme

\section{Subjects}

The study participants were the students of the Year 3 cohort in the academic year 2003-2004. This cohort consisted of 223 students, who were divided into four groups of some 56 students each. This was the first cohort to undertake the new Year 3 programme.

\section{Instruments}

For this study we analysed the results of the anonymous questionnaire of the regular curriculum evaluation, which is administered routinely to all students 
at the end of each cluster. This means that each student could complete four questionnaires over the course of the year. The questionnaire is identical for the four clusters and consists of 10 statements with a five-point Likert scale (1=fully disagree, $5=$ fully agree): two statements about the preparation phase, three about the patient encounter phase, two about the self study phase and three about the reporting phase. An example of a statement about the preparation phase is: "The tutorials provided sufficient preparation for the patient encounters." An example of a statement about the patient encounter phase: "I learned much from the patient encounters". (see Table 1)

\section{Analysis}

Data were analysed using the Statistical Package for Social Sciences (SPSS version 12.0.1). Mean item scores across all students were calculated for each cluster separately. In this way 10 scores were obtained for each of the four subject clusters. Mean scores below 3.0 were considered unsatisfactory and indicative of a strong need for improvement. Mean scores of 3.0-3.4 were considered borderline, i.e. necessitating some improvement and mean scores of 3.5 or higher were considered good. We determined $95 \%$ confidence intervals $(95 \%$ $\mathrm{Cl})$ for the mean item scores to determine whether a score differed significantly $(p<0.05)$ from 3.5 .

\section{RESULTS}

The questionnaire was completed for the clusters on abdomen, locomotor system, circulation \& lungs and psychomedical problems \& mental health care by a total of 213 (95\%), 211 (94\%), 218 (97\%) and 221 (99\%) students, respectively.

Figure 3 presents the means and 95\% confidence intervals of the item scores on the different PBL phases for the four clusters. Scores on different items are represented by different symbols. The items can be found in Table 1. The distinction between scores below 3.5 and scores of 3.5 and higher is indicated by a discontinuous line. The results will be presented by phase.

\section{Preparation phase}

The results for the preparation phase were good (see Table 1 and Figure 3), but 
not for psychomedical problems, with preparation for year 3 during previous years (item 1) scoring $3.0(95 \% \mathrm{Cl} \pm 0.15)$ and preparation for patient encounter (item 2) scoring $3.2(95 \% \mathrm{Cl} \pm 0.13)$. The latter item also scored low for the cluster on the locomotor system: $3.1(95 \% \mathrm{Cl} \pm 0.15)$. For the cluster on circulation \& lungs, the mean score on item 1 did not differ significantly from 3.5 .

\section{Patient encounter phase}

The students evaluated the patient encounter phase as good. Learning from patient encounters (item 4) was rated particularly highly, with mean scores of between $3.8(95 \% \mathrm{Cl} \pm 0.14)$ and $4.7(95 \% \mathrm{Cl} \pm 0.07)$. The psychomedical cluster scored rather low on organisation of encounters (item 3; $3.0(95 \% \mathrm{Cl} \pm 0.16)$ ) and explanation by supervisor during patient encounter (item $5 ; 3.1(95 \% \mathrm{Cl} \pm 0.14)$ ). For the cluster on the locomotor system, mean scores on items 3 and 5 did not differ significantly from 3.5 .

\section{Self-study phase}

The answers to the items about the self-study phase showed that learning issues were generated on the basis of the patient encounters (item 6) in the clusters on abdomen $(4.3,95 \% \mathrm{Cl} \pm 0.09)$ and locomotor system $(3.8,95 \% \mathrm{Cl} \pm$ $0.11)$, but less so in the clusters on circulation \& lungs $(3.2,95 \% \mathrm{Cl} \pm 0.13)$ and psychomedical problems $(3.0,95 \% \mathrm{Cl} \pm 0.15)$. They also showed that the scores on clarity regarding educational goals (item 7 ) were borderline or lower, ranging from $2.8(95 \% \mathrm{Cl} \pm 0.14)$ to $3.4(95 \% \mathrm{Cl} \pm 0.12)$. For the cluster on circulation \& lungs, the mean score on this item did not differ significantly from 3.5.

\section{Reporting phase}

Overall, students gave high scores for the reporting phase. Scores were particularly high for the discussion about the patient encounters (item 8), ranging from $4.1(95 \% \mathrm{Cl} \pm 0.11)$ to $4.4(95 \% \mathrm{Cl} \pm 0.10)$, and for linking theory and practice (item 10), ranging from $3.9(95 \% \mathrm{Cl} \pm 0.11)$ to $4.2(95 \% \mathrm{Cl} \pm 0.09)$. Connections between educational activities (item 9$)$ received scores between $3.6(95 \% \mathrm{Cl} \pm$ $0.12)$ and $3.8(95 \% \mathrm{Cl} \pm 0.11)$, but only for the abdominal cluster the mean score on this item differed significantly from 3.5. 


\begin{tabular}{|c|c|c|c|c|c|c|c|c|c|}
\hline \multirow[b]{2}{*}{ Questionnaire items } & \multicolumn{3}{|c|}{$\begin{array}{l}\text { ABDOMINAL } \\
\text { REGION }\end{array}$} & \multicolumn{2}{|c|}{$\begin{array}{l}\text { LOCOMOTOR } \\
\text { SYSTEM }\end{array}$} & \multicolumn{2}{|c|}{$\begin{array}{l}\text { CIRCULATION } \\
\text { AND LUNGS }\end{array}$} & \multicolumn{2}{|c|}{$\begin{array}{l}\text { PSYCHOMEDICAL } \\
\text { PROBLEMS }\end{array}$} \\
\hline & Mear & $\mathrm{Cl}$ & (SD) & Mean $\mathrm{Cl}$ & (SD) & Mean $\mathrm{Cl}$ & (SD) & Mean $\mathrm{Cl}$ & (SD) \\
\hline \multicolumn{10}{|l|}{ Preparation phase } \\
\hline $\begin{array}{l}\text { 1. The courses in } \\
\text { years } 1 \text { and } 2 \text { provided } \\
\text { sufficient preparation for the } \\
\text { programme in this cluster. }\end{array}$ & 3.7 & \pm 0.10 & $(0.8)$ & $3.9 \pm 0.10$ & $(0.8)$ & $3.6 \pm 0.12$ & $(0.9)$ & $3.0 \pm 0.15$ & (1.1) \\
\hline $\begin{array}{l}\text { 2. The tutorials provided } \\
\text { sufficient preparation for the } \\
\text { patient encounters. }\end{array}$ & 3.9 & \pm 0.12 & $(0.8)$ & $3.1 \pm 0.15$ & (1.1) & $4.1 \pm 0.09$ & $(0.6)$ & $3.2 \pm 0.13$ & $(0.9)$ \\
\hline
\end{tabular}

\section{Patient encounter phase}

\begin{tabular}{|c|c|c|c|c|c|c|c|c|c|c|c|}
\hline $\begin{array}{l}\text { 3. The patient encounters } \\
\text { were well organised. }\end{array}$ & 4.3 & \pm 0.10 & $(0.7)$ & 3.6 & \pm 0.13 & (0.9) & 4.0 & \pm 0.10 & $(0.7)$ & $3.0 \pm 0.16$ & (1.2) \\
\hline $\begin{array}{l}\text { 4. I learned much from the } \\
\text { patient encounters. }\end{array}$ & 4.7 & \pm 0.07 & (0.5) & 4.5 & \pm 0.08 & (0.6) & 4.5 & \pm 0.09 & $(0.6)$ & $3.8 \pm 0.14$ & (1.0) \\
\hline $\begin{array}{l}\text { 5. During the patient } \\
\text { encounters the supervisor } \\
\text { explained clearly what was } \\
\text { done and why. }\end{array}$ & 3.6 & \pm 0.10 & $(0.7)$ & 3.5 & \pm 0.12 & $(0.9)$ & 3.7 & \pm 0.10 & $(0.7)$ & $3.1 \pm 0.14$ & (1.1) \\
\hline
\end{tabular}

\section{Self study phase}

\begin{tabular}{|c|c|c|c|c|c|c|c|c|}
\hline $\begin{array}{l}\text { 6. At the end of the patient } \\
\text { encounters learning issues } \\
\text { were formulated. }\end{array}$ & $4.3 \pm 0.09$ & $(0.7)$ & $3.8 \pm 0.11$ & $(0.8)$ & $3.2 \pm 0.13$ & (1.0) & 3.0 & \pm 0.15 \\
\hline $\begin{array}{l}\text { 7. It was clear to me what } \\
\text { was expected of me in terms } \\
\text { of knowledge and performan- } \\
\text { ce at the end of the cluster. }\end{array}$ & $3.2 \pm 0.13$ & (0.9) & $2.8 \pm 0.14$ & (1.0) & $3.4 \pm 0.12$ & (0.9) & 3.1 & \pm 0.13 \\
\hline
\end{tabular}

\section{Reporting phase}

\begin{tabular}{|c|c|c|c|c|c|c|c|c|c|c|c|}
\hline $\begin{array}{l}\text { 8. The patient encounters } \\
\text { were discussed adequately } \\
\text { during the tutorials. }\end{array}$ & 4.4 & \pm 0.10 & $(0.7)$ & 4.3 & \pm 0.11 & $(0.8)$ & 4.1 & \pm 0.11 & $(0.8)$ & 4.1 & \pm 0.10 \\
\hline $\begin{array}{l}\text { 9. There were clear connec- } \\
\text { tions between the different } \\
\text { educational activities during } \\
\text { the cluster. }\end{array}$ & 3.8 & \pm 0.11 & $(0.8)$ & 3.6 & \pm 0.10 & $(0.7)$ & 3.6 & \pm 0.12 & (0.9) & 3.6 & \pm 0.11 \\
\hline $\begin{array}{l}\text { 10. The links between theory } \\
\text { and practice became clear } \\
\text { during the tutorials. }\end{array}$ & 4.2 & \pm 0.09 & $(0.7)$ & 4.0 & \pm 0.12 & (0.9) & 4.2 & \pm 0.09 & $(0.7)$ & 3.9 & $\pm 0.11 \quad(0.8)$ \\
\hline
\end{tabular}


Preparation phase

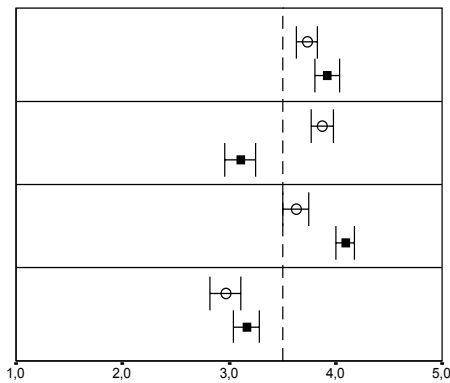

$\mathrm{O}=$ item $1 \quad 95 \% \mathrm{Cl}$

- $=$ item 2

\section{Self-study phase}

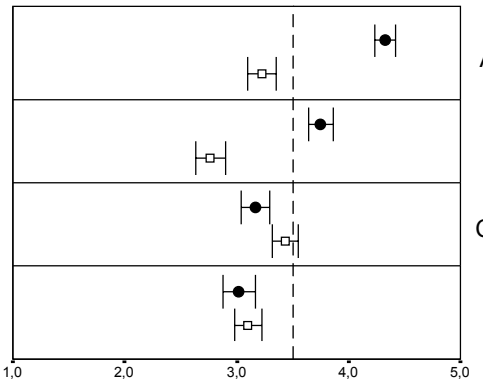

= item $6 \quad 95 \% \mathrm{Cl}$

$\square=$ item 7

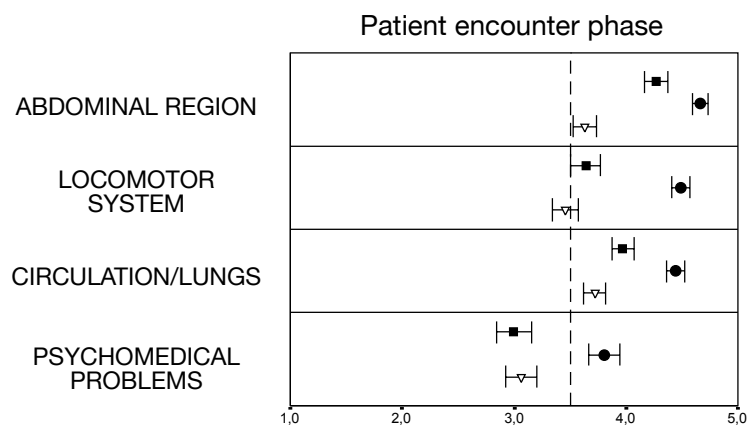

$$
\begin{aligned}
\mathbf{\square} & =\text { item } 3 \quad 95 \% \mathrm{Cl} \\
\mathbf{0} & =\text { item } 4 \\
\nabla & =\text { item } 5
\end{aligned}
$$

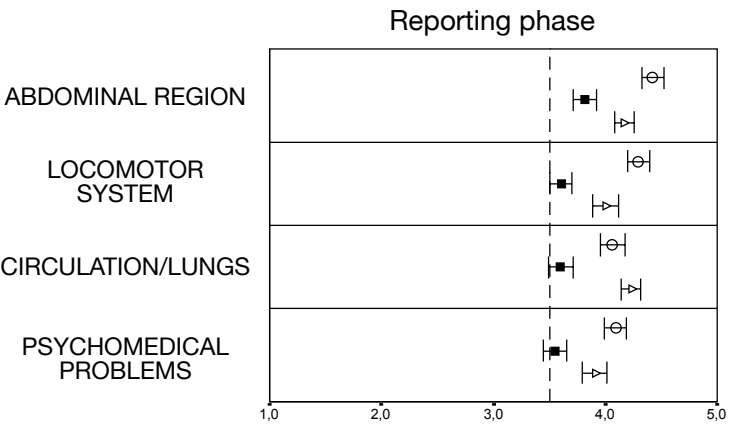

$$
\begin{aligned}
O & =\operatorname{item} 8 \quad 95 \% \mathrm{Cl} \\
\mathbf{D} & =\operatorname{item} 9 \\
D & =\text { item } 10
\end{aligned}
$$

Figure 3 95\% Confidence intervals per PBL-phase for the different clusters.

Discontinuous line at 3.5 represents the distinction between scores below 3.5 and scores of 3.5 and higher

Table 1 Results of the questionnaire: means, $95 \%$ confidence intervals $(\mathrm{Cl})$ and standard deviations (SD) of the item scores (Likert scale $1-5$ ) by cluster 


\section{CONCLUSIONS AND DISCUSSION}

Overall, students appear to be satisfied with the patient encounter phase and indicate that they learn a great deal from it. This supports Dornan's findings that early patient contacts have the potential to enhance learning. ${ }^{7}$ The reporting phase is also rated highly. Students strongly agree that the patient encounters are discussed adequately during this phase. This positive view is reinforced by the relatively high scores concerning connecting theory and practice. These results are indicative of positive effects of the early introduction of real patient encounters in a PBL curriculum. ${ }^{7}$ This can be seen as support for the view that real patient encounters can act as a powerful driving force for meaningful and profound learning. ${ }^{1,2,7,8}$ It should be taken into account though that further research is needed to further investigate the value-added of real patients in PBL.

However, the results also reveal that there are areas where improvement is needed. First of all, students are less satisfied with the preparation phase. An explanation for this may be that the preparation phase does not follow the intended pattern, for instance when prior knowledge is not activated or the preparation phase is omitted altogether. Lower satisfaction with preparation may also be due to a patient who fails to show up at the outpatient clinic being replaced by another patient with a different problem than the one prepared for during the tutorial. Another negative finding is the relatively low scores for the self-study phase. The main problem appears to be that it is not clear to the students what is expected of them in terms of knowledge and performance at the end of the clusters. This may be caused by problems in relating the stated objectives to practical experience, for instance when a patient problem does not fit the theme of the cluster. ${ }^{10}$ Low scores were also found for the learning issues the students are expected to generate on the basis of the patient encounter. The clinical supervisor is supposed to guide this process.

Possibly, the low scores may be attributable to clinical supervisors providing too little or unsatisfactory guidance.

Finally, students appear to be less satisfied in general with the cluster on psychomedical problems. The explanation for this may be that this domain receives only limited attention during Years 1 and 2 and students have little prior knowledge in this area. It has been shown that absence or insufficiency of prior knowledge may inhibit favourable learning effects. ${ }^{14}$ This might be resolved by 
changing the curriculum to the effect that more attention is paid to psychomedical problems before Year 3.

Several recommendations can be derived from the results. Students' uncertainty as to what is expected of them in terms of knowledge and performance at the end of the clusters may be remedied by giving them better information on the educational objectives. It is important that this information should also be provided to coaches and clinical supervisors, because they must be aware of what students are expected to achieve. Knowing what is expected might also have a beneficial effect on clinical supervisors' guidance of students in generating learning issues. Teacher training can also be a crucial factor in the successful implementation of real patient encounters in a PBL environment. ${ }^{15}$ Further improvement of the programme will require more time for teacher training, which may include information about the topics that have to be dealt with in order to make clear to the teachers how to work on the objectives of the courses.

Patient selection is a crucial factor in the success of PBL with real patients. Using real patients as opposed to paper patients brings the risk of patients not turning up at the appointed time. As stated above this may interfere with educational goals, because the patients who replace the no-show patients may not fit the cluster's theme and educational goals. ${ }^{4,5,10,11}$ Being suddenly faced with a patient presenting with another problem than the one prepared for demands great flexibility from students and may severely detract from the effectiveness of the preparation phase. In summary, patient selection deserves very careful consideration in setting up a programme with a large number of real patient encounters. One of the limitations of this study is that it is based exclusively on students' opinions and that teachers' views were not considered. Another limitation is that the roles of the coaches and clinical supervisors were not evaluated in the questionnaire, although these roles are generally assumed to be crucial for the success of such programmes. ${ }^{15}$ More in-depth research will have to shed light on how students learn from patient encounters.

This study shows that in the opinion of the students integration of theory and practice is promoted by real patient encounters. This supports the idea that using real patients as the driving force for learning early in medical education might offer a solution to the transition problem between pre-clinical and clinical training. ${ }^{2,3}$ More in depth research will have to be conducted to validate this finding. 


\section{REFERENCES}

1. Norman GR, Schmidt, HG. The psychological basis of problem-based learning: A review of the evidence. Academic Medicine 1992;67:557-565.

2. Prince, KJAH, van der Wiel, M, Scherpbier,AJJA, van der Vleuten, CPM, Boshuizen HPA. A qualitative analysis of the transition from theory to practice in undergraduate training in a pbl-medical school. Advances in Health Sciences Education 2000;5:105 - 116.

3. Prince, KJAH, Boshuizen HPA, van der Vleuten CPM, Scherpbier AJJA. Students' opinions about their preparation for clinical practice. Medical Education 2005;39:704-712.

4. O'Neill PA, Morris J, Baxter, CM. Evaluation of an integrated curriculum using problem-based learning in a clinical environment: The Manchester experience. Medical Education 2000;34:222-230.

5. O'Neill PA, Willis SC, Jones A. A model of how students link problem-based learning with clinical experience through "elaboration". Academic Medicine 2002;77:552-561.

6. Dammers J, Spencer J, Malcolm T. Using real patients in problem-based learning: Students' comments on the value of using real, as opposed to paper cases, in a problem-based learning module in general practice. Medical Education 2001;35:27-34.

7. Dornan T, Bundy C. What can experience add to early medical education? Consensus survey. British Medical Journal 2004;329:834-837.

8. Littlewood S, Ypinazar V, Margolis, SA, Scherpbier A, Spencer J, Dornan T. Early practical experience and the social responsiveness of clinical education: Systematic review. British Medical Journal 2005:331:387-391.

9. Parsell G, Bligh J. Recent perspectives on clinical teaching. Medical Education 2001;35:409-414.

10. van Bokhoven MA, van Dalen J, Metsemakers JFM, van Enckevort C. The Maastricht adoption programme in general practice: The students' view. Education for Health 1998;11:57-64. 
11. Mainhard T, van den Hurk MM, van der Wiel, MWJ, Crebolder HFJM, Scherpbier, AJJA. Learning in a clinical education programme in primary care: The Maastricht adoption programme. Medical Education 2004;38:12361243.

12. van der Wiel MWJ, Schaper NC, Scherpbier AJJA, van der Vleuten CPM, Boshuizen HPA. Students' experiences with real-patient tutorials in a problem-based curriculum. Teaching and Learning in Medicine 1999;1:12-20.

13. Eva KW. What every teacher needs to know about clinical reasoning. Medical Education 2005;39:98-106.

14. Schmidt HG. Foundations of problem-based learning: Some explanatory notes. Medical Education 1993;27:422-432

15. Dent JA. AMEE Guide No 26: clinical teaching in ambulatory care settings: making the most of learning opportunities with outpatients. Medical Teacher 2005;27:302-315. 


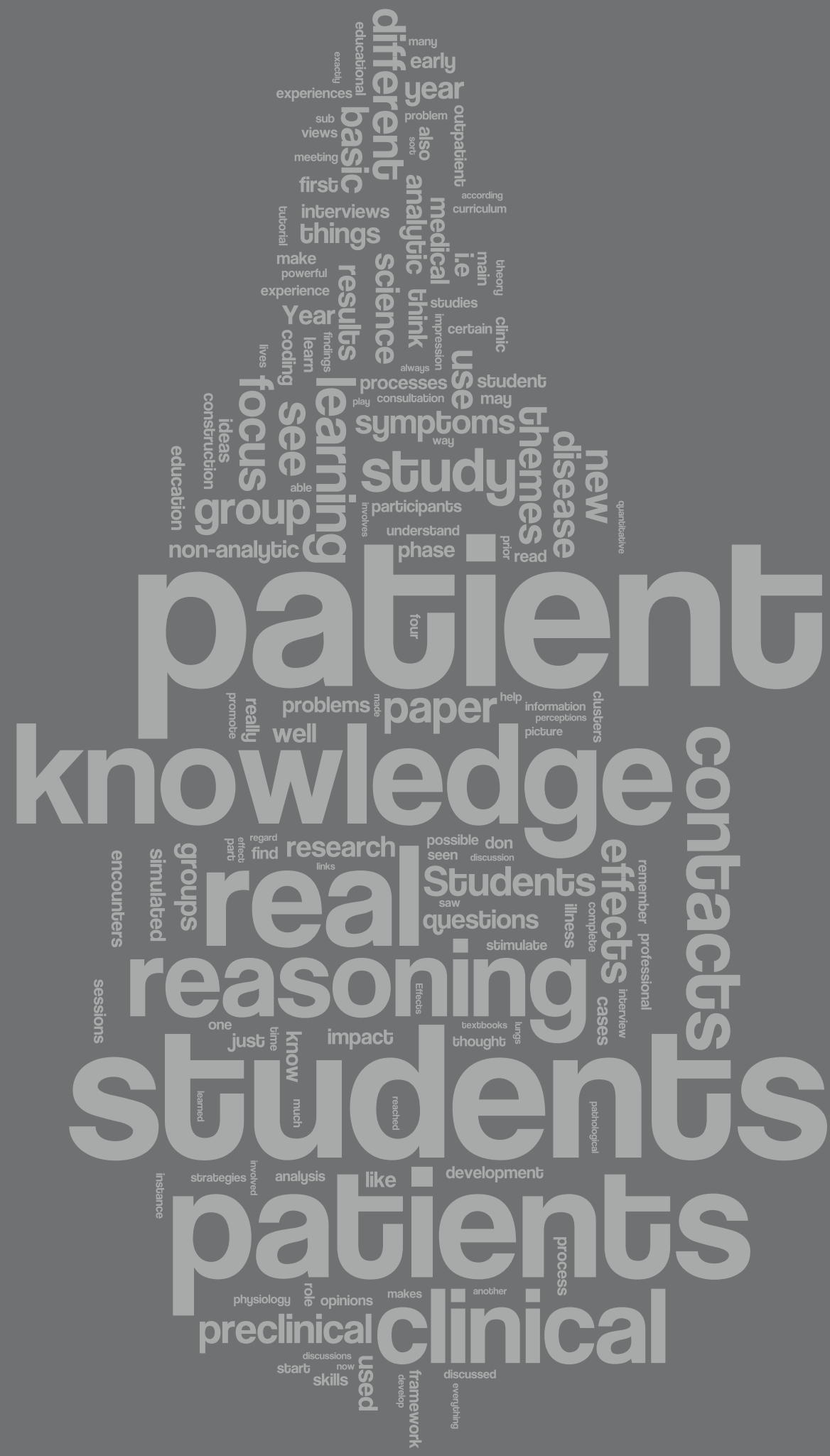




\section{CHAPTER 4}

Students' opinions about the effects of preclinical patient contacts on their learning

Agnes D Diemers, Diana HJM Dolmans, Maarten GM Verwijnen, Erik Heineman, Albert JJA Scherpbier

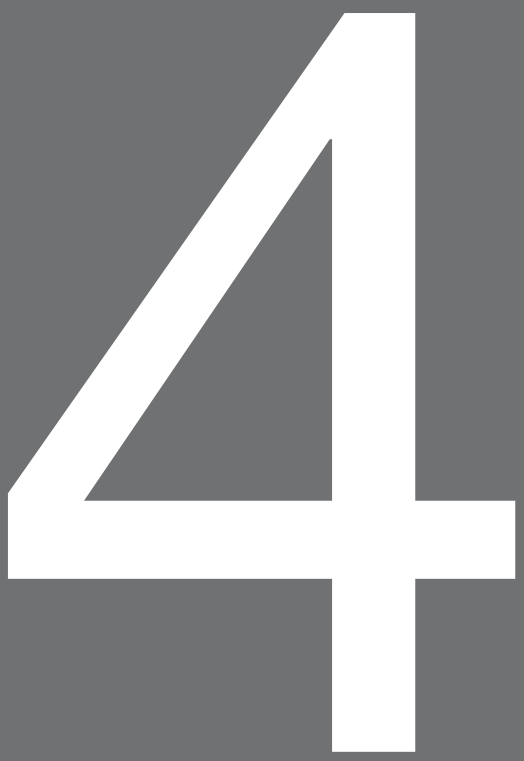

Published in Advances in Health Sciences Education 2008; 13: 633-647 


\section{ABSTRACT}

\section{Introduction}

Several reasons have been given why students should have contacts with real patients early in the undergraduate medical curriculum, i.e. in the preclinical phase. However, it is not clear exactly what effects early patient contacts have with regard to knowledge construction and the development of clinical reasoning skills. We sought students' views of the effects of preclinical real patient contacts on their learning, knowledge construction and development of clinical reasoning.

\section{Method}

Twenty-four students in the third and last preclinical year of a 6-year undergraduate medical programme were divided into three focus groups which met twice, after which saturation was reached. The discussions were recorded and transcribed. Summaries of the discussions were approved by the students after some modifications. Atlas-ti software was used to create a coding framework resulting in identification of main themes and sub themes.

\section{Results}

Early patient contacts motivate students to study, help them understand the impact of illness on patients' lives, and enhance professional socialisation and memory processes. Students distinguish between analytic and non-analytic clinical reasoning in connection with real patients. Analytic reasoning involves clinical and basic science knowledge. Non-analytic reasoning involves pattern recognition and is made possible by experiential learning from different patient contacts.

\section{Discussion}

The students indicate that seeing real patients early in their training has several positive effects on their learning. The contacts enhance knowledge construction and clinical reasoning. Although our results will have to be validated by quantitative, observational and experimental research, they imply that educational benefits are to be gained from real patient contacts in the preclinical phase of medical education. 


\section{INTRODUCTION}

Real patient contacts early in medical education, i.e. in the preclinical phase, have been advocated for several reasons. They are assumed to ease the transition from preclinical to clinical training, motivate students to learn, and help them forge their professional identity. ${ }^{1-4}$ Students have been reported to feel more comfortable performing physical examination and be more aware of the impact of illness on patients as a result of seeing real patients. ${ }^{3,5,6} \mathrm{~A}$ systematic review of early patient contacts cited positive effects on professional socialisation. ${ }^{7}$ Reported positive effects also include improved acquisition and retention of knowledge and contextualisation of basic science knowledge by linking real patients with theory. ${ }^{1-3,8}$ However, no detailed studies have addressed exactly in what way early patient contacts impact on how students acquire knowledge, use basic science knowledge and integrate basic science and clinical knowledge during clinical reasoning. In a paper in which he synthesised the literature on clinical reasoning Norman ${ }^{9}$ contended that research on clinical reasoning generally focuses on "the processes doctors use to arrive at an initial diagnosis based on history and physical examination". He distinguishes basic science knowledge, i.e. formal knowledge, including illness scripts and schemas, and experiential knowledge, i.e. informal knowledge, consisting of a store of exemplars resulting from past experience. Norman ${ }^{9}$ suggests that experts resort to basic science knowledge mainly when solving "rare and complex" patient problems but rely mainly on similarity-based reasoning when it comes to common and less complex problems. Accordingly, Eva ${ }^{10}$ made the distinction between analytic and non-analytic clinical reasoning. Experts use analytic reasoning to explain and understand the mechanisms involved in relating symptoms and diagnosis. Non-analytic reasoning refers to pattern recognition involving comparison of new and past cases, combined with assessing the probability of a new case falling within a particular diagnostic category. Given the strong role of experience in both Eva's ${ }^{10}$ and Norman's ${ }^{9}$ views on clinical reasoning, patient contacts may have a prominent part to play in expertise development in this area.

Earlier studies of students' patient contacts were mostly limited to the clinical phase of undergraduate education, investigating the effect of student contacts 
with patients during the clinical phase, or the assumed effects of preclinical patient contacts. ${ }^{1,2}$ Manchester implemented PBL in the clinical years of the medical curriculum using paper cases as the starting point for learning, with students seeking clinical experiences linked to the paper cases. Students stated that their clinical experiences helped them elaborate on their knowledge. ${ }^{11}$ However, none of the described studies used real patients as the starting point for learning in the preclinical phase of medical education, which may lead to additional effects on student learning and more specific on clinical reasoning. Recently, Maastricht Medical School introduced real patient encounters in Year 3 of their preclinical medical PBL curriculum. A first evaluation of the preclinical real patient contacts indicated that according to the students the encounters enhanced integration of theory and practice. ${ }^{12}$ The limitations of that study were, however, that it elicited only superficial information about the effects of the implementation of preclinical patient contacts on students' learning. Because of the assumed effects of experience with patient contacts on the learning of students and more specifically on the development of their clinical reasoning ability, we conducted a study aimed at in-depth investigation of the effects of preclinical real patient contacts. We sought students' perceptions of the effects of preclinical real patient contacts on their: 1) learning; 2) knowledge construction; and 3) development of clinical reasoning.

\section{METHODS}

\section{Setting}

We explored the opinions of students in Year 3 of the 6-year problem-based learning $(\mathrm{PBL})$ curriculum of Maastricht Medical School. Year 3 is the last preclinical year, after which clinical clerkships start in year 4. In Years 1-2 small group tutorials, using paper patients, are the predominant educational format. A recent curriculum change discarded the paper patient based tutorials in Year 3 and replaced them by real patient encounters in the teaching outpatient clinic in the academic hospital. These patient encounters are used as triggers for learning in the tutorials related to the encounters. Clinical skills are learned during a 5 year clinical skills programme starting in Year 1 and continuing through Year 5.

In Year 3 the students rotate through four 10-week clusters, each dedicated to a 
different domain of chronic disease. For logistical reasons all students in Year 3 are divided into four groups which complete the four clusters in different order. The basic educational unit is the tutorial group of 10 students and a tutor, the so-called coach. Coaches are staff members of the disciplines participating in the thematic clusters. Group composition and coaches change every cluster. The weekly recurring PBL cycle in Year 3 starts with a session in which students prepare for their upcoming patient encounter by discussing vignettes of the (type of) patient problem they will see in the hospital. During the patient encounter phase, 1-2 days after the tutorial, student pairs see patients with chronic disorders in the teaching outpatient clinic of the University Hospital of Maastricht. The students perform the first part of the consultation, i.e. they take a history and examine the patient. After that they consult the patient's attending physician, the so-called clinical supervisor, and together they return to the patient to complete the consultation. Subsequently, the clinical supervisor discusses the encounter with the students, helps them derive learning objectives and gives feedback on their performance. The students pursue the learning objectives through self study and present and discuss their findings in the next tutorial, taking place one week after the first (preparatory) session.

\section{Research methodology}

In exploring students' perceptions of the effects of early patient encounters, we focused on students perceptions of how their learning was affected by the contacts and why they thought this was so. Students' opinions were explored in focus group interviews. This method has been shown to be effective in eliciting a rich variety of opinions from groups. ${ }^{13}$ Participants in focus groups share, compare, and explore their ideas and experiences about specific issues and by doing so generate their own interpretations. ${ }^{14}$ They are asked to contemplate their own ideas in the context of the ideas of others. ${ }^{15}$

\section{Subjects}

All students in Year 3 in the academic year 2004-2005 were invited to participate in a focus group. An email was sent to all the students, explaining the purpose and procedure of the study and inviting volunteers to participate. Next, all the students were approached in person by the principal researcher during skills 
training sessions at the end of the academic year 2004-2005, when the students had completed almost all of the four clusters in Year 3. Three focus groups, each consisting of eight students, were composed by purposive sampling. Purposive sampling was used to achieve a relevant mix of educational experiences. It involved selecting the students in chronological order of response. The selection criteria required that each focus group should consist of four pairs of students who were attending different clusters at the time of the interview and who had preferably not been in the same tutorial group at any time during the year. In this way we aimed to achieve representation of experiences with as many different tutorial groups and coaches as possible to maximise diversity of experiences in the groups and thereby stimulate discussion. ${ }^{16}$ This resulted in two focus groups of 6 female students (75\%) and 2 male students (25\%) and one focus group of 5 female students $(62.5 \%)$ and 3 male students (37.5\%). Gender distribution in the cohort was 201 (70\%) female and 90 (30\%) male students. Participation was voluntary and students received a small compensation. Students were assured that the results would be reported anonymously. Currently, educational studies reporting students' opinions do not require approval from the ethics committee in the Netherlands.

\section{Instruments}

The focus groups were asked to answer open-ended questions about three topics (Appendix A):

1 The effects of real patient contacts on their learning;

2 The effects of real patient contacts on their knowledge construction;

3 The effects of real patient contacts on their clinical reasoning.

\section{Procedure}

Each focus group met twice for 90 minutes. A third meeting was not considered necessary since by the end of the second meeting no new points of view were emerging, i.e. saturation had been reached. A second focus group meeting was considered necessary, because in the debriefing sessions and in the initial analysis of the summaries of the first focus group meetings, topics were identified that were clearly in need of further clarification or more in depth discussion. The first moderator (MV) of the focus group sessions had more than 30 years of 
experience with small group education. He guided the interview and stimulated the discussion by asking additional questions and encouraging all participants to contribute to the discussion. The assistant moderator (AD), the principal researcher, observed, took notes and audio taped the interviews. At the beginning of each interview MV stated the rules of the meeting: participants were invited to share and compare their views and ideas, and modify them in light of the ideas of other participants. They were informed that analysis and reporting of the results would be anonymous. In debriefing sessions following each interview, the moderators shared their impressions of the session. They discussed whether appropriate information had been gathered and whether it was necessary to adjust the questions for the next interview in light of the research questions. Initial identification of major themes was established during these sessions.

The recordings of all the interviews were transcribed literally by the principal researcher. Summaries were written and submitted to the participants for approval. The students were asked to send comments and suggestions for modifications to the moderators before the next meeting. All the students responded and approved the summaries after some minor adjustments had been made.

\section{Analysis}

The transcripts of the interviews were imported into the software program ATLAS-ti. ${ }^{17}$ Initial coding of text fragments based on content was done through multiple coding by two researchers (AD and AS) independently. ${ }^{18}$ The coding framework was discussed by the researchers and modified until agreement was reached. The transcripts were re-read and modifications in the coding were established in accordance with the agreed coding framework. In the same way agreement was reached on a thematic framework, consisting of main themes and sub themes (Table 1). The main themes correspond with the main research questions discussed by the focus groups, with new themes that were raised by the participants during the discussions and with analytical themes that emerged during the analysis. ${ }^{19}$ The sub themes resulted from our analysis of the data using the coding framework. In this way we identified new themes and sub themes during analysis of the data alongside the main themes established through our research questions. ${ }^{20}$ All text units belonging to a code of the coding framework were sorted according to the themes of the thematic framework. Text units were 
re-read to be sure that no "emerging themes" had been overlooked. Illustrative quotes were selected, translated, and, when necessary, edited to improve clarity without changing meaning.

\section{RESULTS}

We present the results for the main themes and the sub themes (Table 1) and illustrate them with quotations from the focus group sessions.

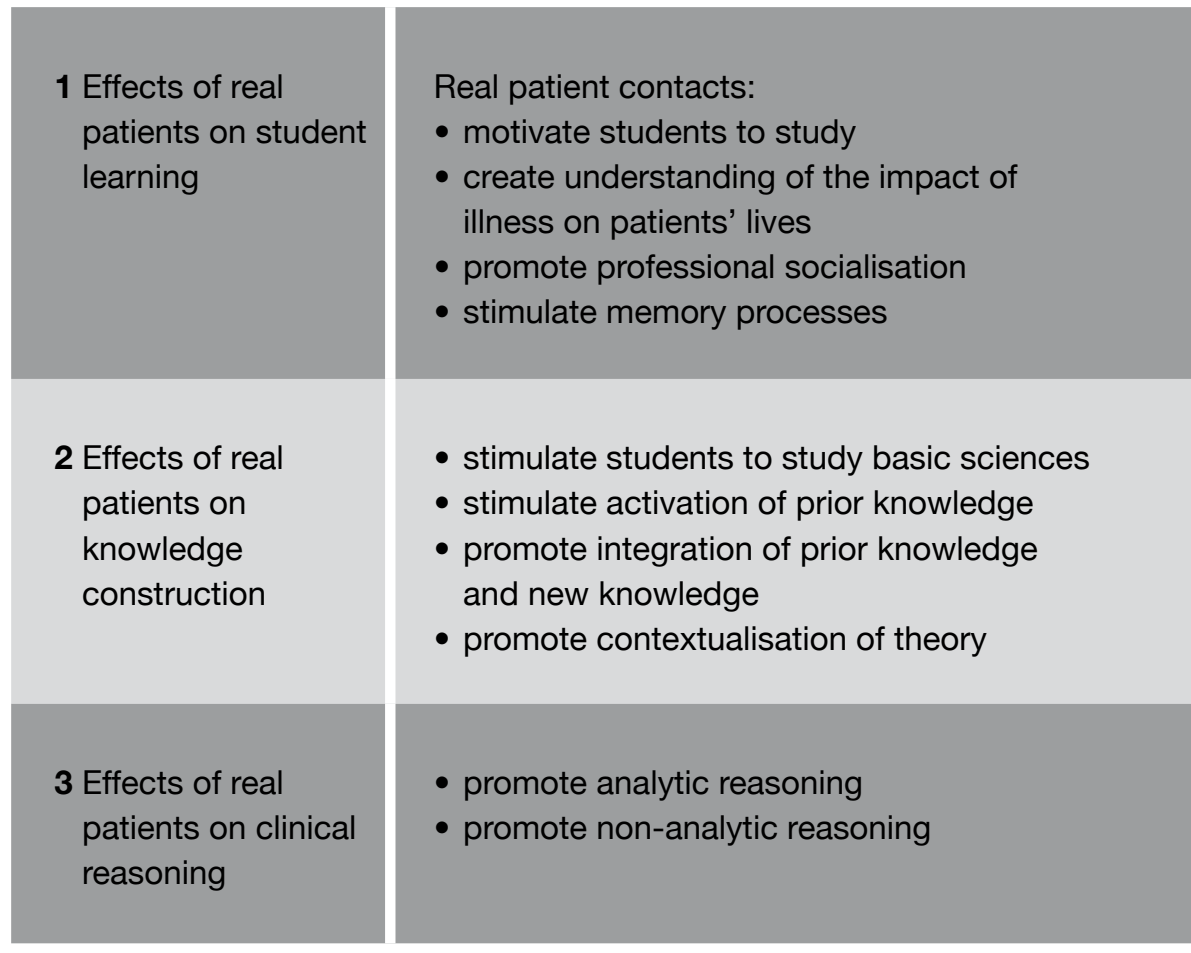

Table 1 Main themes and subthemes discussed during the focus group interviews

\section{Effects of real patient contacts on student learning}

\section{Motivation to study}

Taking part in a real consultation with a real patient is a strong incentive for students to prepare for the contact. They are keen to avoid failure in front of a 
patient and take the responsibility for their part in the process of patient care very seriously. No paper patient can provoke comparable, powerful feelings.

"When you know you are going to see a real patient, you study really hard, because you want to do your best and not be stuck for answers. . . you don't have the same sense of urgency with paper patients." (S7.2.1)

"Before you go to the outpatient clinic, you feel stimulated to study because you are given responsibility." (S4.3.1) "It is not as if you have to make real decisions but it is your responsibility to conduct the consultation and treat the patient with respect and you can actually mean something to that patient." (S2.3.1)

Seeing real patients excites students' curiosity. It is a more powerful motivator to study the literature than paper patients could ever be.

"When I have seen a real patient I am much more motivated to study than after discussing a paper patient." (S5.1.1)

\section{Understanding the impact of illness}

Students say that the contacts are a real eye opener with respect to the impact of illness on patients' lives. They see that the limitations experienced by patients due to symptoms can have a farther reaching impact on patients' lives than they had thought possible.

"I learn a lot about what a disease does to a patient's life. You see that even the most insignificant, trivial disorders can have a huge impact. You don't realise that when you only read about it. For instance when you read in textbooks about Dupuytren's contracture. And then, when you see it for real, you think: yes, I would be really fed up if I had that." (S2.2.1)

Because the students see many different patients, they come to realise that illness affects different patients in different ways. This can help them put patients' stories into perspective. 
"I once saw a lady in the outpatient clinic who . . thought her disorder was severely limiting, whereas earlier I had seen a man with heart failure who had only a few more weeks left to live. That makes you put things somewhat into perspective for this lady." (S1.2.2)

\section{Professional socialisation}

Students report that patient encounters help them get used to dealing with real patients and their future professional role as a doctor. In their opinion, this cannot be achieved by paper patients.

"When I saw my first patient in the outpatient clinic, I thought like "strange a real patient". But after a while it makes no difference. But that takes time. And getting used to the role of doctor-patient. You don't learn that from paper cases." (S1.2.1)

\section{Memory processes}

Students say that they remember more about a disease when they see a real patient than when they only read about it. Seeing real patients intensifies self study and efforts to link theory and patients. This promotes retention and facilitates retrieval of knowledge.

Students' active involvement in consultations with real patients when they take a history and examine the patient encourages them to think actively about patients' problems, which in turn may enhance storage and retrieval of knowledge.

"When you have conducted the consultation yourself, you remember the patient and the things you or the supervisor have said about it much better." (S7.1.2)

"When the coach asks critical questions you are stimulated to think about where your knowledge is stored or something. You know which drawer to open. And that makes it easier to remember things." (S7.3.2)

The students say that memorable cases, i.e. patients who arouse strong emotions or patients who make a specific impression, are easier to remember. 
"Some patients you will never forget." (S3.3.2) "They have to be really different, trigger an emotional response, no matter what sort, but the impression has to be powerful." (S7.3.2)

The power to bolster knowledge storage and retrieval is an important distinction between real patients and paper patients. Students do not remember much about paper patients because they make less of an impression.

"Paper patients make less of an impression on you." (S8.2.1)

The same applies for simulated patients. Students are aware of participating in role play in consultations with simulated patients. The patients' emotions do not seem real to them. Another drawback of simulated patients is that some physical signs are difficult to simulate realistically, which reinforces students' sense of play-acting.

"Somehow you just don't believe in simulated patients. You know it is just play acting. You do try and get into the part and all that, but it is different all the same." (S4.2.1)

"In a simulated patient you cannot see the impression. You hear everything. But when his ankle is broken, the ankle is not red or swollen. All he can simulate is that he is unable to stand on it. It is just not complete. A real patient has everything, or in any case has real complaints and that like creates the picture. With a simulated patient there will always be a gap." (S7.3.2)

\section{The effects of real patient contacts on knowledge construction}

\section{Basic sciences}

Students perceive basic science knowledge as a prerequisite for understanding how patient problems are related to underlying concepts. Seeing real patients motivates students to brush up on their basic science knowledge. 
"With real patients you are sort of forced to use your old knowledge of physiology, anatomy." (S2.2.2)

It is like this, physiology, when you understand it, it becomes much easier to learn about pathology. Then you have some idea of where the patient's symptoms are coming from.' (S4.2.2)

\section{Prior knowledge}

Real patients stimulate not only acquisition of new knowledge but also activation of existing knowledge. Forging new links between new and prior knowledge strengthens students' knowledge networks.

"Because a patient makes you want to study new things, you are more motivated. So then you activate the knowledge you already have and the new information you are going to learn." (S3.2.2)

"You have to know both. New knowledge and old knowledge. When they are both separate, they are of no use to you." (S5.3.2) "You find that you can place things. That you don't think it strange that a patient should have a certain complaint because you can relate it to your basic science knowledge from year 1 and year 2." (S2.3.2)

\section{Integration of prior knowledge with new knowledge}

Integrating prior and new knowledge increases students' awareness that they are connecting pieces of information and creating a coherent knowledge network.

"You know a certain disease because you have learned the theory. And then you see a real patient who fits into that and then, well you get the full picture." (S2.3.2)

"You are better able to see the whole picture. As if some things just fall into place, whereas first they just floated around loosely inside my head." (S3.2.2) 
Students feel that this process happens unconsciously and automatically. Critical questions asked by the coach or other students make them aware of this process and this reinforces integration of new and old knowledge.

"You are like constructing new knowledge on top of your old knowledge, making links. In my opinion it is a passive process." (S2.2.2)

"Yes it is an automatic thing. And that you start to think much more for yourself when you are studying." (S8.2.2)

"When I am studying I am not really aware of it. Then I think that you are not consciously making links, like for yourself, and when you have to explain things to some-one else or you have to answer a question, that is the time when you are actively engaged in it. And in those cases, at least for me, it is rather more productive." (S7.2.2)

\section{Contextualisation of theory}

Experiences with real patients improve students' comprehension of subject matter, because real patients are powerful illustrations of pathological mechanisms described in textbooks.

“. . . when you have studied a certain disease, pathology, and you have seen a patient with the disease, then you can make the link. . . . When I read about it in a book, I can suddenly understand the patient." (S4.2.2)

"For instance, you read in textbooks that some-one has difficulty breathing when they lie down flat. But, well you don't really see it happening. And when you have seen a patient in the outpatient clinic who lies down on the examination table and turns all red, then you see it immediately before you when you read about it afterwards." (S1.2.1)

Students say that real patient problems help them form a more complete picture of disease and underlying mechanisms. They also obtain a more holistic view of patients, which goes beyond the organ system(s) involved in the presenting problem. 
$\therefore$.. when you see real patients more and more pieces of the jigsaw start to fall into place. Because with paper cases, then you, like we are doing the lungs, you just focus on the lungs. And now, in practice, I find that it is not just about the lungs, it is about the whole system and everything else that is involved. Much more complete when you see real patients." (S8.2.1)

Due to contacts with different patients with similar disorders students discover that diseases often do not conform to the typical picture or course described in textbooks but have different dimensions. This furthers comprehension as well.

"Another thing that makes a patient easy to remember is when something does not fit with what is in the book. And again that is actually really helpful to better understand both the real patient and pathophysiology." (S8.1.2)

"When you see a real patient, you see that things are not always exactly according to the description of the disease. It can look very differently." (S5.2.2)

"And you start to see that a disease can have different manifestations. One patient has different symptoms from another one. And when you read it (disease) in a book, you think, yes ... But when you are looking at a real patient then for instance he does not have the first three symptoms but he does have the last four ones. That is also possible. And then you realise that a disease has many dimensions because you see many different patients" (S1.3.2)

Students say that simulated patients always portray a typical patient, i.e. the standard textbook presentation of a particular disease. That is why simulated patients add nothing to what they learn from real patients. The same comment is made about paper patients.

"Simulated patients always have symptoms exactly by the book" (S3.1.2)

"Most paper patients are very typical, very characteristic." (S5.2.2) 
"With a real patient you have to find things out for yourself and ask questions. With paper patients you don't even have to find things out, for it is all written down in the paper case, all the information you need." (S2.1.2)

\section{The effects of real patient contacts on clinical reasoning}

With regard to clinical reasoning skills, students say that initially they ask questions from memorised checklists. After a while they are able to abandon these lists and move on to more deliberately structured clinical reasoning. The fact that both their basic science knowledge and their clinical knowledge increase during the year facilitates this transition.

"For example in year 1, when I had to learn about a disease I would memorise lists of symptoms and now I try to find out what is going on and what causes the symptoms. And then I can explain them, and then I no longer need that list. I have more background knowledge now. Then I only learned lists by heart, and I have totally stopped doing that now." (S4.2.2)

". . . I could really think in certain steps. It was a chronic patient with multiple symptoms and then you find that you can start to sort of order them. Well, I know for sure that at the beginning of third year I would definitely not have been able to do that." (S2.2.2)

During the year students become increasingly able to integrate the knowledge from the different clusters. One student described how he used knowledge about circulation and lungs to understand symptoms of impotence in a patient he saw in the cluster on abdominal region.

"For instance I saw a man with complaints about impotence and he proved to have a history of cardiac complaints and vascular problems. And then you think like, well, but that can also occur there so that you get those problems. And in that way, eh, you use different things, like in the urology outpatient clinic you saw this and in cardiology you learned that, well, but those things can also be combined." (S4.3.2) 


\section{Analytic reasoning}

The analysis of the discussions revealed that students use two types of clinical reasoning. The first one involves explaining and understanding relations between signs and symptoms and disease. To this end students use what they know about pathological mechanisms of disease and basic science. This is a conscious process, which is frequently triggered by questions from teachers or peers.

"When for instance you have something pathological and you say this is the physiology we have just discussed that or it is assumed that it is known, then you say, eh, well the patient is vomiting, what might cause this? Yes, you know physiology, you know how food is swallowed normally, how it is digested and everything. Why should a vomiting reflex occur? Suppose large chunks of food come out. How is that possible? Which pathological mechanism would be more likely than another one? You start to reason from physiology to find out about pathology." (S4.3.2)

\section{Non-analytic reasoning}

The second method of clinical reasoning involves recognising patterns in patient problems. This is often an unconscious process which starts as soon as students have seen one patient with a certain problem.

"Suppose you see another patient with a complaint that is sort of similar, then that rings a bell like hey this looks familiar. It might be this and that, this I have seen before. I think you are not conscious of it." (S6.2.2)

"A little boy had pneumonia and I had done that together with the GP. And the next time I was at the GPs, it was winter again, so another boy turns up with very similar symptoms. And then I immediately thought well, that might be pneumonia as well. And it actually turned out that it was and I had really spotted it." (S5.3.2) 


\section{CONCLUSIONS AND DISCUSSION}

The results of our study indicate that in the students' opinion their learning benefits from real patient contacts. The results furthermore demonstrate that, according to the students, different kinds of knowledge constructions are emerging and different ways of clinical reasoning, i.e. problem solving strategies, are developing.

The results of our study are consistent with earlier findings about the effect of real patients on student learning: the real patient leads to better acquisition and retention of knowledge, motivates learning, vividly demonstrates the impact of disease on patients' lives, and stimulates the process of professional socialisation. 1,2,4-6,21 However, our study revealed additional effects of preclinical patient contacts on student learning. According to the students analytic as well as non-analytic reasoning strategies were being developed. Experts have been shown to use both types of reasoning, either separately or in combination, when addressing clinical problems. ${ }^{10,22-24}$ Novices on the other hand have been found to use analytic reasoning strategies in favour of non-analytic strategies because they do not have enough experiential knowledge. ${ }^{24}$ Conversely, recent studies showed that pattern recognition is a powerful tool in diagnostic accuracy in experts as well as in novices after they had been explicitly instructed to use pattern recognition, especially when used in combination with other reasoning strategies. ${ }^{25,26}$ The results of our study suggest that medical students, who are clearly novices, are able to develop and use both ways of clinical reasoning even without explicit instruction but with real patients as the driving force for their learning. With regard to analytic reasoning, students argue that real patient encounters stimulate them to study basic science. Combined use of basic science and clinical knowledge helps them to explain connections between signs, symptoms and diagnosis. When students use analytic reasoning, they give meaning to the symptoms of the patient but also to their basic science knowledge. This is supposed to enhance recall and retention. ${ }^{27}$ With regard to non-analytic reasoning, it seems that students think that practice with multiple patient examples helps them build experiential knowledge structures. Experiential knowledge networks are built upon examples derived from past experience. Both kinds of clinical reasoning, analytic and non-analytic, are needed to ensure transfer of knowledge and problem solving 
strategies so that they can be used to resolve new patient problems. ${ }^{10,27}$

Students indicate that coaches and clinical supervisors have an important role to play in relation to the development of their clinical reasoning skills. Students said that they started to actively use clinical reasoning and thinking as a result of their teachers or peers asking critical questions. This supports findings reported in the literature that students did not automatically of their own accord study the pathophysiology underlying patients' problems or make links across patient problems. ${ }^{10,28}$

In conclusion, the results of this study appear to demonstrate that students indicate that they develop both analytic and non-analytic types of clinical reasoning as a result of real patient contacts early in medical education, i.e. in the preclinical phase. According to the students, paper patients and simulated patients have less learning potential for the development of clinical reasoning in this phase of their medical education. For medical education the implication appears to be that students should be given ample opportunities not only to acquire formal knowledge to develop analytic reasoning skills but also to build experience to collect many exemplars of patient cases, i.e. to amass informal knowledge, for use in non-analytic reasoning. ${ }^{29}$

This study has some limitations. First of all we investigated the effects of preclinical patient contacts by enquiring into students perceptions of this educational format. This means that it would be desirable to complement this qualitative research with quantitative research to determine the generalisability of our findings. Even though our results are partly consistent with earlier findings, additional research should validate students' opinions about the processes of analytic and non-analytic reasoning. Secondly, such quantitative studies should be performed among randomly selected larger groups of students. Because the participants in this study were not selected at random, it cannot be excluded that the study sample consisted of mainly highly motivated students who volunteered. This may have influenced our results. Although we used focus groups to explore students' opinions, we did not analyse the group processes during these group sessions. The reason we used focus groups rather than one-to-one interviews was 
to create the possibility for the participants to share ideas, views and meanings and change them or develop new ones if they thought this was appropriate. This is not possible in individual interviews and adds to the richness of the data. We did not examine agreements or disagreements between group members or the influence of group processes on the discussion. This may have caused us to overlook unspoken views or ideas that were not shared because of certain group dynamics during the interviews.

Finally, some students knew the main moderator as the head of the Skillslab. Although this may have led to students withholding views or ideas, we feel such an effect is likely to be minimal since the research topic was not directly related to the Skillslab programme. Also, the analysis of the data revealed no indications of such an effect.

Several recommendations for further research may be derived from the results. The teachers' contribution to early patient contacts deserves further investigation, the more so since students consider the teacher's role to be crucial, especially in activating clinical reasoning processes. Finally, future research should focus on validation of the results of this qualitative study by quantitative as well as observational and experimental research. 


\section{REFERENCES}

1. Prince $\mathrm{KJAH}$, van de Wiel $M$, Scherpbier AJJA, van der Vleuten CPM, Boshuizen HPA. Qualitative analysis of the transition from theory to practice in undergraduate training in a PBL-medical school. Advances in Health Sciences Education 2000;5(2):105-116.

2. Seabrook M. Clinical students' initial reports of the educational climate in a single medical school. Medical Education 2004;38(6):659-669.

3. O’Brien-Gonzales A, Blavo C, Barley G, Steinkohl DC, Loeser H. What did we learn about early clinical experience? Academic Medicine 2001;76(4, supplement):S49-54.

4. Pitkala $\mathrm{KH}$, Mantyranta T. Professional socialization revised: medical students' own conceptions related to adoption of the future physician's role a qualitative study. Medical Teacher 2003;25(2):155-160.

5. Cooper HC, Gibbs TJ, Brown L. Community-orientated medical education: extending the boundaries. Medical Teacher 2001;23(3):295-299.

6. Frank D, Handfield-Jones R, Dawson DJ, Russel R, Steinert Y, Boillat M, Yaffe M, Guzder J, Keyserlingk E. An integrated curriculum for teaching preparatory clinical skills at a traditional medical school. Teaching and Learning in Medicine 1996;8(1):4-9.

7. Dornan T, Littlewood S, Margolis SA, Scherpbier A, Spencer J, Ypinazar Y. How can experience in clinical and community settings contribute to early medical education? A BEME systematic review. Medical Teacher 2006;28(1):3-18.

8. Mann MP. A light at the end of the tunnel: the impact of early clinical experiences on medical students. Annual Meeting of the American Educational Research Association. New Orleans, LA, 1994.

9. Norman G. Research in clinical reasoning: past history and current trends. Medical Education 2005;39:418-427.

10. Eva KW. What every teacher needs to know about clinical reasoning. Medical Education 2005;39:98-106.

11. O'Neill PA, Willis SC, Jones A. A model how students link problem-based learning with clinical experience through "elaboration". Academic Medicine 2002;77(6):552-561. 
12. Diemers AD, Dolmans DHJM, van Santen M, van Luijk SJ, Janssen-Noordman AMB, Scherpbier AJJA. Students' perceptions of early patient encounters in a PBL curriculum: a first evaluation of the Maastricht experience. Medical Teacher 2007;29:135-142.

13. Kitzinger J. Introducing focus groups. British Medical Journal 1995;311:299302.

14. Morgan DL. The focus group guidebook. London: Sage Publications 1998.

15. Patton MQ. How to use qualitative methods in evaluation. Newbury Park, CA: Sage Publications 1987.

16. Barbour RS. Making sense of focus groups. Medical Education 2005;39:742750.

17. Muhr T. ATLAS/ti-Visual qualitative data analysis - management - model building in education, research and business. Release $4.1 \mathrm{ed}$. Berlin: Scientific Software Development 1997.

18. Barbour RS. Checklists for improving rigour in qualitative research: a case of the tail wagging the dog. British Medical Journal 2001;322:1115-1117.

19. Ritchie J, Spencer L. Qualitative data analysis for applied policy research. In: Bryman A. (Ed). Analyzing qualitative data. London: Routledge 1994:173-194

20. Melia KM. Producing "plausible stories": interviewing student nurses. In: Miller G, Dingwall R (Eds). Context and method in qualitative research. London: Sage 1997;26-36.

21. Dornan T, Bundy C. What can experience add to early medical education? Consensus survey. British Medical Journal 2004;329:834-837.

22. Norman GR, Brooks LR. The non-analytical basis of clinical reasoning. Advances in Health Sciences Education 1997;2:173-184.

23. Elstein AS, Schwarz A. Clinical problem solving and diagnostic decision making: selective review of the cognitive literature. British Medical Journal 2002;324:729-732.

24. Bowen JL. Educational strategies to promote clinical diagnostic reasoning. The New England Journal of Medicine 2006;355(21):2217-2225.

25. Coderre S, Mandin H, Harasym PH, Fick GH. Diagnostic reasoning strategies and diagnostic success. Medical Education 2003;37:695-703. 
26. Ark TK, Brooks LR, Eva KW. The benefits of flexibility: the pedagogical value of instructions to adopt multifaceted diagnostic reasoning strategies. Medical Education 2007; 41:281-287.

27. Woods NN, Brooks LR, Norman GR. The value of basic science in clinical diagnosis: creating coherence among signs and symptoms. Medical Education 2005;39(1):107-112.

28. Van de Wiel MWJ, Schaper NC, Scherpbier AJJA, van der Vleuten CPM, Boshuizen HPA. Students' experiences with real-patient tutorials in a problem-based curriculum. Teaching and Learning in Medicine 1999;11(1):1220.

29. Norman G. Building on experience - the development of clinical reasoning. New England Journal of Medicine 2006;355(21):2251-2252. 
Appendix A Interview questions

1. What are the effects of real patients vs. paper patients and simulated patients on your learning?

-in relation to knowledge acquisition

-in relation to use of knowledge

2. What happens in Year 3 with the knowledge you have at the start of the year?

- How do you use it?

- How is that stimulated?

- When do you use it?

- Why do you use it?

- How do you know that you are using it, how can you tell?

- How can you tell that your basic science knowledge is deficient (as was mentioned in the first interview round)?

- How can you tell that your basic science knowledge is barely adequate?

3. How is your new knowledge integrated with your existing knowledge?

- Does integration occur at all?

- How can you tell?

- Where does this occur?

- What do you do with that when it happens?

- How do paper patients compare to real patients in regard to this integration?

4. a. How do you make use of your patient encounters?

- When you are studying.

- During other clinical encounters.

- In other educational settings.

b. The same question is asked with regard to:

- other students' patient encounters (presentations).

- examples given by the coach or clinical supervisor. 


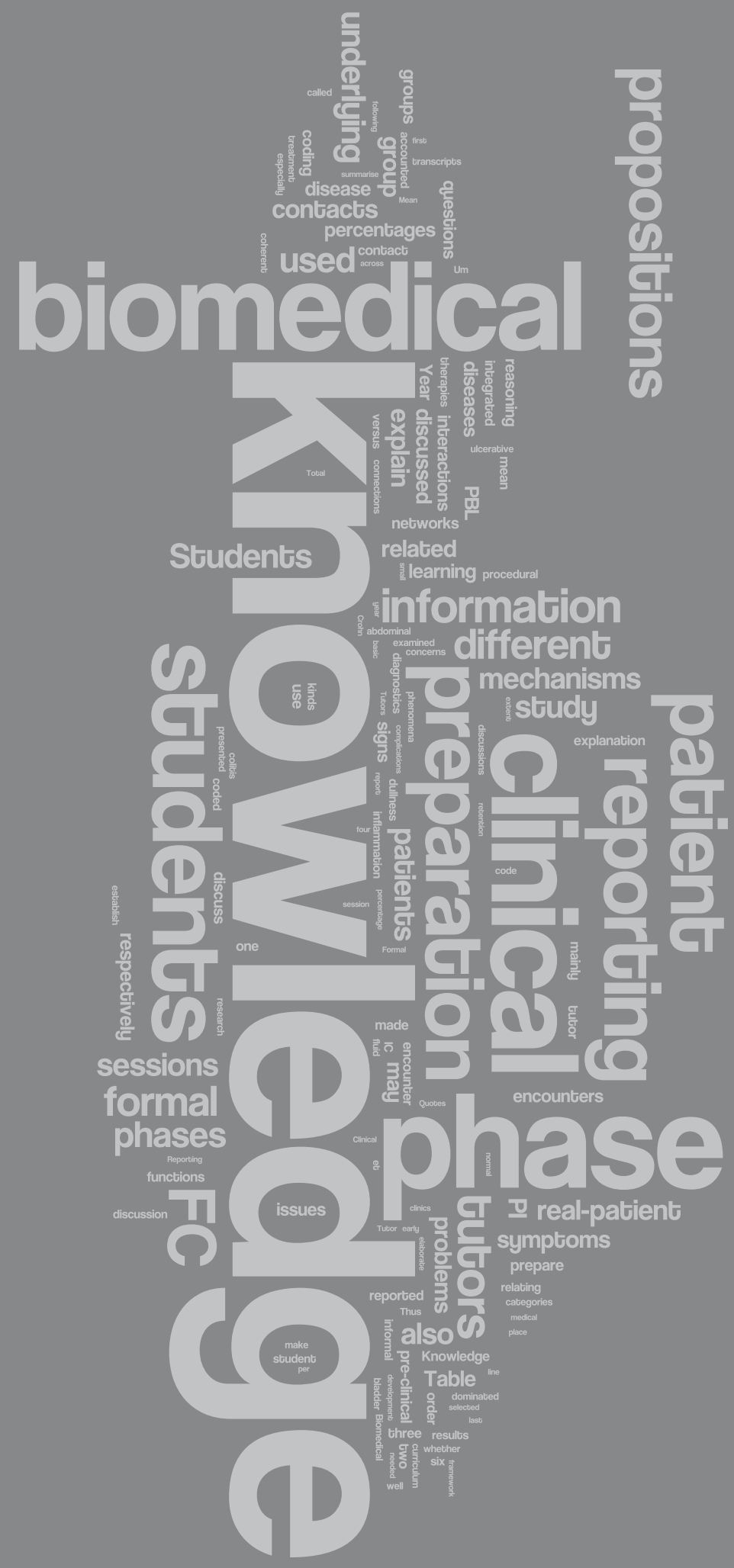




\section{CHAPTER 5}

Preclinical patient contacts and the application of biomedical and clinical knowledge

Agnes D Diemers, Margje WJ van de Wiel, Albert JJA Scherpbier,

Erik Heineman, Diana HJM Dolmans.

Published in Medical Education 2011; 45: 280-288

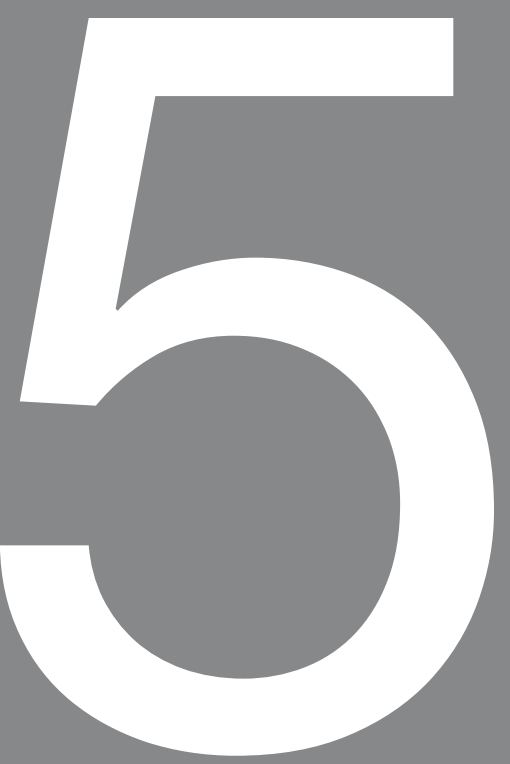




\section{ABSTRACT}

\section{Context}

Real-patient contacts in problem-based undergraduate medical education are promoted as a good way of introducing biomedical and (in)formal clinical knowledge early in the curriculum and thereby to foster the development of coherent and integrated knowledge networks. There are concerns, however, that such contacts may cause students to focus on clinical knowledge to the neglect of biomedical knowledge, and that group discussions may be dominated by teachers. We examined these concerns by addressing the following questions in the context of group sessions in which students prepare for and report on realpatient contacts: To what extent are biomedical and (in)formal clinical knowledge addressed? To what extent are these knowledge types addressed by students or tutors? Are connections made between biomedical and clinical knowledge?

\section{Methods}

We videotaped and transcribed six preparation and six reporting group sessions (two preparation and two reporting phases of each of three groups) held with students in the Year 3 of the problem-based curriculum at Maastricht University. During this year, real-patients rather than paper patients are used. Qualitative analysis software was used to code propositions in the transcriptions in order to identify different kinds of knowledge and different functions of biomedical knowledge.

\section{Results}

Formal clinical knowledge was the subject of $40.7 \%$ and $34.8 \%$ of propositions during the preparation and reporting phase, respectively. The corresponding percentages for biomedical knowledge were $15.0 \%$ and $28.0 \%$. Tutors accounted for $63.4 \%$ of propositions during the preparation phase, and students for $80.1 \%$ during the reporting phase. Nearly all biomedical knowledge was related to clinical knowledge.

\section{Conclusion}

It appears that pre-clinical patient encounters can stimulate students to pay attention to both clinical and biomedical knowledge and to how they are connected. Tutor dominance was evident only during the preparation phase. Further research is needed to investigate whether pre-clinical patient contacts promote the development of coherent and integrated knowledge networks. 


\section{INTRODUCTION}

Medical expertise research suggests that experienced physicians have access to elaborate knowledge networks in which biomedical, clinical and experiential knowledge are closely integrated and through which they interact when activated during different reasoning processes. ${ }^{1-3}$ When solving routine, non-complex problems, expert doctors quickly arrive at accurate diagnoses through a process of pattern recognition in which a disease category or previously seen patient case is directly retrieved. ${ }^{2,4}$ These non-analytic reasoning processes are, thus, based on the automatic and unconscious activation of knowledge in the doctor's elaborate network. Episodic memories of previously encountered patients in the experiential knowledge base are referred to as 'informal' clinical knowledge. When faced with non-routine cases, such as difficult or rare problems, expert clinicians tend to take recourse to analytic reasoning, explaining causes and consequences of diseases. For this, they deliberately activate clinical as well as biomedical knowledge from their extensive knowledge networks. ${ }^{6,7}$ The type of clinical knowledge used in analytic reasoning relates to signs and symptoms of disease, predictive test values, treatment strategies etc. It is referred to as 'formal' clinical knowledge.,25 Biomedical knowledge comprises all knowledge about the functioning and malfunctioning of the human body (knowledge about anatomy, physiology, biochemistry, pathology and pharmacology) that is used to link and explain clinical features. ${ }^{3,8}$

As students are novice diagnosticians, their knowledge networks require further elaboration and organisation. Woods et al. ${ }^{9}$ found that instructing students to use biomedical knowledge to explain mechanisms underlying clinical features improved the accuracy of their diagnostic reasoning, especially over time and under time constraints. A possible explanation for this may be that biomedical knowledge promotes the coherence of knowledge networks by giving meaning to different kinds of knowledge, resulting in more accurate diagnoses and better retention and recall of knowledge..$^{8-11}$

Early introduction of patient problems in medical education is assumed to promote the formation of coherent and integrated knowledge networks. ${ }^{12}$ Contacts with real-patients are one way of presenting students with patient problems. Research has shown that early real-patient contact is associated 
with several benefits, such as improved acquisition and retention of knowledge, increased motivation to learn, better understanding of the impact of disease on patients' lives and enhanced professional socialisation. ${ }^{13-}{ }^{18}$ Additionally, Diemers et al $^{16}$ reported contentions by students that pre-clinical real-patient contacts helped them to develop both analytic and non-analytic clinical reasoning skills.

Despite these beneficial effects, a major potential pitfall of pre-clinical real-patient contact is the risk that such contact might stimulate students to focus on clinical knowledge and diagnostic skills to the neglect of underlying basic science mechanisms. Van de Wiel et al. ${ }^{19}$ reported that real-patient contacts did not automatically incite students to study the pathophysiology underlying patient problems. Students have been reported to experience difficulties in transferring biomedical knowledge to clinical problems in other studies ${ }^{14,20}$ and similar difficulties probably occur during clinical and early postgraduate training. ${ }^{8}$ Both van de Wiel et $\mathrm{al}^{19}$ and Eva ${ }^{6}$ therefore argue that students should be explicitly instructed to link patient problems and basic science knowledge and to make connections across patient problems. In other words, medical curricula should be structured in such a way that the relationships between biomedical and clinical knowledge are made explicit to students. ${ }^{8,19}$

A concern relating to early patient contacts that is particularly relevant to problem-based learning (PBL) is that teachers rather than students will dominate the discussion during tutorials in which students prepare for and report on their patient encounters. This concern is mainly fed by pre-clinical students' paucity of prior experience with real-patients.

In order to confirm or alleviate those concerns, we examined the extent to which biomedical and formal and informal clinical knowledge were addressed during tutorial group sessions in a PBL course and whether this differed between the phases in which students, respectively, prepared for and reported on real-patient contacts. We additionally examined the extent to which interactions during both phases were led by students or tutors. Furthermore, we examined which part of biomedical knowledge was used to explain underlying mechanisms of diseases, signs and symptoms to investigate whether connections were made between biomedical and clinical knowledge during the discussions. 


\section{METHODS}

\section{Educational background}

The study was conducted in the third and last pre-clinical year of the PBL 6-year curriculum at Maastricht Medical School. An extensive description of the curriculum can be found elsewhere. ${ }^{21}$ The central theme of Year 3 is chronic diseases. The year is divided into 10-week clusters, each of which addresses one of four areas: the abdominal region; the locomotor system; the circulation and lungs, and psychomedical problems and mental health care. The Year 3 cohort is divided into four groups, which attend the clusters in different orders. In Year 3, the paper patients used in the PBL sessions of the first two years are replaced by real patients, whom students see during consultations in the teaching outpatient clinics at Maastricht University Hospital. Students prepare for and report on the contacts during weekly group sessions. Thus, the PBL cycle in the Year 3 consists of four phases.

Students prepare for each patient encounter (preparation phase) during a smallgroup session one or two days before the actual contact. Students discuss short vignettes of the patients they are going to meet. Each student pair sees a different patient (patient encounter phase). Immediately after the encounter, which usually involves a history and physical examination, the students discuss the consultation with their clinical supervisor and set learning issues to be pursued during the following days (self-study phase). During this phase, students prepare a patient presentation to give in the group session the following week. During that session, students also discuss what they have learned in relation to their learning issues during self study (reporting phase). The preparation and reporting phases take place in small-group sessions attended by ten students and a tutor. Sessions last four hours, of which the first three hours are dedicated to the reporting phase and the last hour is devoted to the preparation phase for the next patient contact. The tutors are clinical staff members who participate in the different clusters.

The preparation phase is intended to activate and elaborate on prior knowledge, including knowledge about history taking and physical examination, in order to prepare students for the patient encounter. During this phase students may

discover gaps in their knowledge and skills, which indicate the learning issues to 
be studied before the student meets the patient. It is the tutor's responsibility to make sure that problems are elaborated in sufficient depth to prepare students adequately for the patient encounter.

The purpose of the reporting phase is to promote integration of theory and practice and to stimulate students to discuss clinical knowledge, as well as underlying biomedical mechanisms and processes. During this phase students are expected to use their newly acquired knowledge to solve patient problems; for instance, they use basic science and clinical knowledge to explain the symptoms and signs presented by patients. During this phase, the tutor is tasked with stimulating students to elaborate on new information in sufficient depth and to discuss and establish connections between relevant clinical and biomedical knowledge.

\section{Procedure}

This study was performed during the cluster on the abdominal region at the end of the Year 3. In order to obtain deeper insight into which knowledge is actually discussed during the group meetings, we videotaped and made literal transcriptions of sessions of three student groups in two preparation and two reporting phases for a total of six preparation and six reporting sessions. The group sessions were recorded in weeks 2 (preparation phase), 3 (reporting phase), 8 (preparation phase) and 9 (reporting phase) of the cluster. In all, 24 hours of group session work were recorded. The transcriptions were coded to detect the type of knowledge discussed, by whom (students or tutors) it was discussed and which part(s) of biomedical knowledge was related to clinical knowledge.

\section{Subjects}

Using purposive sampling, we selected three student groups and their tutors. Sampling was based on tutor and patient criteria. We selected tutors who were highly experienced in guiding Year 3 groups, who had received the highest marks in student evaluations and who came from different departments. Additionally, we strove to include patients from as many different out-patient clinics as possible, an effort that generated a total of 29 patients, each attending one of the following outpatient clinics: general surgery; urology; gastroenterology; radiotherapy, or obstetrics and gynaecology. The selected students and tutors all consented to participate in the study. Patients were asked by their doctors if they would participate and their histories were reported anonymously by the students. 


\section{Instruments}

We searched the literature for any existing coding framework that might be appropriate for our study. The framework developed by Boshuizen and van de Wiel ${ }^{22}$ appeared to be most suitable to examine the application and integration of biomedical and clinical knowledge in our study. We adjusted this framework according to the results of a pilot study and established a final coding framework. In order to answer the research questions, the codes were aggregated in several main categories (Table 1), including: patient information (PI); formal clinical knowledge (FC); biomedical knowledge (B); informal clinical knowledge (IC); procedural information $(P)$, and other information $(\mathrm{O})$. These descriptions of the coding categories are illustrated by quotations (Table 1).

\section{Analysis}

The transcripts were imported into the software Atlas- $\mathrm{ti}^{23}$ and coded iteratively. The transcripts of the preparation and reporting phases of group 1 were coded independently by two researchers (ADD and MWJvdW) based on the code descriptions (Table 1). ADD then coded all the other transcripts and MWJvdW randomly coded parts of the other transcripts; both authors consulted in cases of doubt. Differences in coding $(7 \%)$ were discussed until agreement was reached and the transcripts were then re-read and codes modified to conform to the agreements. Differences in coding mainly concerned the distinction between the codes for biomedical knowledge (B) and formal clinical knowledge (FC). Codes were assigned to the smallest items of knowledge, called 'propositions'24, and each proposition (16 538 in total, 3337 in the preparation phase, 13201 in the reporting phase) was given one code, which enabled us to calculate the proportion of the different types of knowledge applied. As the patterns of topics were similar across groups, mean percentages of propositions were calculated across groups and across sessions for each code, for the different phases and for both students and tutors.

Finally, in order to establish any links made between biomedical and clinical knowledge, we described the functions of biomedical knowledge during the preparation and reporting phases, such as, for example, to explain signs and symptoms. Mean percentages of propositions relating to biomedical knowledge were calculated per function and per phase. 


\section{CATEGORY}

Patient information

(PI)

\section{DESCRIPTION}

Students or tutors present or summarise patient information: (literal presentation of patient data in vignettes during the preparation phase or in presentations during the reporting phase)

\section{Formal \\ Clinical Knowledge (FC)}

\section{Students or tutors discuss, summarise or ask questions about formal clinical knowledge.}

Biomedical Knowledge (B)
Students or tutors discuss, summarise or ask questions about biomedical knowledge
QUOTES ILLUSTRATING THE CATEGORIES

S4-2DN1 'We saw a 35 year old woman $(\mathrm{Pl})$ who used to be a sports instructor (PI). Currently, she has an administrative job, also in sports (PI). It started when she was a little girl (PI). She had frequent abdominal pains $(\mathrm{Pl})$, vomiting $(\mathrm{PI})$ and diarrhoea (PI). When she was 17 years old, her present complaints started $(\mathrm{PI})$, i.e. constipation and blood loss (PI). But there were also periods when she was free of symptoms (PI). Later investigation showed inflammation of the last centimetres of the rectum (PI).'

\section{S4-1DN1 'Um, what you see above} is actually characteristic of ulcerative colitis; it is a pseudo polyp (FC). This is very common in ulcerative colitis (FC) and they can become malignant over time (FC). The risk of malignancy is greater in ulcerative colitis than in Crohn's disease (FC). In Crohn's disease it is more strongly associated with the small intestine, so....the place where it also occurs (FC).'

S3-1EN1 'Bile is produced in the liver (B). Then it is basically the same as blood plasma (B). Isotonic (B), and its composition is almost the same (B). If it is stored in the gall bladder (B), active transport of ions occurs (B), so that it becomes more concentrated $(\mathrm{B})$ and then chloride $(\mathrm{B})$ and bicarbonate $(B)$ are pumped out (B) by specific pumps for that $(B)$.' 


\section{CATEGORY \\ SCRIPTION}

Clinical

Informal

Knowledge

(CI)
Students or tutors discuss, summarise or ask questions about patients other than the patients seen in the out-patient clinics.
Procedural information

(P)
Students or tutors state learning issues about informal or formal clinical and biomedical knowledge; propositions aimed at preparation for patient contact; discussion or questions about other procedural information; social or emotional information about the patient contact; interventions aimed at involving other students in the discussion.
Other information (O)

\section{Students or tutors identify gaps} in knowledge, affirm knowledge, express doubts about knowledge, repeat what was said by someone else; propositions inaudible due to technical problems.
QUOTES ILLUSTRATING THE CATEGORIES

S1-2EN2 'I think BdG (Dutch television celebrity) also died from that (IC). Because he developed kidney insufficiency (IC) and he did not have a kidney transplant (IC), so all waste accumulated in his blood (IC) and death occurred (IC).'

TDV2 'Which other questions are you going to ask this patient $(\mathrm{P})$ ?'

S3-2EN1 'Our learning issues relate to the anatomy of the liver(P), pancreas $(P)$ and biliary duct $(P)$, gall stones $(\mathrm{P})$ and biliary pancreatitis (P).'

S5-2WV2 'I do not know if there are Vitamin $\mathrm{K}$ dependent coagulation factors (O).'

TEV2 'Yes, I agree, that is true $(\mathrm{O})$.'

$\mathbf{S}=$ Student

$\mathbf{T}=$ Tutor

Table 1 Descriptions of the coding categories, illustrated by quotes 


\section{RESULTS}

Table 2 shows the mean percentages of propositions during the preparation and reporting phases relating to biomedical knowledge, formal and informal clinical knowledge, and other kinds of information. Mean percentages were also calculated for the propositions accounted for by students and tutors.
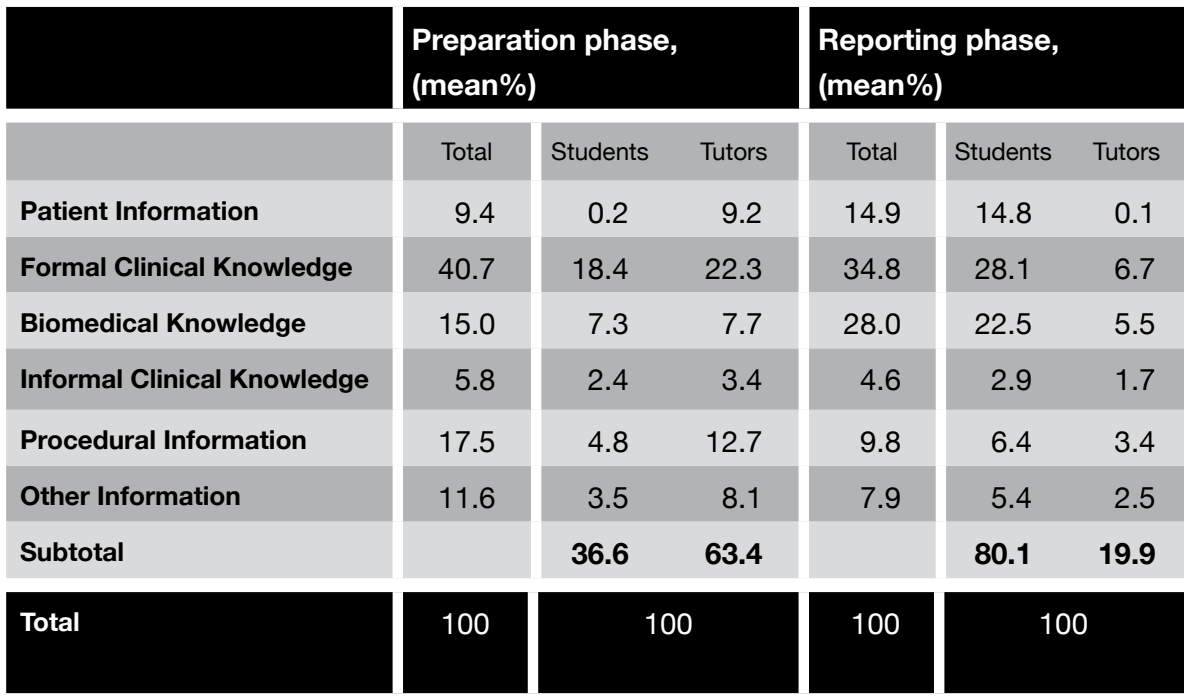

\begin{tabular}{|r|r|r|r|r|r|}
\hline Total & Students & Tutors & Total & Students & Tutors \\
\hline 9.4 & 0.2 & 9.2 & 14.9 & 14.8 & 0.1 \\
\hline 40.7 & 18.4 & 22.3 & 34.8 & 28.1 & 6.7 \\
\hline 15.0 & 7.3 & 7.7 & 28.0 & 22.5 & 5.5 \\
\hline 5.8 & 2.4 & 3.4 & 4.6 & 2.9 & 1.7 \\
\hline 17.5 & 4.8 & 12.7 & 9.8 & 6.4 & 3.4 \\
\hline 11.6 & 3.5 & 8.1 & 7.9 & 5.4 & 2.5 \\
\hline & 36.6 & 63.4 & & 80.1 & 19.9 \\
\hline 100 & & & 100 & \multicolumn{2}{|c|}{100} \\
\hline
\end{tabular}

Table 2 Mean percentages of propositions relating to the different kinds of knowledge per phase, for all propositions and for students' and tutors' propositions separately

\section{Knowledge applied per phase}

Of the propositions addressed during the preparation and reporting phases $40.7 \%$ and $34.8 \%$, respectively, related to formal clinical knowledge. The corresponding percentages for biomedical knowledge and informal clinical knowledge were $15.0 \%$ and $28.0 \%$, and $5.8 \%$ and $4.6 \%$, respectively. As well as analysing knowledge types, we examined the propositions in terms of whether they presented patient information, procedural information or other information. As Table 2 shows, the percentage of procedural information presented was higher during the preparation phase $(17.5 \%)$ than the reporting phase $(9.8 \%)$, reflecting the type of information that was thought to be needed to prepare students for the forthcoming patient encounters. More patient information was introduced during 
the reporting phase than the preparation phase ( $14.9 \%$ versus $9.4 \%$ ), which is only to be expected as students presented their findings from the patient encounters. In general, formal clinical knowledge and biomedical knowledge accounted for high percentages of the propositions, especially during the reporting phase.

\section{Student- and tutor-led interactions}

Students accounted for $36.6 \%$ of the propositions during the preparation phase and $80.1 \%$ during the reporting phase. Tutor propositions during the preparation phase mainly concerned the use of formal clinical knowledge (22.3\%), procedural information (12.7\%) and patient information (9.2\%). The prominent input of students during the reporting phase consisted mainly of formal clinical knowledge (28.1\%), biomedical knowledge (22.5\%) and patient information (14.8\%). Students and tutors were almost equally responsible for the $40.7 \%$ of propositions concerning formal clinical knowledge during the preparation phase (18.4\% versus $22.3 \%$ ). They were also equally responsible for the $15.0 \%$ of propositions related to biomedical knowledge during the preparation phase ( $7.3 \%$ and $7.7 \%$, respectively). Tutors were almost solely responsible for the propositions relating to patient information during the preparation phase $(9.2 \%$ versus $0.2 \%$ ). Students were predominantly responsible for the propositions concerning formal clinical knowledge (28.1\% versus $6.7 \%)$ and biomedical knowledge (22.5\% versus $5.5 \%$ ) during the reporting phase. They also accounted for most of the propositions dedicated to patient information during that phase ( $14.8 \%$ versus $0.1 \%)$. Thus, although the tutors made a significant contribution during the preparation phase, especially concerning formal clinical and procedural knowledge, the largest contribution to the discussions during the reporting phase came from the students and related mainly to formal clinical and biomedical knowledge. Students and tutors contributed equally to the use of formal clinical and biomedical knowledge during the preparation phase. 


\section{FUNCTIONS OF BIOMEDICAL KNOWLEDGE}

\section{Disease}

explanation of underlying

mechanisms of diseases

\section{QUOTES}

S4-1DN1 'Um, I will first explain what IBD is, inflammatory bowel disease $(P)$. But first we need to understand the normal conditions in the bowel( $P)$. I have made a brief summary $(P)$. In a normal situation there is low grade inflammation in the bowel $(\mathrm{B})$. Low grade inflammation is needed to maintain the commensal flora $(B)$. The normal situation is based on secretion of interleukin $10(B)$ and TIF-beta $(\mathrm{B})$, and that keeps the inflammation low $(\mathrm{B})$. If it is reduced, inflammation increase $(B)$. And that is what happens in Crohn's disease and ulcerative colitis (FC).'

\section{Signs or symptoms}

explanation of underlying

mechanisms of signs or

symptoms of diseases

\section{Diagnostics}

explanation of underlying

mechanisms of diagnostics
S3-2DN2. 'Um, the underlying pathology in urinary retention usually is weakness of the bladder muscle $(B)$, so the muscle is not functioning properly $(\mathrm{B})$. There is a chronic obstruction of the exit of the bladder $(B)$ or the urethra $(B)$ which means that increased straining is needed to pass urine $(B)$ and a small amount of urine always remains in the bladder $(\mathrm{B})$ where it accumulates $(\mathrm{B})$. And that can cause urine retention (FC)'.
TEV2 'What is urethrocystoscopy (FC)?'

S4-1EV2 'Via the urethra $(B)$ you can look inside the blad$\operatorname{der}(\mathrm{FC})$.'

TEV1 'And then you can use percussion to determine if the abdomen is extended due to fluid (B.) You are over the bowels $(\mathrm{B})$ and they contain air $(\mathrm{B})$ and then you hear what is called varying degrees of tympany (FC). And then you go down to the flank $(B)$ and there is fluid $(B)$ and you hear dulIness (FC) And then you position the patient on his side and you do the same (FC). And then you find that the dullness moves to a different place (FC). So inside the abdominal cavity something must be happening that causes fluid to shift (B). In English that is called shifting dullness (FC). That is the trick to establish ascites (FC).'

\section{$\mathbf{S}=$ Student}

$\mathbf{T}=$ Tutor 


\section{FUNCTIONS OF BIOMEDICAL KNOWLEDGE}

\section{Therapies}

explanation of underlying

mechanisms of therapies

\section{QUOTES}

S2-2DN1 'And then anti-TNF treatment (FC). TNF means tumour necrosis factor $(\mathrm{B})$. It is a cytokine in the body $(\mathrm{B})$. And it is involved in inflammation (B). And TNF has also been shown to be elevated in patients with ulcerative colitis and Crohn's disease (FC). And then you have Remicade $(\mathrm{FC})$, that is the brand name (FC), and it is a TNF anti body (B).'

S1-1WN1 'Yes, so conservative treatment is a pessarium (FC). It presses against the front $(B)$ and back walls $(B)$ of the vagina and finds support on the medial walls of the levator muscle $(B)$ and the urogenital diaphragm (B).'

S3-1 EN1 'Well if the stones end up in the ductus choledochus $(B)$, bile reflux may occur $(B)$ in the pancreatic duct (B). If bile gets in there $(B)$, the pancreas can become inflamed $(B)$ and then you have pancreatitis (FC). This is a very serious complication (FC).'

S5-2WN2 'Um, nitrates cause increased action (B). Because of that a hypotensive reaction may occur $(B)$, possibly with fainting (FC).'

TEN1 'Why does it occur more often in men than in women, inguinal hernia(B)?'

S2-2EN1'Because of the opening they have there $(B)$. Because of that truncus $(B)$, um, well the spermatic chord (B) which passes through it (B).'

S3-2EN1 'In women only the round ligament passes through it $(\mathrm{B})$ and in men larger things pass through it $(\mathrm{B})$.'

TDN2 'Please start, that is a nice picture $(P)$.' S5-2DN2 'Um, we are looking at the rectum (B) a coronal section (B). You can also see the sigmoid (B). It comes down (B). This is called the anal canal (B). The anal canal consists of three zones $(B)$ : the intermediate zone $(B)$, the cutaneous zone $(\mathrm{B})$ and um the columnar zone $(\mathrm{B})$.'

Table 3 Quotes illustrating different functions of biomedical knowledge 


\section{Functions of biomedical knowledge}

Different functions of biomedical knowledge were distinguished during the preparation and reporting phases. Biomedical knowledge was used to explain underlying mechanisms of diseases, signs and symptoms, diagnostics, therapies, complications (of diseases, diagnostics or therapies) and epidemiological phenomena (such as the greater frequency of urinary tract infections in women compared with men). Table 3 presents quotations to illustrate the different functions of biomedical knowledge.

Table 4 presents the mean percentages of propositions related to biomedical knowledge used in different functions during the preparation and reporting phases.

\begin{tabular}{|l|c|c|}
\hline $\begin{array}{l}\text { Functions of } \\
\text { biomedical knowledge }\end{array}$ & $\begin{array}{c}\text { Preparation phase } \\
\text { (mean\%) }\end{array}$ & $\begin{array}{c}\text { Reporting phase } \\
\text { (mean\%) }\end{array}$ \\
\hline Disease & 39.7 & 20.5 \\
\hline Signs and symptoms & 42.6 & 58.9 \\
\hline Diagnostics & 3.1 & 1.5 \\
\hline Therapy & 10.3 & 8.6 \\
\hline Complications & 4.3 & 2.7 \\
\hline Epidemiological phenomena & 0.0 & 0.1 \\
\hline Reporting learning issues & 0.0 & 7.7 \\
\hline Total & 100 & 100 \\
\hline
\end{tabular}

Table 4 Mean percentages of biomedical knowledge propositions used for different functions during the preparation phase and the reporting phase

During the preparation and reporting phases, biomedical knowledge was mainly used to explain signs and symptoms of diseases ( $42.6 \%$ and $58.9 \%$, respectively) and underlying mechanisms of disease ( $39.7 \%$ and $20.5 \%$, respectively), which is in line with one of the goals of the Year 3 curriculum. Students also explained clinical features using knowledge about normal anatomy and physiology by contrast with pathophysiology. Furthermore, during the preparation and reporting phases, biomedical knowledge was used, albeit less extensively, to 
explain therapies (10.3\% and $8.6 \%$, respectively), diagnostics $(3.1 \%$ and $1.5 \%$, respectively) and complications (4.3\% and $2.7 \%$, respectively). Biomedical knowledge was used to explain epidemiological phenomena during the reporting phase only $(0.1 \%)$. For obvious reasons, the use of biomedical knowledge in relation to 'reporting on learning issues' occurred only during the reporting phase (7.7\%). This means that none of the interactions during the preparation phase and only a small percentage of interactions during the reporting phase were not at all related to clinical knowledge.

Thus, biomedical knowledge was related to clinical knowledge during both phases and was mainly used to explain underlying mechanisms of diseases and signs and symptoms.

\section{DISCUSSION}

Formal clinical knowledge and biomedical knowledge accounted for a substantial percentage of propositions delivered during the group sessions, especially during the reporting phase. It thus seems that there is no justification for concerns regarding lack of attention to biomedical knowledge when using realpatient contacts during PBL group sessions. This is in line with earlier findings of Diemers et al. ${ }^{16}$ who reported that, according to students' perceptions, pre-clinical real-patient encounters were an incentive for the study of basic sciences. The observational data collected in the present study lend support to this contention. Furthermore, the results of the current study show that, during the reporting phase, the interaction was dominated by the students, especially concerning formal clinical knowledge and biomedical knowledge, which is in line with the student-centredness of PBL. ${ }^{25}$ However, the results also reveal that the tutors dominated the interactions during the preparation phase. In conclusion, concerns that PBL sessions in which real patients are discussed might lead to more teacher-dominated and less student-centred interactions in tutorial groups are supported for the preparation phase, but are definitely not for the reporting phase. Teacher dominance during the preparation phase was probably associated with Year 3 medical students' lack of experience with real patients. In accordance with one of the goals of the preparation phase, tutors may have felt obliged to take the initiative in the discussion in order to make sure that students were 
adequately prepared for patient contacts and, accordingly, may have dominated the discussion. However, PBL sessions in which students report on their realpatient encounters were clearly dominated by the students' and not the tutors' interactions. Finally, our study demonstrates that a substantial percentage of the propositions related to biomedical knowledge were used to explain underlying mechanisms of disease, signs and symptoms. This finding is in line with previous studies into the use of biomedical knowledge during clinical reasoning. ${ }^{8}$ Additionally, our study shows that biomedical knowledge is also used to explain other clinical knowledge, such as the underlying mechanisms of diagnostics, therapies and complications. This appears to indicate that biomedical knowledge is also used in decisions regarding treatment and management strategies. Thus, during sessions in which real-patient contacts were discussed, biomedical knowledge was related to different kinds of clinical knowledge.

One of the limitations of this study is that it does not allow us to draw conclusions with regard to the assumption that interactions during discussions on real-patient contacts automatically lead to the development of coherent and integrated knowledge networks or to improved clinical reasoning or more accurate diagnoses, although interactions during the reporting phase were, for the most part, dedicated to formal clinical knowledge and biomedical knowledge. We did find, however, that nearly all of the biomedical knowledge discussed was used in connection with clinical knowledge and this may contribute to the development of coherent and integrated knowledge networks. Another limitation is that we do not know if and how the patient encounter phase (including the role of the clinical supervisor) and the self-study phase contribute to the results of our study.

Although we clearly defined when a proposition should be scored as representing either formal clinical knowledge (FC) of biomedical knowledge (B), the raters initially differed most in coding these propositions. All the propositions that raised doubt in subsequent coding were discussed and often the context of the discussion led us to decide upon the code. Therefore, it is possible that some of the propositions that were coded as FC were closely related to pathogenesis, which may have led to a slight underestimation of the biomedical knowledge applied. In addition, in this study we decided to make no distinction between tutor input that consisted of asking questions and tutor input that represented the provision of information. Thus it is important to remember that, although tutors 
were quite dominant in the preparation phase, their contributions included both stimulating questions and explanatory information. Finally, only three purposively selected student groups were analysed, guided by three highly experienced and highly graded tutors. Despite the small numbers of participating students and tutors, however, we analysed six preparation and six reporting phases (24 hours of recording) during which 29 different patients were presented and discussed, and this may have enhanced the representativeness of our results.

More research is required to establish whether pre-clinical real-patient encounters promote the formation of the integrated knowledge networks necessary for different kinds of clinical reasoning and lead to accurate diagnosis and treatment and management decisions. Further research is also necessary to determine the influences of the patient encounter and the self-study phases on the subsequent reporting phase, as well as to further examine the role of the tutor in PBL sessions during which real-patient encounters are discussed. Nonetheless the results so far appear to demonstrate that PBL tutorials during which real-patient encounters are prepared and reported are effective in stimulating students to actively engage in discussions on and to make connections between biomedical and clinical knowledge. 


\section{REFERENCES}

1. Norman G. Building on experience - the development of clinical reasoning. New England Journal of Medicine 2006;355:2251-2252.

2. Norman G, Eva K, Brooks L, Hamstra S. Expertise in medicine and surgery. In: Anders Ericsson K, Charness N, Feltovich P, Hoffman R, eds. The Cambridge handbook of expertise and expert performance. Cambridge University Press, New York 2006;339-353.

3. van de Wiel M, Boshuizen HP, Schmidt HG. Knowledge restructuring in expertise development: evidence from pathophysiological representations of clinical cases by students and physicians. European Journal of Cognitive Psychology 2000;12:323-355.

4. Elstein AS, Schwarz A. Evidence base of clinical diagnosis: Clinical problem solving and diagnostic decision making: selective review of the cognitive literature. British Medical Journal 2002;324:729-732.

5. Norman G. Research in clinical reasoning: past history and current trends. Medical Education 2005;39:418-427.

6. Eva KW. What every teacher needs to know about clinical reasoning. Medical Education 2005;39:98-106.

7. Norman GR, Trott AD, Brooks LR, Smith EK. Cognitive differences in clinical reasoning related to postgraduate training. Teaching and Learning in Medicine 1994;6:114-120.

8. Woods NN. Science is fundamental: the role of biomedical knowledge in clinical reasoning. Medical Education 2007;41:1173-1177.

9. Woods NN, Howey EHA, Brooks LR, Norman GR. Speed skills? Speed, accuracy, encapsulations and causal understanding. Medical Education 2006;40:973-979.

10. Woods NN, Brooks LR, Norman GR. The value of basic science in clinical diagnosis: creating coherence among signs and symptoms. Medical Education 2005;39:107-112.

11. Woods NN, Brooks LR, Norman GR. The role of biomedical knowledge in diagnosis of difficult cases. Advances in Health Sciences Education 2007;12:417426.

12. Schmidt HG, Rikers RMJP. How expertise develops in medicine: knowledge encapsulation and illness script formation. Medical Education 2007;41:11331139. 
13. Bell $\mathrm{K}$, Boshuizen $\mathrm{H}$, Scherpbier A, Dornan $\mathrm{T}$. When only the real thing will do: junior medical students' learning from real patients. Medical Education 2009;43:1036-1043.

14. Prince KJAH, van de Wiel M, Scherpbier AJJA, van der Vleuten CPM, Boshuizen HPA. A Qualitative Analysis of the Transition from Theory to Practice in Undergraduate Training in a PBL-Medical School. Advances in Health Sciences Education 2000;5:105-116.

15. Seabrook M. Clinical students' initial reports of the educational climate in a single medical school. Medical Education 2004;38:659-669.

16. Diemers AD, Dolmans DHJM, Verwijnen MGM, Heineman E, Scherpbier AJJA. Students' opinions about the effects of preclinical patient contacts on their learning. Advances in Health Sciences Education 2008;13:633-647.

17. Cooper HC, Gibbs TJ, Brown L. Community-orientated medical education: extending the boundaries. Medical Teacher 2001;23:295-299.

18. Dornan T, Bundy C. What can experience add to early medical education? Consensus survey. British Medical Journal 2004;329:834-837.

19. van de Wiel MWJ, Schaper NC, Scherpbier AJJA, van der Vleuten CPM, Boshuizen HPA. Students' experiences with real-patient tutorials in a problembased curriculum. Teaching and Learning in Medicine 1999;11:12-20.

20. Patel VL, Groen GJ, Scott HM. Biomedical knowledge in explanations of clinical problems by students. Medical Education 1988;22:398-406.

21. Diemers AD, Dolmans DHJM, van Santen M, van Luijk SJ, Janssen-Noordman AMB, Scherpbier AJJA. Students' perceptions of early patient encounters in a PBL curriculum: A first evaluation of the Maastricht experience Medical Teacher 2007;29:135-142.

22. Boshuizen HPA, van de Wiel MWJ. Using multiple representations in medicine: how students struggle with them. In: van Someren MW, Boshuizen HPA, de Jong T, Reimann P, eds. Learning with multiple representations. Elsevier, Amsterdam 1998;237-262.

23. Muhr T. ATLAS/ti-Visual qualitative data analysis - management - model building in education, research and business. Release 5.2. Berlin: Scientific Software Development 1997.

24. Patel VL, Groen GJ. Knowledge based solution strategies in medical reasoning. Cognitive Science 1986;10:91-116.

25. Schmidt HG. Foundations of problem-based learning: some explanatory notes. Medical Education 1993;27:422-432. 


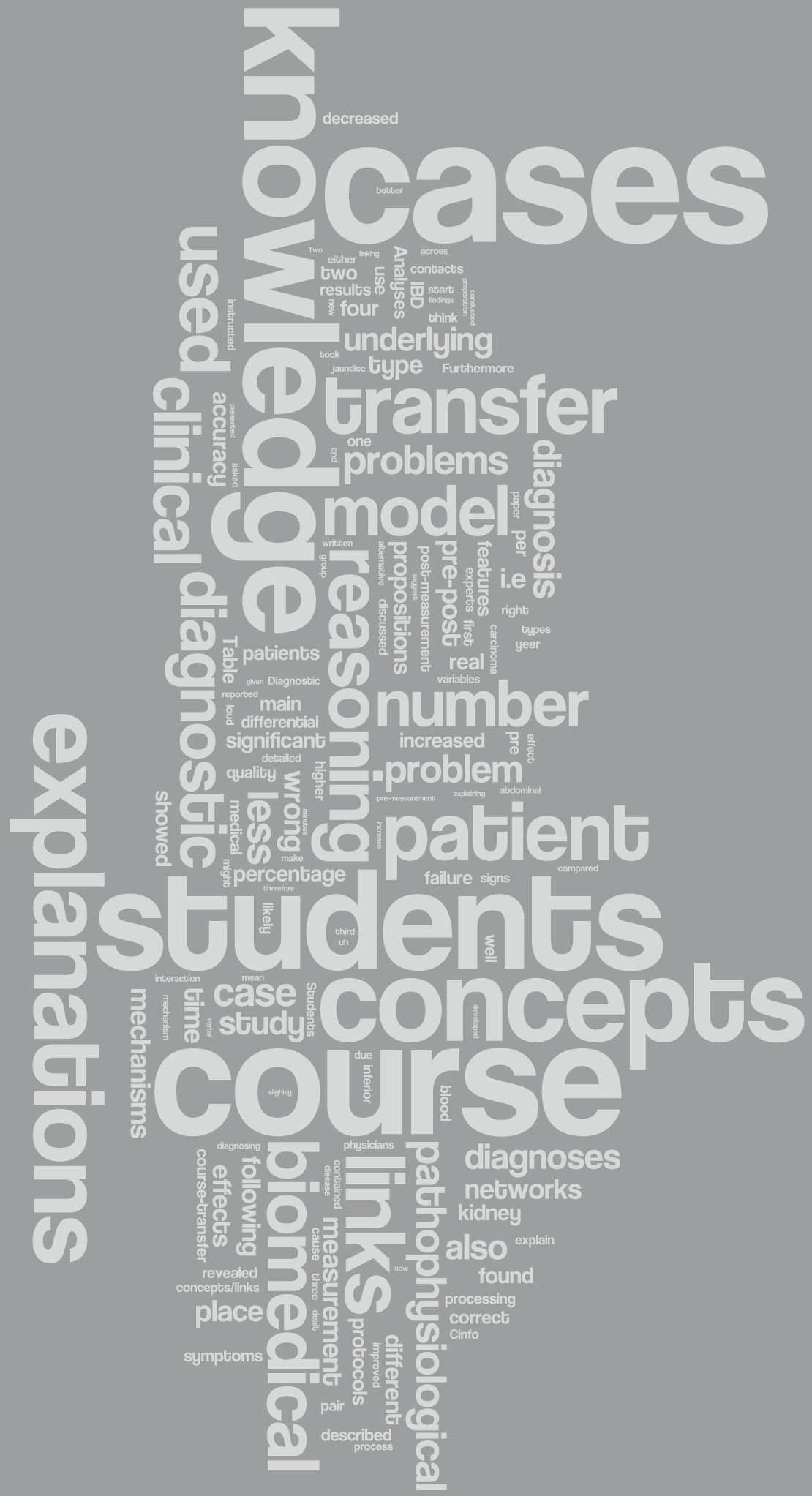




\section{CHAPTER 6}

Effects of problem-based tutorials with real patients on the development of students' diagnostic reasoning and underlying knowledge

Agnes D Diemers, Margje WJ van de Wiel, Albert JJA Scherpbier,

Frank Baarveld, Diana HJM Dolmans

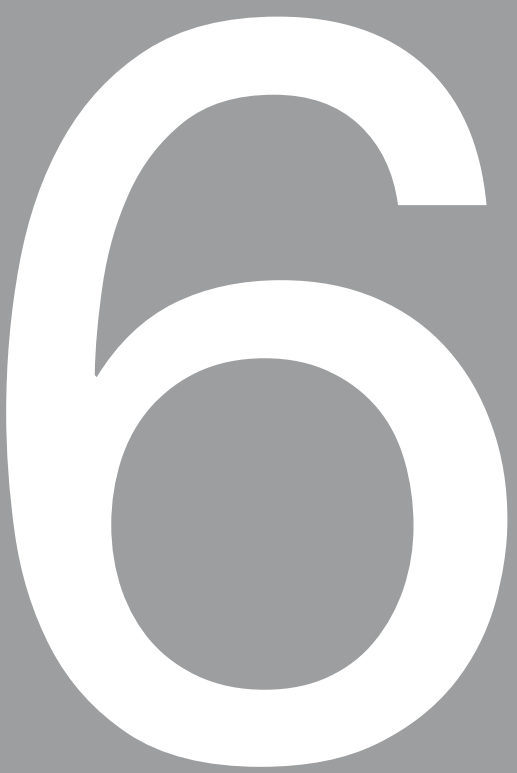

Submitted 


\section{ABSTRACT}

\section{Context}

Expert physicians have access to elaborate and integrated knowledge networks that lead to more accurate diagnoses in a shorter time. Their knowledge networks consist of biomedical and clinical knowledge that interact closely during diagnostic reasoning. Students' knowledge networks are less organized and students also have difficulties linking theory and practice and transferring acquired knowledge. In this study we explore the development and transfer of knowledge of third-year preclinical students of a PBL-based course with real patient contacts.

\section{Methods}

We conducted a pre-post course measurement in which third-year medical students think out loud while diagnosing four types of paper patient problems (two course cases and two transfer cases), and explain the underlying pathophysiological mechanisms of the patient features before and after a 10week PBL course with real patients. The verbal think-out-loud protocols and explanations were qualitatively and quantitatively analyzed.

\section{Results}

Diagnostic accuracy increased, case processing time decreased, and students used less biomedical and clinical knowledge during diagnostic reasoning. The quality of the pathophysiological explanations increased. Less wrong concepts and links were used. The findings differed across course and transfer cases. The effects were generally less strong for transfer cases.

\section{Conclusions}

Students' improved diagnostic accuracy and the improved quality of their knowledge networks suggest that integration of biomedical and clinical knowledge took place during a 10-week course. The reported differences across cases demonstrate that knowledge is case-specific and that transfer is complex and time-consuming.

We therefore suggest offering students many varied real patient contacts with the same underlying pathophysiological mechanism and encouraging students to link biomedical and clinical knowledge. 


\section{INTRODUCTION}

Medical experts have access to elaborate and integrated knowledge networks consisting of biomedical and clinical knowledge that interact in clinical reasoning. ${ }^{1-5}$ Biomedical knowledge describes the normal and abnormal functioning of the human body, such as anatomy, physiology, biochemistry, which is necessary to explain the underlying mechanisms of clinical features. ${ }^{1,6}$ Clinical knowledge relates to signs and symptoms of diseases, predictive values, treatment strategies, etcetera. ${ }^{3,5}$ When solving routine, non-complex problems expert physicians use non-analytic reasoning, activating clinical knowledge from their knowledge networks. This process is based on pattern recognition through which a disease category or previously seen patient case is automatically and unconsciously retrieved from the knowledge base. ${ }^{5,7}$ When faced with non-routine, rare or complex cases experts use analytic reasoning strategies, deliberately activating biomedical and clinical knowledge from their knowledge network. ${ }^{1,2,8}$ The diagnostic reasoning process is considered to be a process in which analytic and non-analytic reasoning interact continuously. The type of patient problem and the familiarity of the physician with the situation at hand determine if the problem-solving process either moves more towards pattern recognition (i.e. more intuitive) or to analytic reasoning. ${ }^{9}$

With growing expertise, physicians generate more accurate diagnoses in a shorter time, use less biomedical knowledge when solving patient problems, and when asked to explain underlying mechanisms of patient features they generate qualitatively better explanations that are less elaborate than novices and intermediates. ${ }^{1,10,11}$ These phenomena are explained as the result of knowledge encapsulation. ${ }^{10}$ Through repeated application of knowledge and practice with real patients, biomedical knowledge is encapsulated into higher-level clinical concepts activated by experienced physicians during clinical reasoning.

The role of biomedical knowledge in the knowledge networks of expert physicians has been extensively researched. Woods et al. ${ }^{12,13}$ found that when students are instructed to use biomedical knowledge to explain the underlying mechanisms of clinical features, this results in improved diagnostic reasoning and in better retention and recall of knowledge. Additionally, students who were offered causal explanations of underlying mechanisms are able to quickly recognize 
encapsulated as well as novel clinical features presented after studying a related clinical case, which resembles how experts work. ${ }^{13-15}$ It is suggested that biomedical knowledge is closely linked to clinical knowledge, creating coherence in the knowledge networks of expert physicians, and activated alongside clinical knowledge during clinical reasoning. ${ }^{1,12,15}$

However, students have difficulty identifying meaningful links between theory and practice and across problems. ${ }^{1,16}$ They tend to jump to diagnosing without trying to understand the underlying mechanisms. Moreover, students who learned a concept in one problem context are in less than $30 \%$ of cases successful in applying this concept in a new problem context. ${ }^{17}$ Transfer seems to benefit when students actively compare and explain the features of problems that appear to be different in order to identify deep structural similarities. ${ }^{18}$ It is also known that it is not self-evident that students spontaneously apply, i.e. transfer, their biomedical knowledge to patient problems. ${ }^{8,13,16}$ Students should therefore be explicitly instructed to make links and should be supported and given feedback when analyzing clinical problems to help them build coherent and integrated knowledge networks..$^{8,19,20}$

Students can be further helped to integrate biomedical mechanisms into knowledge networks that can be applied in and transferred to different patient problems by exposing them to varied and real patient problems. ${ }^{21,22}$ In a focus group study on the effect of real patients on student learning, students reported that real patient problems helped them to develop analytic as well as non-analytic clinical reasoning skills. ${ }^{23}$ Findings from a consecutive observational study of problem-based small group discussions revealed that real patient contacts not only stimulated students to discuss biomedical knowledge and clinical knowledge, but also that students make links between biomedical and clinical knowledge. ${ }^{24}$ This study, however, did not reveal if this resulted in coherent and integrated knowledge networks and neither did it show if students were able to transfer their knowledge to patient problems they had not previously encountered.

So to explore the development and transfer of knowledge we conducted a prepost course measurement in which we asked third-year medical students to think out loud while diagnosing four types of paper patient problems, and to explain the underlying pathophysiological mechanisms of the signs and symptoms of the 
patients presented. Two problem types were dealt with during the course and two problem types were beyond the content of the course, the so-called transfer problems. For each problem type two patient cases were presented, one in the pre- and one in the post-measurement.

We wanted to know if diagnostic reasoning and the use of clinical and biomedical knowledge during diagnostic reasoning changed pre- and post-course, and if the quality of pathophysiological explanations of patient features increased. Finally, we wanted to know if this differs between cases discussed during the course versus transfer cases.

\section{METHODS}

\section{Educational background}

The study was conducted in the third (last preclinical) year of the 6-year problembased Maastricht medical curriculum. The central theme of the third year is chronic diseases, and the year is divided into four thematic courses, i.e. the abdominal region, the locomotor system, circulation \& lungs and psychomedical problems \& mental health care. In this third year, medical students are divided into four subgroups, which rotate through the four thematic courses in different orders. The paper patients, as used in the first two years are replaced by real patient contacts taking place at the different outpatient clinics participating in the different courses at Maastricht University Hospital. The PBL-cycle follows four phases. Students prepare for the upcoming patient encounter in groups of 10 students by discussing short vignettes describing the patient problem (preparation phase). One to two days after the preparation, each student pair meets a different patient at the outpatient clinic taking a history and performing physical examination (encounter phase). After the patient encounter each student pair discusses the patient problem with the clinical supervisor and together they set learning issues to be studied during the following days (self-study phase). During the following group meeting, one week after the preparation meeting, each pair of students reports a patient presentation and their studied learning issues (reporting phase), so five patient problems are usually presented and discussed each week during a period of ten weeks. The group meetings take 4 hours of which the first 3 hours are devoted to the reporting of the former patient contacts and the last hour 
is dedicated to the preparation of the upcoming patient encounter. Each group meeting is guided by a tutor who is a staff member of the disciplines participating in the course. An extensive description of the third year of this curriculum can be found elsewhere. ${ }^{25}$

\section{Ethical procedure}

The study was approved by the Ethical Committee of the Dutch Federation of Medical Education.

\section{Participants}

At the start of the academic year 2010-2011 all students of the third year of the Maastricht medical curriculum who would participate in the abdominal course of the second rotation were invited by email to participate. Since not enough students were recruited after the first email, a second email was sent. A total of 15 students agreed to participate. They were sent an information letter, describing the study in more detail, according to the requirements of the Ethical Board of the Dutch Federation of Medical Education. Two students decided to withdraw from participation for practical reasons. Finally, 13 students, all female, participated. They all signed the consent form. The students were given an incentive of 50 euros for participation.

\section{Materials}

\section{Cases}

For this pre-post measurement study, four pairs of paper patient cases were used. Each pair described a different type of patient problem, i.e. the same underlying pathophysiological mechanism. Two problems described patients students had met and discussed during the course (course cases). The other two problems described patient problems that were not seen nor discussed during the course (transfer cases). The (biomedical) knowledge needed to solve these transfer problems was dealt with during the course. (Table 1)

The first pair of course cases described patients with signs and symptoms belonging to the underlying mechanism of inflammation in the abdominal tract, caused by inflammatory bowel diseases (IBD), i.e. Crohn's disease (premeasurement) and Ulcerative colitis (post-measurement). The second pair of 
course cases described patients with a disturbed bilirubin metabolism, resulting in jaundice either due to a post-hepatic cause, i.e. gallstones (pre-measurement) or a hepatic liver disease, i.e. liver-cirrhosis (post-measurement).

The first pair of transfer cases described patients with signs of symptoms belonging to the underlying mechanism of a malignancy, either caused by a colon carcinoma (pre-measurement), which was in accordance with the theme of the course, or a lung carcinoma (post-measurement), which was not dealt with in the course. The second pair of transfer cases described patients with features of renal insufficiency, leading to kidney failure either due to a pre-renal cause, i.e. atherosclerosis (pre-measurement) or a renal cause, i.e. recurrent ascending urinary tract infections (post-measurement). The anatomy and pathophysiological mechanisms of the kidney are dealt with during the course. The causal mechanisms though were not discussed in relation to kidney failure.

\begin{tabular}{|c|c|c|c|}
\hline & $\begin{array}{l}\text { Problem type, } \\
\text { i.e. underlying } \\
\text { mechanism }\end{array}$ & Case Pre-test & Case Post-test \\
\hline \multirow[t]{3}{*}{ Course cases } & Inflammation & Crohn's disease & Ulcerative colitis \\
\hline & $\begin{array}{l}\text { Disturbed bilirubin } \\
\text { metabolism }\end{array}$ & $\begin{array}{l}\text { Jaundice: post- } \\
\text { hepatic cause }\end{array}$ & $\begin{array}{l}\text { Jaundice: hepatic } \\
\text { cause }\end{array}$ \\
\hline & & (Gall stones) & (Liver cirrhosis) \\
\hline \multirow[t]{3}{*}{ Transfer cases } & Malignancy & Colon carcinoma & Lung carcinoma \\
\hline & Renal insufficiency & $\begin{array}{l}\text { Kidney failure: } \\
\text { pre-renal cause }\end{array}$ & $\begin{array}{l}\text { Kidney failure: renal } \\
\text { cause }\end{array}$ \\
\hline & & (Atherosclerosis) & $\begin{array}{l}\text { (Recurrent ascending } \\
\text { urinary tract } \\
\text { infections) }\end{array}$ \\
\hline
\end{tabular}

Table 1 Problem types and cases 


\section{Instruments for measuring diagnostic reasoning}

Diagnostic accuracy measure

To score the diagnostic accuracy per case, we developed a scoring list, based upon differential diagnoses of four experts (three general practitioners and one specialist of internal medicine). Like the participants these experts were asked to provide a differential diagnoses of three diagnoses with the most important one listed on top.

The diagnoses of the students were appraised using two criteria:

1. the quality of the diagnoses: if their diagnoses matched the diagnoses of the experts, this was called the 'correct diagnosis'. If they matched in general terms, this was called an 'inferior diagnosis'.

2. the place of the diagnoses in the differential diagnoses list (the most likely is on the top), either being right or wrong.

Table 2 shows how the quality and place of the diagnoses were assessed, ranging from 0-4 points.

\section{POINTS CRITERIA}

0

1 - no correct diagnosis

-1 correct diagnosis at the wrong place, plus 1 inferior diagnosis

-1 correct diagnosis, right place

-1 inferior diagnosis at the right place

-2 correct or inferior diagnoses at the wrong place, or 1 at the right places -most likely diagnosis at the wrong place

-1 correct diagnosis and 2 inferior ones, regardless of the place
3

4 -3 correct diagnoses at the right place

-2 correct or inferior diagnoses or 3 correct diagnoses, of which 1 or 2 at the right place

-2 correct and 1 inferior diagnoses regardless of the place -most likely diagnosis at the right place

Table 2 Accuracy of diagnosis expressed as correctness of diagnosis and place of diagnosis in the differential diagnosis list 
Coding scheme for think-aloud protocols of diagnostic reasoning

To analyze the transcripts of the diagnostic reasoning process we used the coding framework of a previous study, which was slightly adjusted to answer the research questions. ${ }^{24}$ The codes were aggregated into three main categories: Biomedical knowledge (B), Clinical knowledge (C), Other information (O) (Table 3).

\section{Instrument for measuring the quality of the pathophysiological explanations}

Some cases and model explanations had previously been used and some cases were new. For these new cases, two investigators ( $A D$ and $M W$ ) developed model explanations that contained all the signs and symptoms in these cases by linking them to biomedical and clinical concepts describing the underlying pathophysiological mechanisms. The expert specialist of internal medicine checked all the cases and model explanations for accuracy.

\section{Procedure}

Measurements took place at the start and at the end of the abdominal course (pre- and post-course), with an intervening period of 10 weeks. On both occasions (pre and post), students were given the four different paper patient problems described above. To prevent order effects, the order of case presentation was balanced over students. In the first session, the experimental procedure was practiced with a case of abdominal pain due to diverticulitis.

During recruitment, students were told that they would be asked to diagnose and explain four cases before and after the course. In explaining the experimental procedure, students were instructed to diagnose each case and to provide a differential diagnosis describing the three most likely diagnoses with the most likely one at the top of the list. They were asked to think aloud while diagnosing, i.e. they had to read the cases out loud and to say everything that came to their minds. The investigator encouraged the students to keep on speaking out loud when they were silent for more than 5 seconds. No time constraints were given, but after 10 minutes students were encouraged to write down their differential diagnosis. When they were done, the investigator took the paper case including the written differential diagnosis. 


\section{CODING CATEGORY}

\section{Clinical knowledge (C)}

\section{Biomedical knowledge (B)}

\section{QUOTES}

All clinical propositions used during diagnostic reasoning, including conclusions of data and explaining symptoms

\section{$\mathrm{AB} 12$}

But um, how can you become nauseous from that again. (C) Seems to me that the weight loss (Cinfo*) is because she keeps on vomiting the whole time (...). (C). But it could also be due to a malignancy, (B) but why do you vomit if your kidney does not get enough blood? (C) Perhaps no, now um, perhaps there are too many toxic substances in her blood, (B) because her other kidney does not work well either (B) due to all those urinary tract infections (...). (Cinfo)

\section{CS4}

Because she is a woman (Cinfo), the gall stones are well uh, ... even more likely, $(\mathrm{C})$ because they occur more often than in men ....(C) Uh, ...but normally that pain also disappears ....(C) I think.(O) So only after the meal $(C)$ and then it is once again better in the case of gall stones $(C)(\ldots$.

All biomedical knowledge used during diagnostic reasoning, including conclusions of data and explaining symptoms

\section{KK1}

And losing weight, (Cinfo) yes, that also has something to do with the fact that he I think, uh eats less (Cinfo) and that if the intestines, if there is an inflammation (B), can of course absorb food less well. (B) So in that case my first thought is Crohn's disease, $(C)$ because that is also found in the small intestine $(B)$, rather than colitis, $(C)$ as that is only found in the large intestine $(\mathrm{B})$ and no nutrients are absorbed there. (B) 


\section{CODING CATEGORY}

\section{QUOTES}

NS7

Nevertheless he is now starting to become concerned (Cinfo), because he thought um, he had seen some blood in the feces during the past few days (Cinfo).

So you can make a distinction between blood what lies on it (C) or blood that is mixed in it (C). Uh, if it is therefore uh, on the feces, it is a low hemorrhage $(B)$ if it is mixed, it is a higher hemorrhage, higher in the abdomen (B). Uh, ...it can also be differentiated as black (C) or red blood (C). Red blood is fresh (C), black blood is uh somewhat longer (C), so that also points to a higher hemorrhage (B).

\section{Other knowledge (0)}

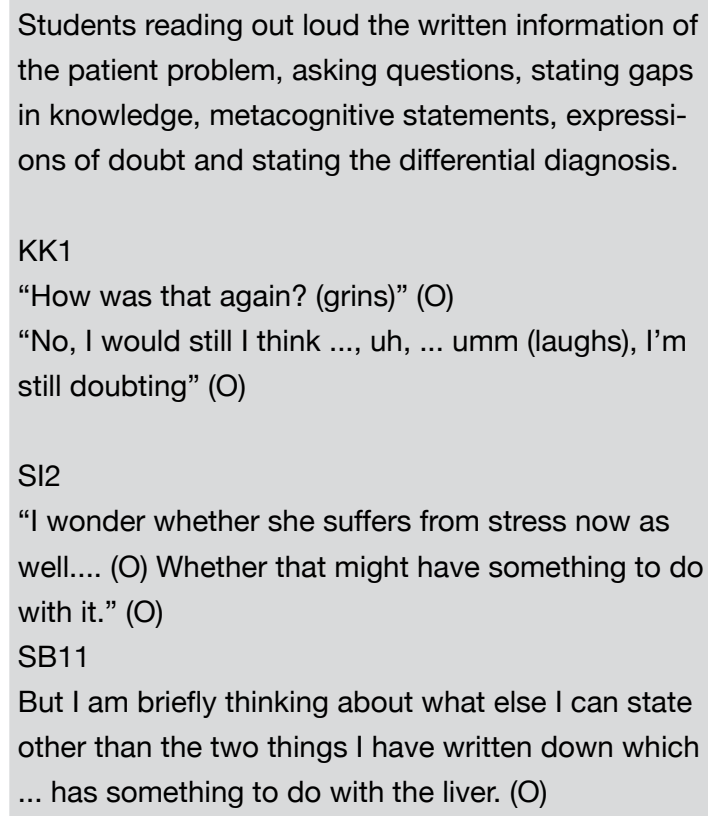

But I am briefly thinking about what else I can state other than the two things I have written down which ... has something to do with the liver. (O)

Table 3 Coding scheme for think-aloud protocols of diagnostic reasoning, illustrated by quotations 
Next, students were instructed to write down their explanation of the signs and symptoms of the patient in terms of the underlying pathophysiological mechanisms according to their most likely diagnosis. When they stopped writing within 5 minutes, they were encouraged to think deeper for more explanations for at least 5 minutes. After 10 minutes they were instructed, when needed, to finalize their explanations.

The time used to diagnose the case was measured, from the start of reading the case out loud until finishing the written differential diagnoses. Diagnostic reasoning while thinking aloud was audio-recorded and transcribed literally into verbal protocols.

\section{Analysis}

\section{Diagnostic reasoning}

For analysis of the verbal protocols Atlas.ti software was used. ${ }^{26}$ Two researchers $(A D$ and $M W$ ) first coded five protocols together to establish the final coding scheme. Next, they separately coded four other protocols of different students and different cases. Differences in coding were discussed until consensus was reached. The protocols were then re-read and codes adjusted to the agreements. Codes were assigned to small meaningful information units, the so-called propositions. ${ }^{27}$

The main dependent variables regarding diagnostic reasoning were mean diagnostic accuracy (score 0-4), case processing time (in seconds) and three variables regarding the use of knowledge in diagnostic reasoning derived from analyzing the verbal protocols: mean number of biomedical, clinical and other propositions.

\section{Pathophysiological explanations}

For each case, the explanations of the signs and symptoms of the patients were translated into networks linking patient features to higher-level clinical concepts and underlying biomedical concepts. These networks were compared to the model explanations that were developed with medical experts.

The dependent variables were the mean number of concepts, further specified as: the number of model concepts, the number of alternative and detailed concepts, and the number of wrong concepts in the students' explanations. ${ }^{1}$ As a measure of 
explanation quality the percentage of model concepts (of the number of concepts used in students' explanations) was calculated. Furthermore, the number of biomedical and clinical concepts in the students' explanations were determined. Finally, the mean number of links between concepts was calculated and further specified as the number of model links, the number of alternative and detailed links, the number of wrong links, the number of shortcuts indicating abbreviations in reasoning, and the percentage of model links (of the number of links between concepts used in the students' explanations). For further descriptions of these variables, see Table 4.

\section{CATEGORY}

Model concepts/links

Detailed concepts/links

Alternative concepts/links

Wrong concepts/links

\section{DESCRIPTION OF CONCEPTS/LINKS}

Concepts/ links that are identical or equivalent to the concepts/links of the model explanations

Concepts/links between concepts at a more detailed level than the concepts in the model explanations

Concepts/links between concepts that are not wrong, but are not described in the model explanations due to a different diagnosis.

Concepts or links between concepts that are wrong regardless of the diagnosis.

Links between model concepts but skipping intermediate concepts.

Table 4 Description of concepts/links used in the pathophysiological explanations 


\section{DIAGNOSTIC REASONING ( $\mathrm{N}=13$ )}

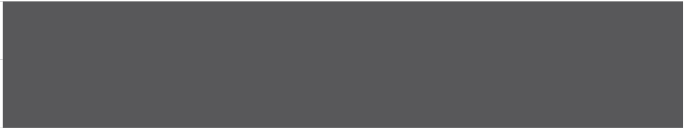

\section{Course}

PRE-MEASUREMENT

Diagnostic accuracy (max 4)

Case processing time (seconds)

Use of knowledge

$\mathrm{N}$ of propositions

$\mathrm{N}$ of biomedical propositions

$\mathbf{N}$ of clinical propositions

$\mathrm{N}$ of other propositions
IBD

$0.7(0.9)$

$517(113)$
Transfer

Carcinoma

Kidney failure
Carcinoma

$1.4(1.0)$

$0.6(0.9)$

\section{$1.4(1.0)$}

$538(169)$

644 (134)

\section{Nof other propositions}

\section{POST-MEASUREMENT}

Diagnostic accuracy (max 4)

Case processing time (seconds)
66.7 (19.6)

$$
9.6(5.7)
$$

$19.2(8.4)$

$37.9(16.4)$

IBD

$3.0(1.2)^{*}$

$417(91)^{\star}$
$58.5(31.5)$

$4.1(4.3)$

$19.5(10.2)$

$34.9(20.4)$

$36.3(20.4)$
$80.5(28.9)$

$9.4(8.6)$

$18.4(7.2)$

$52.7(20.0)$
Jaundice

Carcinoma

Kidney failure

\section{Use of knowledge}

$\mathrm{N}$ of propositions

$\mathrm{N}$ of biomedical propositions

$\mathrm{N}$ of clinical propositions

$\mathrm{N}$ of other propositions $46.0(21.4)^{\star}$

$5.9(4.4)^{*}$

$15.2(7.8)$

$24.9(16.3)^{*}$
$53.5(27.0)$

$7.8(6.1)$

$12.8(7.4)$

$32.9(17.5)$
$48.4(23.4)$

$2.6(2.9)$

$12.9(6.2)$

$32.9(19.5)$ $55.7(24.1)^{\star}$

$5.9(6.1)$

$12.2(6.8)^{*}$

$37.6(14.0)^{*}$

${ }^{*}=$ paired t-test per pair of cases $\mathrm{p}<.05$

Table 5 Mean diagnostic accuracy, mean case processing time, and mean number of propositions used in diagnostic reasoning for all cases in pre- and post-measurement, and course-transfer conditions. Standard deviations are provided between brackets 


\section{Statistical analysis}

To examine the main effect of the course on the cases in the pre- and post-measurement, on the course and transfer cases and their interaction effect, all dependent variables were analyzed in SPSS using ANOVA repeated measures in a 2 (preversus post-measurement) $\times 2$ (course versus transfer cases) $\times 2$ (problem-type) within-subject design. To examine differences between the two parallel cases in the pre-post measurement for each of the four problem types, paired t-tests were used. Only results with a significance level of $<.05$ are reported.

\section{RESULTS}

\section{Diagnostic reasoning}

Table 5 provides an overview of the data for all variables measured in diagnostic reasoning.

\section{Diagnostic accuracy}

Analyses revealed significant main effects for pre-post measurement $(F(1,12)=$ $107.294, p=.000$ ) showing that diagnostic accuracy increased after following the course. There was a significant interaction effect between pre-post measurement and the course-transfer cases $(F(1,12)=5.928, p=.031)$. At the end of the course, the diagnostic accuracy of the transfer cases increased more than the accuracy of the course cases. Analyses per problem type revealed that diagnostic accuracy increased from pre- to post-test for the IBD course cases $(t(12)=-5.571, p=$ $.000)$, the carcinoma transfer cases $(t(12)=-5.734, p=.000)$, and the kidney failure transfer cases $(\mathrm{t}(12)=-8.066, \mathrm{p}=.000)$.

\section{Case processing time}

We found significant main effects for both pre-post measurement $(F(1,12)=$ $5.287, p=.040)$, and course-transfer cases $(F(1,12)=7.312, p=.019)$ showing that processing time decreased after following the course and that transfer cases took longer to process than course cases. Analyses per problem type revealed that processing time decreased for the IBD course cases $(t(12)=3.264, p=.007$ ) and the kidney failure cases $(t(12)=3.739, p=.003)$ 


\section{Knowledge use during diagnostic reasoning}

The results showed significant main effects for pre-post measurement on the number of total and clinical propositions in the think-aloud protocols and for course-transfer cases on the number of biomedical and other propositions.

The students used less propositions while reasoning through the cases after they followed the course $(F(1,12)=6.437, p=.026)$. Analyses per problem type showed that the number of propositions decreased for the IBD course cases $(t(12)=3.360, p=.006)$ and the kidney failure transfer cases $(t(12)=2.706, p=$ $.019)$.

After following the course they also used less clinical propositions in diagnostic reasoning $(F(1,12)=7.892, p=.016)$. Analyses per problem type revealed that the number of clinical propositions decreased in the kidney failure cases $(t(12)=$ 3.038, $p=.010$ ).

The think-aloud protocols showed that students used less biomedical propositions after following the course, but this was only marginally significant $(F(1,12)=4.710, p=.051)$. Analyses per problem type showed that they used less biomedical propositions in the IBD course cases after the course $(t(12)=2.336$, $p=.038$ ). Additionally, compared to the course cases, they used less biomedical propositions in the transfer cases $(F(1,12)=11.603, p=.005)$.

Finally, in diagnostic reasoning students used more 'other' propositions (i.e. expressing questions, lack of knowledge, metacognitive statements, doubts) in the transfer cases compared to the course cases $(F(1,12)=8.210, p=.014)$. Analyses per problem type showed that after following the course less 'other' propositions were used while reasoning through the IBD course cases $(t(12)=$ $2.919, \mathrm{p}=.013)$ and the kidney failure transfer cases $(\mathrm{t}(12)=2.236, \mathrm{p}=.045)$.

\section{Pathophysiological explanations}

Table 6 provides an overview of the concepts and the links between concepts used by students in their pathophysiological explanations.

\section{Concepts}

We found significant main effects for pre-post measurement and course-transfer cases for the number of concepts $(F(1,12)=10.043, p=.008 ; F(1,12)=11.946, p$ $=.005$ resp. $)$, the number of model concepts $(F(1,12)=18.793, p=.001 ; F(1,12)$ 
$=16.690, p=.002$ resp. $)$ and the percentage of model concepts $(F(1,12)=5.809$, $p=.033 ; F(1,12)=6.324, p=.027)$. There were significant interaction effects for the number of concepts and model concepts between pre-post measurement and course-transfer cases $(F(1,12)=22.449, p=.000 ; F(1,12)=8.407, p=$ .013 resp.). After following the course, students used more concepts and more model concepts in their pathophysiological explanations and the percentage of model concepts raised. Furthermore, all three were higher in the explanations of the course cases compared to the transfer cases. At the start of the course, students used slightly less concepts in the explanations of the course cases than in transfer cases. At the end of the course, the explanations of the course cases showed a considerable increase in the number of concepts, whereas the number of concepts of the transfer cases decreased slightly. The students used more model concepts in the explanations of the course cases than of the transfer cases at the start as well as at the end of the course, but the increase in the use of model concepts was higher in the course cases.

Furthermore, we found significant main effects for pre-post measurement for the number of wrong concepts $(F(1,12)=5.772, p=.008)$, showing that after following the course students used less wrong concepts.

Analyses per problem type revealed that after following the course students used more concepts and model concepts and less wrong concepts in the explanations of the IBD course cases $(t(12)=-3.583, p=.004 ; t(12)=-2.998, p=.011 ; t(12)$ $=2.248, p=.044$ resp.). The explanations of the jaundice course case also contained more concepts after the course $(t(12)=-3.665, p=.003)$.

The results also showed significant main effects on the number of biomedical concepts for pre-post measurement $(F(1,12)=8.331, p=.014)$ and coursetransfer cases $(F(1,12)=77.266, p=.000)$ as well as a significant interaction effect $(F(1,12)=17.696, p=.001)$. Students not only used more biomedical concepts after the course, they also used more biomedical concepts in the course cases than in the transfer cases. The increase in the use of biomedical concepts was higher for the course cases. Analyses per problem-type revealed that the explanations of the course cases IBD $(\mathrm{t}(12)=-2.774, \mathrm{p}=.017)$ and jaundice $(\mathrm{t}(12)$ $=-3.402, p=.005)$ contained more biomedical concepts after the course. 


\section{Course}

\section{PRE-MEASUREMENT}

\section{Concepts}

$\mathrm{N}$ of concepts

$\mathrm{N}$ of model concepts

$\mathrm{N}$ of detailed \& alternative concepts

$\mathrm{N}$ of wrong concepts

Percentage of model concepts

Biomedical concepts

Clinical concepts

\section{Links}

$\mathbf{N}$ of links
$\mathbf{N}$ of model links
$\mathbf{N}$ of detailed \& alternative links
$\mathbf{N}$ of wrong links
$\mathbf{N}$ of shortcuts
Percentage of model links

\section{POST-MEASUREMENT}

\section{Concepts}

N of concepts
N of model concepts
N of detailed \& alternative concepts
$\mathbf{N}$ of wrong concepts
Percentage of model concepts
Biomedical concepts
Clinical concepts

$\mathbf{N}$ of links
$\mathbf{N}$ of model links
$\mathbf{N}$ of detailed \& alternative links
$\mathbf{N}$ of wrong links
$\mathbf{N}$ of shortcuts
Percentage of model links

\section{Links}

\section{Percentage of model links}

Transfer

Carcinoma

Kidney failure

Jaundice

\begin{tabular}{|c|c|c|c|}
\hline $12.7(4.4)$ & $14.7(4.0)$ & $13.1(3.6)$ & $14.8(3.9)$ \\
\hline $8.0(3.8)$ & $9.8(4.2)$ & $7.7(1.9)$ & $8.1(3.2)$ \\
\hline $2.2(1.8)$ & $3.9(2.0)$ & $3.9(2.4)$ & $4.8(2.0)$ \\
\hline $2.5(2.1)$ & $0.9(0.9)$ & $1.5(1.7)$ & $1.9(1.3)$ \\
\hline $62.6(12.2)$ & $64.8(12.9)$ & $60.2(11.7)$ & $53.6(13.4)$ \\
\hline $4.7(2.5)$ & $7.0(2.1)$ & $3.5(1.9)$ & $6.3(2.2)$ \\
$8.0(2.6)$ & $7.7(3.3)$ & $9.6(2.3)$ & $8.5(3.0)$ \\
\hline $9.5(2.8)$ & $12.3(2.5)$ & $10.3(3.6)$ & $10.9(3.4)$ \\
$1.1(1.8)$ & $3.4(2.4)$ & $1.4(1.5)$ & $1.2(1.2)$ \\
$3.9(2.8)$ & $5.5(2.6)$ & $5.9(3.2)$ & $6.4(3.6)$ \\
$3.8(3.2)$ & $1.9(2.1)$ & $2.0(2.5)$ & $2.7(2.2)$ \\
\hline $0.7(0.8)$ & $1.5(1.4)$ & $1.0(1.2)$ & $0.6(1.0)$ \\
\hline $9.4(12.9)$ & $26.6(17.3)$ & $12.1(12.7)$ & $10.9(10.5)$
\end{tabular}

\section{IBD}

$18.3(6.1)^{\star}$

$12.9(4.8)^{\star}$

$4.2(4.0)$

$1.2(2.4)^{\star}$

72.4 (19.3)

$8.4(4.9)^{\star}$

$9.9(3.1)$

$14.9(6.3)^{\star}$
$4.9(3.8)^{\star}$
$6.6(4.1)^{\star}$
$1.4(3.0)^{\star}$
$2.0(2.0)^{\star}$
$33.0(21.2)^{\star}$

Jaundice

Carcinoma

\section{Kidney failure}

$19.2(4.6)^{*}$

$12.4(3.2)$

$14.9(4.0)$

12.4 (3.6)

8.5 (2.6)

8.7 (3.0)

5.7 (3.4)

$3.4(2.1)$

$5.1(3.1)$

1.1 (1.3)

$0.5(0.8)$

$1.1(1.4)$

$65.8(12.9)$

$68.1(12.9)$

$60.0(18.0)$

$11.4(3.8)^{\star}$

$4.2(1.9)$

$6.2(3.7)$

$7.8(3.1)$

$8.2(3.2)$

$8.7(2.4)$

\begin{tabular}{|c|c|c|}
\hline $15.6(4.8)^{\star}$ & $10.1(3.5)$ & $11.7(4.1)$ \\
$4.0(3.8)$ & $2.9(2.4)$ & $1.3(1.8)$ \\
$7.9(4.5)$ & $5.5(3.2)$ & $7.6(3.5)$ \\
$1.9(1.8)$ & $0.7(1.3)$ & $1.9(1.8)$ \\
$1.8(1.9)$ & $1.0(0.9)$ & $0.9(1.0)$ \\
$23.9(20.7)$ & $26.2(18.5)$ & $9.5(11.6)$
\end{tabular}

${ }^{*}=$ paired t-test per pair of cases $p<.05$ 
Table 6 Mean number of concepts, model concepts, etc. and mean number of biomedical and clinical concepts used in the pathophysiological explanations for all cases in pre- and post-measurement and course-transfer conditions. Standard deviations are provided between brackets

\section{Links between concepts}

We found significant main effects for pre-post measurement on the number of links $(F(1,12)=7.544, p=.018)$, model links $(F(1,12)=10.126, p=.008)$, detailed \& alternative links $(F(1,12)=5.085, p=.044)$, wrong links $(F(1,12)=6.685, p=.024)$, and the percentage of model links in students' explanations $(F(1,12)=5.725$, $p=.034)$. We also found main effects for course-transfer cases on the number of links $(F(1,12)=9.029, p=.011)$, model links $(F(1,12)=6.938, p=.022)$ and the percentage of model links $(F(1,12)=6.678, p=.024)$. There were significant interaction effects between pre-post measurement and course-transfer cases on the number of links $(F(1,12)=14.551, p=.002)$.

After following the course, the number of links, model links, detailed \& alternative links and the percentage of model links between concepts increased in the pathophysiological explanations, whereas the number of wrong links between concepts decreased. The explanations of the course cases contained more links, model links and a higher percentage of model links than in the transfer cases. At the start of the course students used slightly more links in the course cases than in the transfer cases, but far more at the end of the course. So the number of links in the explanations of the course cases shows a marked increase, whereas the number of links in the transfer cases hardly increased at all.

Analyses per problem type showed that after following the course the pathophysiological explanations of the IBD course case contained more links $(t(12)=-3.830, p=.002)$, model links $(t(12)=-3.425, p=.005)$, detailed \& alternative links $(t(12)=-2.195, p=.049)$, shortcuts $(t(12)=-2.497, p=.028)$, a higher percentage of model links $(\mathrm{t}(12)=-3.651, \mathrm{p}=.003$ ) and less wrong links (2.792, $p=.016)$. The students also used more links in their explanations of the jaundice course case $(t(12)=-2.896, p=.013)$. 


\section{CONCLUSION AND DISCUSSION}

In this study we wanted to know if students' diagnostic reasoning and their pathophysiological explanations of the patient features change pre- and postcourse and if this differs between cases discussed during the course versus transfer cases. The results show that during the course students' knowledge developed in such a way that their diagnostic reasoning and pathophysiological explanations improved. However, the study also showed that reasoning is casespecific. We will now discuss the results in more detail and outline implications for medical education and further research.

For diagnostic reasoning we found that after following the course, students' case processing time decreased while their diagnostic accuracy increased. These are well-known features of expertise. ${ }^{5,10}$ Furthermore, we found that after following the course, students used less biomedical and clinical knowledge when diagnosing the problem.

The results from the written pathophysiological explanations showed that the students used more concepts after the course, especially biomedical concepts. Furthermore, the results revealed that the quality of explanations increased as students used more model concepts, made more links between model concepts, and reported less wrong concepts and links. Consequently, the percentage of model concepts and model links in their explanations increased. It seems that students acquired relevant knowledge and were able to integrate this knowledge into their knowledge networks by making more links between concepts. Although the explanations of the students contained fewer concepts than model explanations, the percentage of model concepts in students' explanations was high compared to the percentage of model links. These results indicate that although the overall quality of the networks improved, the linking of the concepts is still not very profound and the networks are not yet very coherent. This confirms earlier outcomes that students find it hard to make meaningful links between theory and across patient problems. ${ }^{8,16}$ Consequently, students should be encouraged to actively make those connections ${ }^{19,20}$, especially as the use of biomedical knowledge in explaining underlying mechanisms is thought to improve diagnostic reasoning as well as retention and recall of knowledge. ${ }^{12,13}$ In summary, the findings from our study suggest that early real patient contacts 
might help students to build a knowledge base that will facilitate the hallmarks of expertise: improved diagnostic accuracy, decreased case processing time, and qualitatively better explanations. These findings are in line with the encapsulation theory. ${ }^{1,10}$

Looking at the different type of patient problems used in this study, overall, differences between cases were reported; both for the cases that were dealt with during the course and the transfer cases. This indicates that knowledge is case specific.

We also found that during diagnostic reasoning, case processing took longer in the transfer cases than the course cases and that students used less biomedical knowledge in the transfer cases during diagnostic reasoning and during explanations. Furthermore, their explanations were less elaborate and showed less improvement after the course than the explanations of the course cases, which indicates that transfer of knowledge is complex and takes time. ${ }^{17}$

The effect of the course was most prominent in the IBD course cases, both in students' diagnostic reasoning and the pathophysiological explanations. The course also had positive effects on one of the transfer cases, i.e. the kidney failure cases, in terms of diagnostic reasoning but not the pathophysiological explanations. The reason might be the difference between near and far transfer of knowledge. ${ }^{28}$ In this study near transfer, i.e. transfer of knowledge within the same organ (the kidney), is more likely to occur than far transfer, i.e. transfer of knowledge between different organs (carcinoma of the colon and of the lung). The finding that the course case of jaundice showed fewer effects than we expected might be because students already had prior knowledge about this patient problem type, and probably did not acquire lots of new knowledge during the course about it.

One strength of our study is that we performed a pre-post measurement study over a 10-week period of time. Development over time could therefore be investigated. This adds a new perspective to the mostly cross-sectional studies on medical expertise development. Additionally, we used a mix of quantitative and qualitative measures.

The limitations of our study are the limited number of cases, the limited number of participating students and the fact that all students were volunteers and females. So this might not have been a representative sample of the student population at hand. 
From the findings of our study we conclude that real patient problems early in medical education might support the development of students' knowledge and their integration of biomedical and clinical knowledge. However, to ensure that students fully benefit from the full potential of real patient contacts, teachers should explicitly be instructed to articulate underlying pathophysiological mechanisms, to inspire students to apply their knowledge to varied patient problems, and to actively encourage students to link the features within and across patient problems. Furthermore, to improve the transfer of knowledge we suggest to offer students many varied patient problems with the same underlying pathophysiological mechanisms, which should be explained more explicitly by the teachers.

More studies should be conducted to gain a better understanding of how biomedical and clinical knowledge in the diagnostic reasoning of students develop over time and also to find ways of enhancing the transfer of knowledge. 


\section{REFERENCES}

1. van de Wiel M, Boshuizen $\mathrm{H}$, Schmidt $\mathrm{H}$. Knowledge restructuring in expertise development: evidence from pathophysiological representations of clinical cases by students and physicians. European Journal of Cognitive Psychology 2000;12(3):323-355.

2. Norman GR, Trott AD, Brooks LR, Smith EK. Cognitive differences in clinical reasoning related to postgraduate training. Teaching and Learning in Medicine 1994;6:114-120.

3. Norman G. Research in clinical reasoning: past history and current trends. Medical Education 2005;39:418-427.

4. Norman G. Building on experience - the development of clinical reasoning. New England Journal of Medicine 2006;355(21):2251-2252.

5. Norman G, Eva K, Brooks L, Hamstra L. Expertise in medicine and surgery. In: Anders, E.K., Charness, N., Feltovich, P. and Hoffman, R., eds. The Cambridge handbook of expertise and expert performance. New York 2006:339-353.

6. Woods NN. Science is fundamental: the role of biomedical knowledge in clinical reasoning. Medical Education 2007;41:1173-1177.

7. Elstein AS, Schwarz A. Evidence base of clinical diagnosis: Clinical problem solving and diagnostic decision making: selective review of the cognitive literature. British Medical Journal 2002; 324:729-32.

8. Eva KW. What every teacher needs to know about clinical reasoning. Medical Education 2005;39:98-106.

9. Stolper E, van de Wiel M, van Royen P, van Bokhoven M, van der Weijden T, Dinant GJ. Gut feelings as a third track in general practitioners' diagnostic reasoning. Journal of General Internal Medicine 2011;26(2):197-203.

10. Schmidt HG, Boshuizen HPA. On the origin of intermediate effects in clinical case recall. Memory and Cognition 1993;21:338-351.

11. Boshuizen HPA. Cognitive effects of practical experience in high- and lowachieving medical students. Learning and Instruction 1994;4:313-329.

12. Woods NN, Brooks LR, Norman GR. The value of basic science in clinical diagnosis: Creating coherence among signs and symptoms. Medical Education 2005:39:107-112. 
13. Woods NN, Brooks LR, Norman GR. The role of biomedical knowledge in diagnosis of difficult cases. Advances in Health Sciences Education 2007;12:417-426.

14. Woods NN, Howey EHA, Brooks LR, Norman GR. Speed skills? Speed, accuracy, encapsulations and causal understanding. Medical Education 2006;40:973-979.

15. Rikers RMJP, Loyens S, te Winkel W, Schmidt HG, Sins PHM. The role of biomedical knowledge in clinical reasoning: a lexical decision study. Academic Medicine 2005:80(10):945-949.

16. van de Wiel MWJ, Schaper NC, Scherpbier AJJA, van der Vleuten CPM, Boshuizen HPA. Students' experiences with real-patient tutorials in a problem-based curriculum. Teaching and Learning in Medicine 1999;11:1220.

17. Norman G. Teaching basic science to optimize transfer. Medical Teacher 2009;31:807-811.

18. Norman G. The basic role of basic science. Advances in Health Sciences Education 2012;17:453-456.

19. Boshuizen HPA, van de Wiel MWJ, Schmidt HG. What and how advanced medical students learn from reasoning through multiple cases. Instructional Science 2012;40:755-768.

20. van de Wiel MWJ, van den Bossche P, Koopmans RP. Deliberate practice, the high road to expertise: K.A. Ericsson. In Dochy, F., Gijbels, D., Segers, M. \& van den Bossche, P. (Eds), Theories of learning for the workplace: Building blocks for training and professional development programs (pp. 1-16). London: Routledge 2011.

21. van de Wiel, M. Knowledge encapsulation. Studies on the development of medical expertise. Dissertation, Maastricht University, Maastricht 1997.

22. Schmidt HG, Rikers RMJP. How expertise develops in medicine: knowledge encapsulation and illness script formation. Medical Education 2007;41:11331139.

23. Diemers AD, Dolmans DHJM, Verwijnen MGM, Heineman E, Scherpbier AJJA. Students' opinions about the effects of preclinical patient contacts on their learning. Advances in Health Sciences Education 2008;13(5):633-647. 
24. Diemers AD, van de Wiel MWJ, Scherpbier AJJA, Heineman E, Dolmans DHJM. Preclinical patient contacts and the application of biomedical and clinical knowledge. Medical Education 2011;45:280-288.

25. Diemers AD, Dolmans DHJM, van Santen M, van Luijk SJ, Janssen-Noordman AMB, Scherpbier AJJA. Students' perceptions of early patient encounters in a PBL curriculum: A first evaluation of the Maastricht experience. Medical Teacher 2007;29:135-142

26. Muhr, T. Atlas.ti. Visual Qualitative Data Analysis-Management-Model Building in Education, Research and Business. Release 6.2. Berlin: Scientific Software Development 1997.

27. Patel VL, Groen GJ. Knowledge-based solution strategies in medical reasoning. Cognitive Science 1986;10:91-116.

28. Perkins DN, Salomon G. Transfer of learning, International encyclopedia of education. Oxford: Elsevier 1994:6452-6457. 


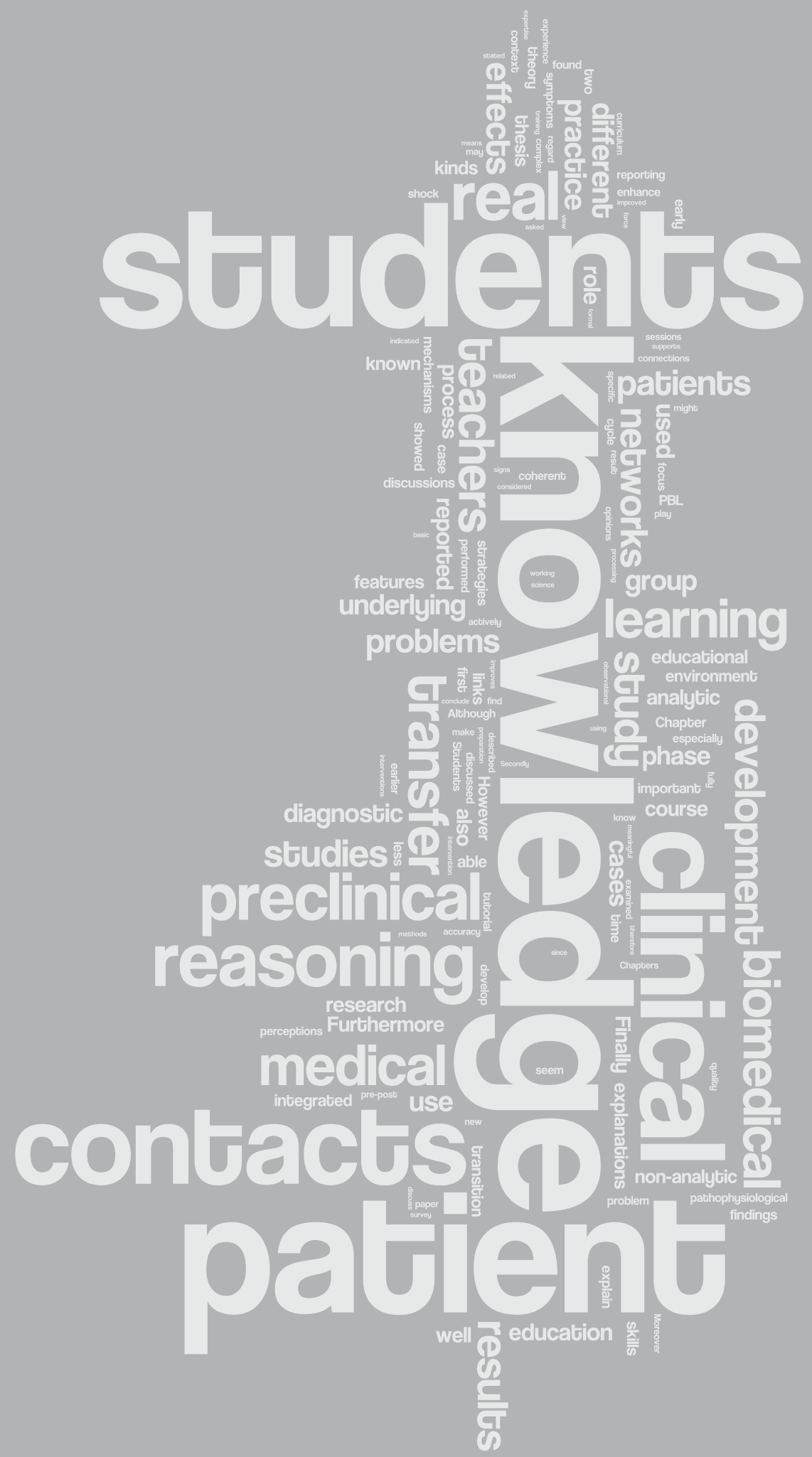


CHAPTER 7

General discussion

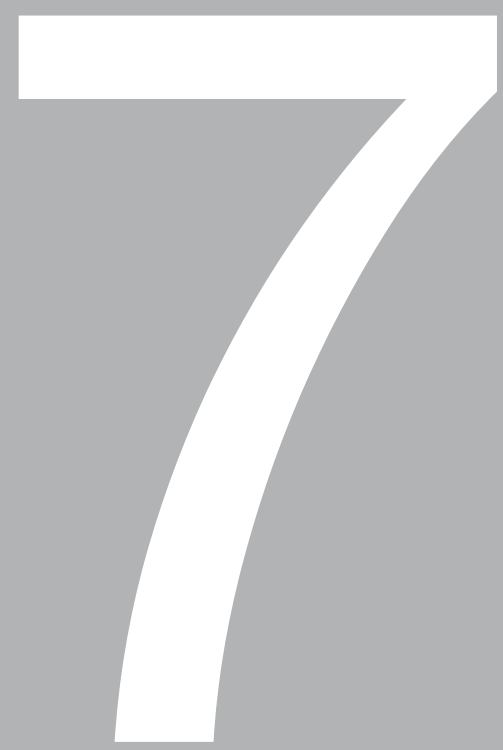


When entering the clinical phase of their medical training, medical students may experience a shock of practice. ${ }^{1-3}$ They were found to have difficulties in making meaningful links between theory and practice and were not able to transfer their knowledge into new and other patient problems. ${ }^{3,4}$ Early real patient contacts are suggested as a way of overcoming this gap between the two phases of medical education. ${ }^{2,3,5,6}$ However, the effects of preclinical real patient contacts, which act as starting point for learning, on student learning are not known. In this thesis we first of all sought students' opinions about the effects of preclinical patient contacts on their transition to the clinical context and on their learning, by means of two focus group studies and a questionnaire survey study. Secondly we wanted to know what the effects of preclinical real patient contacts were on the development and transfer of students' knowledge. At a more specific level, we examined the use of biomedical and clinical knowledge through an observational study of tutorial group discussions. Then we performed a pre-post intervention study to students' diagnostic reasoning, the integration of underlying biomedical and clinical knowledge and the transfer of knowledge.

In this chapter we discuss the results of the studies that explored students' perceptions and views about the effects of preclinical patient contacts on the shock of practice and on their learning, as described in Chapters 2, 3 and 4. Next we discuss the results of the last two studies on the use, development and transfer of knowledge, as reported in Chapters 5 and 6 . The strengths and limitations of this thesis are then considered. Finally, we discuss the valorization of our results.

\section{STUDENTS' PERCEPTIONS OF THE EFFECTS OF PRECLINICAL PATIENTS CONTACTS ON THE TRANSITION TO CLINICAL TRAINING AND ON LEARNING}

Chapters 2, 3, and 4 gave answers to the first research question: What are students' perceptions of the effects of preclinical patient contacts on their transition to the clinical context and on their learning?

In Chapter 2 we described a focus group study in which we asked the students 
how they perceived the transition from the preclinical to the clinical phase of their medical training, and how they value these contacts as preparation for learning in clinical practice. In the last year, before entering the clinical environment, they experienced real patient contacts each week that replaced the paper patient problems in the PBL cycle. The results showed that the students did not experience the shock of practice as was reported in earlier studies. ${ }^{1-3}$ Although they did state that there was a shift from theoretical knowledge to clinical knowledge, they perceived the transition to the clinical environment as a gradual and natural process. Moreover, they said that the real patient contacts enabled them to get used to real practice in the clinical context in a rather protected learning environment. The preclinical patient contacts were considered to bridge the gap between the preclinical and clinical phase. Although the students did not experience the so called 'shock of practice', they still reported negative experiences regarding the transition period that were mainly related to working in the clinical environment. They suffered the huge increase in working hours and intensity of work and they had to get used to their role as a clerk. Finally, according to the students, non-analytic reasoning processes become more important during the clinical years of medical education. However, with respect to analytic reasoning students often did not feel sufficiently challenged to fully exploit their skills in this area, since in the students' opinion their clinical teachers did not give them enough opportunities to explain patients' signs and symptoms and were easily satisfied with their answers.

In Chapter $\mathbf{3}$ we reported a questionnaire survey study into students' perceptions of early patient contacts implemented in the PBL cycle. Questions were asked about the four phases of the PBL cycle. Overall, students appeared to be satisfied with the patient contacts and indicated that they learned a great deal from it, which supports earlier findings that early patient contacts have the potential to enhance learning. ${ }^{7}$ Furthermore, students strongly agreed that the patient contacts were discussed adequately during tutorial group discussions, especially during the reporting phase of the PBL cycle. This positive view was reinforced by relatively high scores for connecting theory and practice. Students stated that the patient contacts were adequately discussed during the reporting group sessions and the links between theory and practice became clear to them. 
In Chapter 4 (Study 3) we reported a focus group study on students' opinions about the effects of patient contacts with regard to their knowledge construction and the development of clinical reasoning. The results of this study were consistent with earlier findings about the effects of real patients on student learning: real patient contacts lead to a better acquisition and retention of knowledge, motivate learning, vividly demonstrate the impact of disease on patients' lives, and facilitate the process of professional socialization. ${ }^{2,6-10}$ However, our study revealed additional effects of real patient contacts on student learning. Students indicated that they developed both analytic and non-analytic types of clinical reasoning as a result of real patient contacts in the preclinical phase of medical education. According to the students, paper patients and simulated patients have less learning potential for the development of clinical reasoning in this phase of their medical education than real patient contacts. With regard to analytic reasoning, students argued that real patient contacts stimulated them to study basic science. Combined use of basic science and clinical knowledge helps students to explain connections between signs, symptoms and diagnosis. In this way, they not only give meaning to the symptoms of the patient but also to their basic science knowledge, which is supposed to enhance recall and retention. ${ }^{11}$ With regard to non-analytic reasoning, students thought that practice with multiple patient examples enabled them to compare and make connections between symptoms and diseases, which facilitates the retrieval of similar patients problems when necessary.

Students also indicated that teachers play an important role in relation to the development of their clinical reasoning skills. Students said that they started to actively use clinical reasoning and thinking as a result of their teachers or peers asking critical questions. This supports findings reported in the literature that students do not study the pathophysiology underlying patients' problems or make links across patient problems on their own accord. ${ }^{3,4}$

Based on the first three studies we therefore conclude that early patient contacts seem to alleviate the earlier reported "shock of practice" students perceive during the transition from the pre-clinical to the clinical years of medical education. However, such contacts do not seem to have the same beneficial effects on their adaptation to the habits of working in the clinical environment. 
Furthermore, students' opinions indicate that early patient contacts enhance learning and integration of theory and practice. This can be seen as support for the view that real patient contacts can act as a powerful driving force for meaningful and profound learnin. ${ }^{2,7,12}$ Finally, medical students seem to be able to develop and use analytic as well as non-analytic ways of clinical reasoning while learning from real patients. Both kinds of clinical reasoning, analytic and non-analytic, are needed to ensure transfer of knowledge and problem-solving strategies so that they can be used to solve new patient problems. ${ }^{11,13}$ Additionally, it is known that when explicitly instructed to use pattern recognition, combined with other reasoning strategies, diagnostic accuracy improves in experts as well as in novices. ${ }^{14,15}$ This supports our findings that according to the students, the role of the teachers is important in stimulating them to actively use both ways of reasoning.

\section{THE EFFECTS OF PRECLINICAL PATIENT CONTACTS ON THE DEVELOPMENT AND TRANSFER OF KNOWLEDGE}

Chapters 5 and 6 gave answers to the second research question: What are the effects of preclinical patient contacts on the development and transfer of knowledge, more specifically on the use and application of biomedical and clinical knowledge as well as on students' diagnostic reasoning, their underlying knowledge and the transfer of knowledge?

When real patient contacts are introduced in the medical curriculum there are concerns that students tend to focus on clinical knowledge to the neglect of biomedical knowledge and that teachers dominate the discussions. To build elaborate and integrated knowledge networks it is important that students can make links between all kinds of knowledge. Although in the perceptions of students the preclinical patient contacts provide them with opportunities to do that, we wanted to know the extent to which biomedical and clinical knowledge are addressed during tutorial group discussions and the relative contributions of students and teachers in this. Furthermore, we wanted to know if connections are made between biomedical and clinical knowledge. To answer these questions we performed an observational study of tutorial group discussions during the 
preparation and reporting phase. This is described in Chapter 5. The results showed that formal clinical and biomedical knowledge accounted for a substantial percentage of all knowledge discussed during the group sessions, especially during the reporting phase.

This study also demonstrated that biomedical knowledge was used to explain underlying mechanisms of diseases and signs \& symptoms as well as to explain underlying mechanisms of diagnostics, therapies and complications. This means that biomedical knowledge is not only used during the problem-solving process, as is already known from previous studies ${ }^{16}$, but also in decisions regarding treatment and management strategies. So during sessions in which real patient contacts are discussed, biomedical knowledge is related to different kinds of clinical knowledge. Moreover, we found that nearly all of the biomedical knowledge that was discussed during the group sessions was used in connection with clinical knowledge. This may contribute to the development of coherent and integrated knowledge networks.

The results also revealed that the group discussions during the reporting phase were dominated by the students and not the teachers, especially with regard to formal clinical and biomedical knowledge. This is in line with the studentcenteredness of PBL. ${ }^{17}$ The preparation on the patient contact is dominated more by the teachers than the students, which might be due to students' limited amount of prior knowledge about the patient problem.

In Chapter 6 we presented a pre-post intervention study (Study 5) in which we measured the effects of a 10 week course with preclinical patient contacts on students' diagnostic reasoning, the quality of pathophysiological explanations of patient features and on transfer of knowledge. Before and after the course, we asked third year medical students to think out loud while diagnosing four types of paper patient problems (two course cases and two transfer cases), and to explain the underlying pathophysiological mechanisms of the patient features. The verbal think-out-loud protocols and written explanations were qualitatively and quantitatively analyzed.

The results showed that after following the course, students' case processing time decreased while their diagnostic accuracy increased, which are well known features of medical expertise. ${ }^{18,19}$ Furthermore, we found that students used less 
biomedical and clinical knowledge during diagnostic reasoning.

Concerning the pathophysiological explanations of patient features, the results revealed that the students used more knowledge after the course, especially biomedical knowledge. Furthermore, the quality of the explanations increased. So students acquired relevant knowledge and were able to integrate this knowledge into their knowledge networks by making more links between different kinds of knowledge. Although the overall quality of the networks improved, the results also showed that the linking of the knowledge is still not very profound and the networks are not yet very coherent.

Finally, concerning the transfer of knowledge, the results showed that during diagnostic reasoning case processing took longer in the transfer cases compared to the course cases. The students used less biomedical knowledge in the transfer cases during diagnostic reasoning and when explaining underlying mechanisms of patient features. Furthermore, the explanations of the transfer cases were less elaborate and showed less improvement after the course than the explanations of the course cases, which indicates that transfer of knowledge is complex and takes time. ${ }^{20-22}$ Additionally, differences were found across both course and transfer cases, demonstrating that knowledge is case specific.

So real patient problems early in medical education help students to develop integrated knowledge networks as they seem to be able to make connections between biomedical and clinical knowledge. Their diagnostic reasoning improves, as shown by decreased processing time and improved diagnostic accuracy. Finally, the quality of the pathophysiological explanations of patient features improves. Students used more clinical concepts in reasoning through the cases and were able to apply relevant biomedical knowledge in their explanation. These findings are in line with theories about the restructuring of medical knowledge, a process supposed to play a central role in the growth towards medical expertise. The biomedical knowledge of the causal networks of students becomes encapsulated into higher-level concepts through repeated application of knowledge and clinical experiences and becomes finally integrated into illness scripts. ${ }^{18,23,24}$ However, the results also confirm findings from earlier research that knowledge is case specific and that transfer is a complex and time-consuming process ${ }^{20-22}$ 


\section{STRENGTHS AND LIMITATIONS OF THE THESIS}

This thesis studied the effects of preclinical patient contacts on students' perceptions of their learning as well as on the learning process itself and its outcomes. We used various research methods to investigate these different perspectives on learning from preclinical patient contacts. We examined students' views on and opinions about preclinical real patient contacts using focus group studies and a questionnaire survey study. Furthermore, we examined the effect of preclinical patient contacts on the development of knowledge networks, the use of biomedical and clinical knowledge and the transfer of students' knowledge by means of an observational study and a pre-post intervention study, using think aloud protocols and written explanations.

This thesis also has some limitations. First of all, the studies described in this thesis were all performed in one medical school with PBL as the educational method. We do not know if the results of our studies can be generalized to other educational methods with preclinical patient contacts. Secondly, teachers' views were only partly considered and their roles were not the subject of any of the studies (with exception of the observation study), even though these roles are generally assumed to be crucial for the success of programs with real patients. ${ }^{25}$ Nevertheless, the results of our studies do confirm the important role played by teachers. Finally, we did not thoroughly investigate the transfer of knowledge. The effects of preclinical patient contacts on transfer were examined in Study 5 , but only with two cases and with a small sample of students.

\section{VALORIZATION OF THE RESULTS}

\section{Implications for future research}

Since this thesis focused on the effects of preclinical patient contacts in the PBL cycle, more in-depth research will have to shed a light on how students learn from preclinical patient contacts in general. To find out if the results of this thesis can be generalized to other educational formats with preclinical real patient contacts, future studies will need to be conducted within the context of different medical curricula based on different kinds of educational formats. More research has to be done to establish whether preclinical real patient contacts promote the 
formation of the integrated knowledge networks needed for different kinds of clinical reasoning and whether this leads to accurate diagnosis, treatment and management decisions.

The students of our studies reported the importance of the teachers' role. They stated that they did start to actively use analytic clinical reasoning as a result of their teachers asking critical questions, although in their view this was not fully exploited. This is in accordance with the outcome that students experience difficulties in finding meaningful links between theory and practice on their own. ${ }^{3,4}$ Furthermore, the students reported that they do develop non-analytic reasoning skills as a result of preclinical patient contacts. However, the role of their teachers in this remains unclear. The fact that the combined use of different reasoning strategies, non-analytic as well as analytic, leads to improved diagnostic accuracy, makes it even more important for students to fully develop both reasoning strategies. ${ }^{13}$ So the teacher might play a crucial role in the structuring and development of students' knowledge networks. Moreover, it is likely that teachers' interventions facilitate and enhance this developmental process, which promotes the growth towards expertise. However, it is not yet known how teachers can contribute to the development of students' clinical reasoning skills or their knowledge networks or what educational interventions promote this process. So first of all, more studies should be performed to gain a better understanding of how biomedical, formal clinical and experiential knowledge develop and interact over time in both analytic and non-analytic reasoning. Secondly, the contribution of teachers to the development of coherent and integrated knowledge networks and clinical reasoning skills merits further investigation as well.

Finally, future research is needed to find out if preclinical patient contacts enhance the transfer of knowledge. Although it is already known that transfer takes time, the results of our studies confirm the fact that knowledge is case specific. ${ }^{21,22}$ Whether students are indeed capable of applying and transferring their acquired knowledge to different patient problems needs to be investigated by other prepost experimental research methods in which different kinds of knowledge have to be applied to different patient problems with the same underlying mechanism. These studies should be performed from a cross-sectional as well as longitudinal perspective to study the developments of individual students over a longer period of time. 


\section{Implications for medical education}

For medical education the implication appears to be that students should be given ample opportunities for the development of their knowledge networks so that they can acquire both clinical and experiential knowledge for use in different kinds of clinical reasoning. ${ }^{26}$ From the results of our studies we conclude that real patient contacts can serve as a driving force for learning and for the growth of expertise when implemented in the preclinical phase of PBL-based medical education. But for this endeavor to be successful, instructional design of the undergraduate medical curriculum should aim at growing authenticity of the educational context, with increasing complexity and fidelity. ${ }^{20,27}$ This could, for example, be realized through an instructional design, which first offers students paper patient problems, then simulated patients, and finally real patient contacts. Preclinical patient contacts are a way to bridge the gap from simulated patients to real patients, especially when they are implemented in a relatively safe learning environment, like small tutorial groups. Implementing real patient problems early in the medical curriculum though deserves careful attention, since we found that real patients have the risk of not turning up at the appointed time. The patient who replaces the no-show patient may not fit the cluster's theme and educational goals, and students are then suddenly faced with a patient presenting with another problem than the one they prepared for, which may hamper effective learning. ${ }^{20}$ It is known that students find it hard to explain the underlying pathophysiological mechanisms of patients' features on their own and do not spontaneously find links between theory and practice, i.e. between biomedical and clinical knowledge. ${ }^{4,13}$ Moreover, it is also known that students are in less than $30 \%$ of cases successful in applying a learned concept to a new problem in another context. $^{22}$ Transfer is reported to benefit when students are offered multiple examples of the same underlying problem or concept preferably accompanied with related other concepts. ${ }^{22,28-32}$ Also, when students are encouraged to actively compare, contrast and articulate the underlying general principles of the problems that appear different in order to identify deep structural similarities, their knowledge becomes even more transferable. ${ }^{20,33}$ So teachers play a crucial role in medical education with real patient contacts. This was confirmed in our first study (Chapter 2) in which students stated that their clinical teachers were not fully prepared for this role since they did not pay enough attention to the development 
of analytic reasoning strategies. Teachers should provide supervision and coaching, while their guidance has to decrease across problems of the same level of complexity. When students are confronted with more complex or new problems, teacher guidance should again be high. ${ }^{20}$ We therefore suggest that faculty development should aim at serving teachers with information about the curriculum, the development of knowledge and reasoning strategies, and principles about transfer of knowledge. When the implication and meaning of the development of structured and coherent knowledge networks are clear to teachers, they might be better able to adjust their educational interventions to this process. Teachers should therefore be offered the didactic skills necessary to facilitate the learning of students, more specifically the development of students' knowledge networks, clinical reasoning skills, and transfer of knowledge. To help students build coherent and integrated knowledge networks, teachers should be able to instruct and challenge students to articulate the underlying mechanisms of patient features and to apply their knowledge to the same and to different patient problems. ${ }^{34,35}$ Finally, students have to be entrusted with increasing responsibility in patient care, whereas learning should take place in a safe learning environment that benefits both students and patients (safety).

\section{IN CONCLUSION}

This thesis focused on the effects of preclinical patient contacts on students' learning. From the results of our studies we conclude that using real patients as the driving force for learning in the preclinical phase of PBL-based medical education might offer a solution to the transition problem between pre-clinical and clinical training from the students' perspective. Furthermore, preclinical real patient problems seem to support the development of knowledge of students and the integration of biomedical and clinical knowledge. Finally we infer that transfer is a time-consuming complex process and is case specific. 


\section{REFERENCES}

1. Boshuizen HPA. The shock of practice: Effects on clinical reasoning. In: Paper presented at the Annual Meeting of the American educational Research Association; 8-14 april; New York 1996.

2. Prince $\mathrm{KJAH}$, van de Wiel $M$, Scherpbier AJJA, van der Vleuten CPM, Boshuizen HPA. A qualitative analysis of the transition from theory to practice in undergraduate training in a pbl-medical school. Advances in Health Sciences Education 2000;5:105-116.

3. Prince KJAH, Boshuizen HPA, van der Vleuten CPM, Scherpbier AJJA. Students' opinions about their preparation for clinical practice. Medical Education 2005;39:704-712.

4. van de Wiel MWJ, Schaper NC, Scherpbier AJJA, van der Vleuten CPM, Boshuizen HPA. Students' experiences with real-patient tutorials in a problem-based curriculum. Teaching and Learning in Medicine 1999;11(1):1220.

5. Brynhildsen J. Attitudes among students and teachers on vertical integration between clinical medicine and basic science within a problem-based undergraduate medical curriculum. Medical Teacher 2002;24:286-288.

6. Dornan T, Littlewood S, Margolis SA, Scherpbier A, Spencer J, Ypinazar Y. How can experience in clinical and community settings contribute to early medical education? A BEME systematic review. Medical Teacher 2006;28(1):3-18.

7. Dornan T, Bundy C. What can experience add to early medical education? Consensus survey. British Medical Journal 2004;329:834-837.

8. Seabrook M. Clinical students' initial reports of the educational climate in a single medical school. Medical Education 2004;38(6):659-669.

9. Cooper HC, Gibbs TJ, Brown L. Community-orientated medical education: extending the boundaries. Medical Teacher 2001;23(3):295-299.

10. Frank D, Handfield-Jones R, Dawson DJ, Russel R, Steinert Y, Boillat M, Yaffe M, Guzder J, Keyserlingk E. An integrated curriculum for teaching preparatory clinical skills at a traditional medical school. Teaching and Learning in Medicine 1996;8(1):4-9.

11. Woods NN, Brooks LR, Norman GR. The value of basic science in clinical diagnosis: creating coherence among signs and symptoms. Medical Education 2005;39:107-112. 
12. Littlewood S, Ypinazar V, Margolis SA, Scherpbier A, Spencer J, Dornan T. Early practical experience and the social responsiveness of clinical education: Systematic review. British Medical Journal 2005;331:387-391.

13. Eva KW. What every teacher needs to know about clinical reasoning. Medical Education 2005; 39:98-106.

14. Coderre S, Mandin H, Harasym PH, Fick GH. Diagnostic reasoning strategies and diagnostic success. Medical Education 2003;37:695-703.

15. Ark, TK, Brooks LR, Eva KW. The benefits of flexibility: the pedagogical value of instructions to adopt multifaceted diagnostic reasoning strategies. Medical Education 2007;41:281-287.

16. Woods NN. Science is fundamental: the role of biomedical knowledge in clinical reasoning. Medical Education 2007;41:1173-1177.

17. Schmidt HG. Foundations of problem-based learning: Some explanatory notes. Medical Education 1993;27:422-432.

18. Schmidt HG, Boshuizen HPA. On the origin of intermediate effects in clinical case recall. Memory and Cognition 1993;21:338-351.

19. Norman G, Eva K, Brooks L, Hamstra S. Expertise in medicine and surgery. In: Anders Ericsson K, Charness N, Feltovich P, Hoffman R, eds. The Cambridge handbook of expertise and expert performance. Cambridge University Press, New York 2006;339-353.

20. Merill MD. First principles of instructions. Educational Technology, Research and Development 2002;50(3);43-59.

21. Norman GR, Schmidt HG. The psychological basis of problem-based learning: a review of the evidence. Academic Medicine 1992:67:557-565.

22. Norman G. Teaching basic science to optimize transfer. Medical Teacher 2009;31:807-811.

23. van de Wiel M, Boshuizen HP, Schmidt HG. Knowledge restructuring in expertise development: evidence from pathophysiological representations of clinical cases by students and physicians. European Journal of Cognitive Psychology 2000;12:323-355. 
24. Schmidt HG, Rikers MJP. How expertise develops in medicine: knowledge encapsulation and illness script formation. Medical Education 2007;41:11331139.

25. Dent JA. AMEE Guide No 26: clinical teaching in ambulatory care settings: making the most of learning opportunities with outpatients. Medical Teacher 2005;27:302-315

26. Norman, G. Building on experience - the development of clinical reasoning. New England Journal of Medicine 2006;355(21):2251-2252.

27. van Merriënboer JJG. Training complex cognitive skills. Englewood Cliffs: Educational Technology Publications 1997.

28. Loewenstein J, Thompson L, Gentner D. Analogical encoding facilitates knowledge transfer in negotiation. Psychonomic Bulletin and Review. 1999;6(4):586-597.

29. Catrambone R, Holyoak K. Overcoming contextual limitations on problemsolving transfer. Journal of Experimental Psychology: Learning, Memory and Cognition 1989;15(6):1147-1156.

30. Kurtz KJ, Lowenstein J. Converging on a new role for analogy in problem solving and retrieval: When two problems are better than one. Memory and Cognition 2007;35:334-341.

31. Roher D, Tyalor K. The shuffling of mathematics problems improves learning. Instructional Science 2007;35:481-498.

32. Hatala RM, Brooks LR, Norman G. Practice makes perfects. The critical role of mixed practice in the acquisition of ECG interpretation skills. Advances of Health Sciences Education, Theory and Practice 2003;8:17-26.

33. Norman G. The basic role of basic science. Advances in Health Sciences Education 2012;17:453-456.

34. Boshuizen HPA, van de Wiel MWJ, Schmidt HG. What and how advanced medical students learn from reasoning through multiple cases. Instructional Science 2012:40:755-768.

35. van de Wiel MWJ, van den Bossche P, Koopmans RP. Deliberate practice, the high road to expertise: K.A. Ericsson. In Dochy F, Gijbels D, Segers M, van den Bossche P. (Eds), Theories of learning for the workplace: Building blocks for training and professional development programs (pp. 1-16). London: Routledge 2011. 


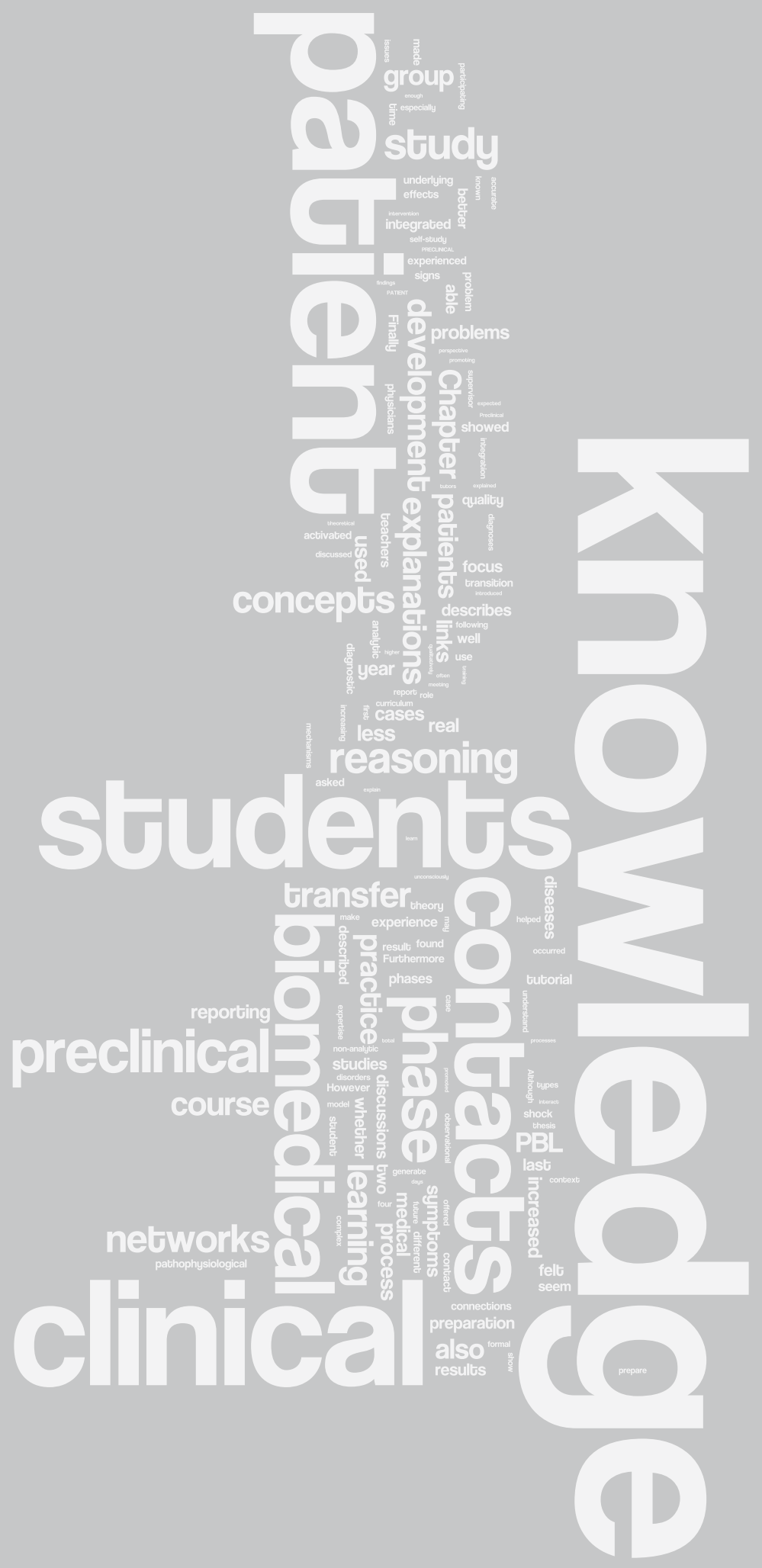


CHAPTER 8

Summary

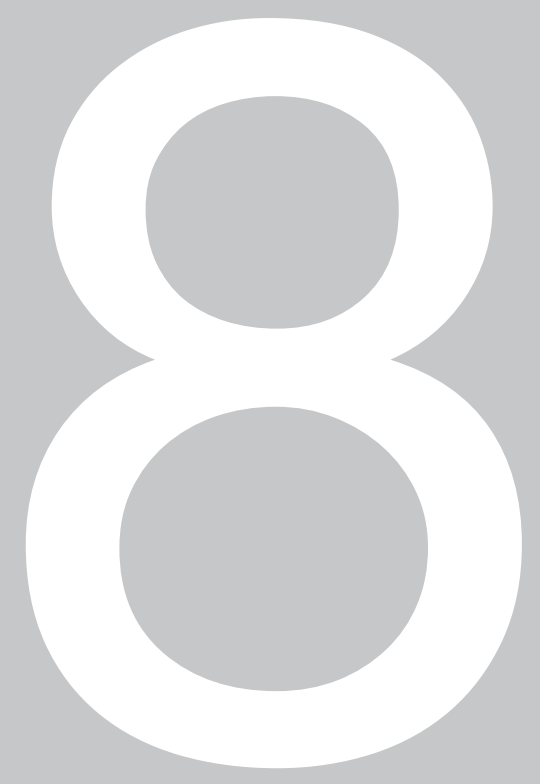


The medical curriculum traditionally consists of two phases. During the preclinical phase, students predominantly learn biomedical knowledge, i.e. the underlying mechanisms of patients' signs, symptoms and diseases. During the clinical phase, clinical knowledge is acquired in the clinical context. The transition from the preclinical to the clinical phase is described as 'the shock of practice'. Students are unable to apply their biomedical knowledge to the clinical context and to make connections between biomedical and clinical knowledge when they enter the clinical phase. The implementation of real patient contacts in the preclinical phase of the medical study is considered to be a way of reducing the 'shock of practice' and promoting the development of integrated knowledge networks so that students are better able to apply their knowledge in clinical practice. However, not much is known about how preclinical patient contacts in PBL affect student learning.

This thesis contains five studies. Two focus group studies and a questionnaire survey (Chapters 2, 3 and 4) report on students' opinions about the effects of preclinical patient contacts in PBL on the transition to the clinical phase as well as on their learning. In the focus group study, described in Chapter 2, the participating students were in their first clinical year, whereas the participating students of the studies in Chapter 3 and 4 were in their last preclinical year.

Subsequently, two studies (Chapters 5 and 6) report on the effects of preclinical patient contacts on the development of students' knowledge networks in their last preclinical year. Chapter 5 describes an observational study on the use of biomedical and clinical knowledge during tutorial group discussions. Chapter 6 describes a pre-post intervention study on the changes in diagnostic reasoning, the quality of students' explanations of patients' signs and symptoms, and the transfer of biomedical and clinical knowledge.

\section{STUDENTS' OPINIONS OF THE EFFECTS OF PRECLINICAL PATIENT CONTACTS ON THE TRANSITION TO THE CLINICAL PHASE AND ON THEIR LEARNING.}

In the third, i.e. last preclinical, year of the PBL-based medical curriculum of Maastricht University, the paper patient problems, as used in the first two years, 
are replaced by real patient contacts. As a result, the PBL cycle of Year 3 covers four phases: i) preparation, ii) patient contact, iii) self-study and iv) reporting. The students prepare their upcoming patient contact with their tutor in tutorial groups of about 10 students by using short vignettes that describe the patient's problem (preparation phase). One to two days later, student pairs meet the patient at the teaching outpatient clinic of the university hospital (patient contact phase). They take the patient's history and perform a physical examination and together with their clinical supervisor they finish the consultation. Afterwards they discuss the patient contact with their supervisor and set learning issues to be studied in the subsequent days (self-study phase). One week after the preparatory meeting, the student pairs present their patient during the tutorial group meeting and report about their learning issues (reporting phase).

Chapter 2 describes a focus group study on students' perceptions about the transition to the clinical phase. The participating students experienced real patient contacts in PBL during the last preclinical year and were in the first weeks of their clinical phase at the time of the interviews. The students felt that the preclinical patient contacts in a protected learning environment prepared them well for the clinical phase. They said that the last preclinical year formed a bridge between the preclinical and clinical phase. Although they experienced a shift from theoretical to more clinical knowledge, they found this a natural and gradual process. However, they did have trouble getting used to the increased number of working hours, increased workload and their role as a clerk in the clinical setting. It was often not clear what was expected from them and they felt they lacked sufficient knowledge, especially biomedical knowledge. In general, the students liked working in the clinical setting. It motivated them to study and it helped them to develop the experiential knowledge necessary for non-analytic reasoning. In the area of analytic reasoning, the students found that their clinical teachers did not encourage them enough to understand the underlying pathophysiological disease mechanisms and the patient's signs. They also thought there was too little time for this. Preclinical patient contacts seem to diminish the 'shock of practice' and seem to prepare students on learning in the clinical context. 
Chapter 3 reports on a quantitative study in which all third-year students were asked to complete a questionnaire to evaluate the four phases of the PBL cycle with real patient contacts.

The students appeared to be satisfied about the patient contacts and reporting phases. They indicated that the patient contacts were well organized, that they learned a lot from these contacts, and that the support from their supervisor during this phase was very instructive. Regarding the reporting phase, the students felt that the patient contacts were adequately discussed during the tutorial group meetings. In particular, they said that links were made between theory and practice during the discussions. The students were less satisfied about the self-study phase. Learning issues were not always sufficiently formulated and the students were not always sure about what was expected from them. So, from the students' perspective preclinical patient contacts in PBL seem to be a powerful driving force for meaningful and profound learning, especially for linking theory and practice.

Chapter 4 describes a focus group study in which students were asked about the effects of preclinical patient contacts on their learning, knowledge development, and clinical reasoning. The students reported that the patient contacts motivated them to study, because they wanted to be well-prepared for the patient contacts and the patient contacts elicited gaps in their knowledge. As a result of the patient contacts, they could better understand the impact of diseases and disorders on patients' lives. Further the patient contacts helped them in their professional socialization process; the patient contacts enabled them to get used to dealing with patients and their future role as a doctor. Regarding their knowledge development, the students felt that the patient contacts not only activated prior knowledge and encouraged them to study biomedical knowledge, but also stimulated them to integrate their knowledge. According to the students, this integration process occurred automatically and unconsciously. However, critical questions that were asked by their teachers or peers stimulated them to actively make links between the different types of knowledge, which promoted further integration. The students also said that the patient contacts made it easier to remember and recall their knowledge. They felt this was because they studied more, were able to make connections between theory and practice, and were actively 
involved in the patient contacts. The emotions and impressions that the patient contacts evoked also helped. Furthermore, the students felt that as a result of the patient contacts they were able to contextualize their theoretical knowledge and they realized that diseases and disorders often do not proceed as typically as described in the textbooks. Finally, the students indicated that the patient contacts promoted the development of both analytic and non-analytic reasoning. Due to the increase in their knowledge, they were better able to understand and explain the relationship between symptoms and diseases, and due to their increasing experience with patients they could recognize patterns in patient problems. So according to students' perceptions, preclinical patient contacts have a positive impact on their learning and enhance the development of their knowledge networks and of various forms of clinical reasoning.

\section{THE EFFECTS OF PRECLINICAL PATIENT CONTACTS ON THE DEVELOPMENT AND TRANSFER OF KNOWLEDGE}

Research on medical expertise suggests that experienced physicians have access to elaborate and integrated knowledge networks, consisting of biomedical and clinical knowledge, which interact closely during clinical reasoning. Biomedical knowledge is knowledge describing the normal functioning and dysfunctioning of the human body, such as anatomy, physiology and biochemistry. There are two types of clinical knowledge, namely, formal and informal clinical knowledge. Formal clinical knowledge describes the course, epidemiology, symptoms and treatment of diseases and disorders. Informal clinical knowledge, also known as experiential knowledge, encompasses all the knowledge about patients that experienced physicians acquire during their training and in practice.

With growing expertise physicians quickly generate accurate diagnoses, use less biomedical knowledge when solving patient problems, and generate high-quality explanations of patient symptoms. These phenomena are explained as the result of knowledge encapsulation. Through repeated application of knowledge and practice with real patients, biomedical knowledge becomes encapsulated into higher order clinical concepts in knowledge networks. With increasing experience, the links between high-level clinical concepts and other clinical 
concepts become stronger than the links between clinical and biomedical concepts. When faced with non-complex and common patient problems, expert physicians use non-analytic reasoning strategies, during which they automatically, unconsciously and quickly activate strongly associated clinical knowledge. Although biomedical knowledge is activated alongside clinical knowledge, the activation level of biomedical concepts is not strong enough to be part of the representation of the patient problem. However, if the patient's problem is complex or rare, the representation of the problem will not be immediately obvious and case processing takes more time. Then, not only clinical knowledge becomes activated, but also biomedical knowledge. This is a conscious, nonautomatic and slow process, and is called analytic reasoning. Non-analytic and analytic reasoning are described as two different processes. They are, however, considered to interact continuously during daily practice.

Preclinical patient contacts in PBL are suggested as a way of introducing biomedical and clinical knowledge early in the curriculum and thereby promoting the development of integrated knowledge networks. There are concerns, however, that such contacts may cause students to focus on clinical knowledge at the expense of biomedical knowledge and that the group discussions may be dominated by the teachers at the expense of active participation of the students.

Chapter 5 reports an observational study on the questions as to what extent biomedical and clinical knowledge are discussed during the group discussions and to what extent this knowledge is introduced by the students or the tutors. This study also examined whether connections are established between biomedical and clinical knowledge during the tutorial discussions. Six preparation and reporting phases in the last preclinical year were observed through video recordings. The transcripts of the recordings were analyzed.

The results showed that both formal clinical knowledge and biomedical knowledge were discussed. During the preparation phase $40.7 \%$ of the total amount of knowledge was dedicated to formal clinical knowledge and $15.0 \%$ to biomedical knowledge. During the reporting phase, these rates were $34.8 \%$ and $28.0 \%$ respectively. Further, during the preparation phase the tutor was responsible for the contribution of $63.4 \%$ of the total amount of knowledge and during the reporting phase, the students were responsible for $80.1 \%$. Further- 
more, it was found that almost all biomedical knowledge was directly related to clinical knowledge. Moreover, biomedical knowledge was not only used for the explanation of the patient's symptoms and the underlying mechanisms of the diseases, but also with respect to additional diagnostics, treatment and complications. So, both biomedical and clinical knowledge are covered and related to each other during group discussions in PBL with preclinical patient contacts. This may contribute to the development of integrated knowledge networks. Finally, it was found that the tutors only dominated the preparation phase, which can be explained by the students' lack of experience with real patients. The teachers had to direct them more to prepare them for the patient contacts.

The observational study in Chapter 5 did not show whether the connections that the students made between biomedical and clinical knowledge actually led to integrated knowledge networks. Nor did the study show whether transfer of knowledge occurred. To investigate the development of knowledge networks and knowledge transfer, we performed a pre-post intervention study, which is described in Chapter 6. At the start and the end of a 10-week PBL course with pre-clinical patient contacts, the students were asked to diagnose, while thinking aloud, four types of patient problems and then to explain the underlying pathophysiological mechanism. In this study we investigated whether the diagnostic reasoning process and the use of biomedical and clinical knowledge during clinical reasoning changed after following the course and whether the quality of the pathophysiologcal explanations increased. Furthermore, we wanted to know whether there was a difference between patient problems that the students were offered during the course (called course cases) and patient problems that were not covered during the course (so-called transfer cases). The verbal think-aloud protocols and written explanations were analyzed both qualitatively and quantitatively.

The results showed that after following the course, the students generated more accurate diagnoses, needed less time to formulate a diagnosis, and that they used less biomedical and clinical knowledge during the diagnostic reasoning process. After following the course, the written pathophysiological explanations of the students showed more concepts, and especially more biomedical concepts. They also showed that the quality of the pathophysiological explanations 
increased: the students used more concepts that also occurred in model explanations, they made more links between these model concepts, and they used less wrong concepts and links. It seems that the students acquired new knowledge and were able to integrate this knowledge in their knowledge networks. The results further revealed that the percentage of model concepts and links in the explanations increased. Although the quality of the explanations increased, the links between the concepts were superficial and the development of the knowledge networks was not yet complete. Furthermore, the results showed that it took the students longer to formulate a diagnosis in the transfer cases than in the course cases. They used less biomedical knowledge in the transfer cases, both during diagnostic reasoning as well as in the explanations. Also the explanations of the transfer cases were less extensive and their quality increased less after the course. Finally, there were differences within the course and transfer cases themselves, indicating case specificity of knowledge.

The results therefore show that after the course, students were better able to generate accurate diagnoses and to provide qualitatively better explanations, which are well known features of expertise. These findings are consistent with the encapsulation theory. By repeatedly applying knowledge and experience, biomedical concepts are encapsulated in higher order clinical concepts that are activated from the knowledge networks while explaining the patient's signs and symptoms. Finally, the results suggest that transfer of knowledge is a lengthy and complex process and that knowledge is case specific.

Chapter 7 describes the general discussion of the studies of this thesis, recommendations for future research and implications for medical education. The main conclusions drawn from the studies are that preclinical patient contacts in PBL seem to alleviate the 'shock of practice' that students experience during the transition to the clinical phase. Further, preclinical patient contacts seem to support the integration of biomedical and clinical knowledge in students' knowledge networks. Finally, we conclude that transfer of knowledge is a lengthy, complex and case-specific process. 
The recommendations for future research are aimed at investigating the effects of preclinical patient contacts on student learning in different medical curricula based on different kinds of educational formats, the transfer of knowledge, and the role of the teacher.

From a practical perspective the findings of this thesis demonstrate that preclinical patient contacts can be introduced in problem-based medical curricula to bridge the gap between learning from paper patients and learning from real patients. If this approach is adopted, students are offered the opportunity to learn in a learning environment with increasing authenticity, complexity, and responsibility. This means that teacher training should focus on information about the development and transfer of knowledge and reasoning processes. Furthermore, teachers should be offered didactic skills to facilitate the development of students' knowledge networks, clinical reasoning skills, and the transfer of knowledge. 
Samenvatting (Summary in Dutch) 
De studie geneeskunde is traditioneel opgebouwd uit 2 fasen. Tijdens de preklinische fase leren de studenten voornamelijk biomedische kennis, i.e. onderliggende pathofysiologische mechanismen van (de symptomen \& verschijnselen) van ziekten en aandoeningen. Tijdens de klinische fase wordt er voornamelijk klinische kennis verworven middels werkplekleren in de klinische context. De overgang van de preklinische- naar de klinische fase wordt beschreven als de 'shock of practice'. Studenten zijn tijdelijk niet in staat om de opgedane biomedische kennis toe te passen in de klinische context en verbindingen te leggen tussen biomedische en klinische kennis. Een van de doelen van het probleem gestuurd onderwijs (PGO) was om de transfer van biomedische kennis naar de klinische context te bevorderen. Echter ondanks PGO gaven studenten nog steeds aan dat ze moeite hadden met de overgang van de preklinische naar de klinische fase en dat ze nog steeds niet in staat waren om de theoretische kennis toe te passen in de praktijk. De invoering van echte patiëntcontacten in de preklinische fase van de studie geneeskunde wordt beschouwd als een manier om de 'shock of practice' te verminderen en om de ontwikkeling van coherente en gestructureerde kennisnetwerken te bevorderen, zodat studenten beter in staat zijn om hun kennis in de klinische context toe te passen. Het is echter niet bekend wat het effect van preklinische patiëntcontacten in probleem gestuurd onderwijs (PGO) is op het leren van de studenten, met name ten aanzien van de ontwikkeling van hun kennis.

In dit proefschrift worden drie studies (hoofdstuk 2, 3 en 4) beschreven over de mening van studenten geneeskunde op het effect van preklinische patiëntcontacten in PGO op de overgang naar de klinische fase en op hun leren. Dit is onderzocht middels 2 focusgroepstudies en een vragenlijstonderzoek. Aan de focusgroepstudie die beschreven is in hoofdstuk 2 namen studenten deel die in het eerste klinische jaar zaten. De onderzoeken beschreven in hoofdstuk 3 en 4 zijn uitgevoerd onder studenten in het laatste preklinische jaar.

Vervolgens worden 2 studies beschreven naar de effecten van preklinische patiëntcontacten op de ontwikkeling van kennisnetwerken van studenten geneeskunde in hun laatste preklinische jaar. In hoofdstuk 5 wordt een observatiestudie gerapporteerd waarin het gebruik van biomedische en klinische kennis in groepsdiscussies is onderzocht. In hoofdstuk 6 is middels een pre-post 
interventiestudie gekeken naar veranderingen in het diagnostisch redeneren, de kwaliteit van de verklaringen van patiëntsymptomen door studenten en de transfer van biomedische en klinische kennis.

\section{DE MENING VAN STUDENTEN OVER DE EFFECTEN VAN PREKLINISCHE PATIENTCONTACTEN OP DE OVERGANG NAAR DE KLINISCHE FASE EN OP HUN LEREN.}

De papieren patiëntproblemen in de eerste twee jaren van het PGO in Maastricht zijn in het derde jaar, i.e. het laatste preklinische jaar, vervangen door echte patiëntcontacten. De PGO cyclus in jaar 3 beslaat daardoor 4 fasen, te weten: de voorbereidings-, patiëntcontact-, zelfstudie- en rapportagefase. De studenten bereiden het patiëntcontact voor met hun tutor in groepen van 10 studenten aan de hand van korte vignetten die het probleem van de patiënt beschrijven (voorbereidingsfase).1-2 Dagen later zien de studenten de patiënt op een polikliniek van het Medisch Universitair Centrum Maastricht (patiëntcontactfase). Ze nemen de anamnese af en doen een lichamelijk onderzoek waarna de poliklinische supervisor samen met hen het patiëntcontact afsluit. Vervolgens bespreken de twee studenten en de supervisor het patiëntcontact en stellen leerdoelen op die de studenten bestuderen in de daaropvolgende dagen (zelfstudiefase). Een week na de voorbereidende bijeenkomst geven de studentduo's een patiëntpresentatie van de patiënt die zij gezien hebben en rapporteren zij de bestudeerde leerdoelen (rapportagefase).

In hoofdstuk 2 wordt een focusgroepstudie beschreven waarin studenten aan het begin van hun klinische fase gevraagd is hoe zij de overgang van de preklinische naar de klinische fase hebben ervaren in PGO met echte patiëntcontacten in het laatste preklinische jaar. De 'shock of practice' werd door de studenten niet gerapporteerd. Naar hun mening hadden de preklinische patiëntcontacten hen goed voorbereid op de klinische fase in een beschermde leeromgeving. Ze zeiden letterlijk dat het laatste preklinische jaar een brug vormde tussen de preklinische en klinische fase. De studenten merkten wel dat de nadruk ging van theoretische kennis naar meer klinische kennis, maar vonden dat proces heel natuurlijk en gradueel verlopen. Ze hadden echter wel moeite om te wennen 
aan het toegenomen aantal werkuren en de toegenomen werkbelasting in de klinische fase en aan hun rol als coassistent in de klinische setting. Het was vaak niet duidelijk wat er van hun verwacht werd en ze hadden het gevoel over te weinig kennis te beschikken.

In het algemeen vonden de studenten het werken in de klinische setting plezierig, het motiveerde hen om te studeren en hielp in de ontwikkeling van ervaringskennis, wat ten grondslag ligt aan het non-analytisch redeneren. Ten aanzien van het analytisch redeneren gaven de studenten aan dat hun klinische docenten hen niet genoeg aanzetten om het onderliggend pathofysiologisch mechanisme van de ziekte en symptomen van de patiënt te begrijpen en bovendien vonden ze dat hier vaak te weinig tijd voor was.

Preklinische patiëntcontacten lijken de 'shock of practice' te verminderen en de studenten voor te bereiden op het leren in de klinische context.

In hoofdstuk 3 wordt een kwantitatieve studie beschreven waarin alle studenten van jaar 3 gevraagd werden een evaluatieve vragenlijst in te vullen over de verschillende fasen van de PGO cyclus met echte patiëntcontacten.

De studenten waren tevreden over de patiëntcontactfase en de rapportagefase. Ze gaven aan dat de patiëntcontacten goed georganiseerd waren, dat ze er veel van leerden en dat de uitleg van de supervisor tijdens deze fase duidelijk was. Ten aanzien van de rapportagefase vonden de studenten dat de patiëntcontacten adequaat werden besproken tijdens de tutorgroepbijeenkomsten. Met name werden er tijdens de groepsdiscussies links gelegd tussen theorie en praktijk. De voorbereidingsfase werd 'overall' goed beoordeeld, alhoewel dit afhankelijk leek te zijn van de voorkennis van de studenten. Over de zelfstudiefase waren de studenten minder tevreden. Er werden niet altijd voldoende leerdoelen geformuleerd aan het einde van het patiëntcontact en het was de studenten niet altijd duidelijk wat er van hen verwacht werd.

Dus preklinische patiëntcontacten in PGO lijken een krachtige impuls te zijn tot betekenisvol en diepgaand leren, met name ook voor het verbinden van de theorie en de praktijk.

Hoofdstuk 4 beschrijft een kwalitatieve studie waarin, middels focusgroepinterviews, de studenten werd gevraagd naar het effect van preklinische patiënt- 
contacten op hun leren, op de ontwikkeling van hun kennis en op het klinisch redeneren.

De studenten vonden dat de patiëntcontacten hen motiveerden om te studeren, omdat ze zowel het patiëntcontact goed wilden voorbereiden als dat de contacten hen nieuwsgierig maakten. Door de patiëntcontacten konden ze de impact van ziektes en aandoeningen op het leven van de patiënten beter begrijpen. Bovendien realiseerden ze zich, doordat ze veel verschillende patiënten zagen, dat ziektes verschillende invloed kunnen hebben op de patiënten. Verder hielpen de patiëntcontacten bij het professionele socialisatieproces. De patiëntcontacten stelden hen in staat om te wennen aan de omgang met patiënten en aan hun toekomstige rol als arts. De studenten zeiden dat ze door het contact met echte patiënten hun kennis beter konden onthouden en herinneren doordat ze meer gingen studeren en ze de theorie konden verbinden met de praktijk, doordat ze actief betrokken waren bij de patiëntcontacten en door de emoties en indrukken die de patiënten bij hen los maakten. Ten aanzien van de ontwikkeling van hun kennis vonden de studenten dat de patiëntcontacten niet alleen voorkennis activeerden en hen stimuleerden om de biomedische kennis te bestuderen, maar ook om de voorkennis en nieuwe kennis te integreren. Volgens de studenten vond deze integratie automatisch en onbewust plaats. Echter kritische vragen die gesteld werden door hun docenten of medestudenten maakten hen hiervan bewust en leidden ertoe dat ze actief links gingen leggen tussen de verschillende soorten kennis, wat de verdere integratie van kennis bevorderde. Tevens vonden de studenten dat ze door de patiëntcontacten hun theoretische kennis konden plaatsen in de context en zagen ze daardoor dat ziektes en aandoeningen vaak niet zo typisch verlopen als in de leerboeken beschreven staat. Tenslotte gaven de studenten aan dat de patiëntcontacten de ontwikkeling van zowel non-analytisch als analytisch redeneren bevorderden. Door de toename van hun kennis waren ze steeds beter in staat om de relatie tussen symptomen en ziektes te kunnen begrijpen en verklaren en door de toenemende ervaring met patiënten konden ze patronen in patiëntproblemen herkennen.

Dus volgens de studenten hebben preklinische patiëntcontacten positieve effecten op hun leren. Ze versterken de ontwikkeling van hun kennisnetwerken en van verschillende vormen van klinisch redeneren. 


\section{DE EFFECTEN VAN PREKLINISCHE PATIENTCONTACTEN OP DE ONTWIKKELING EN TRANSFER VAN KENNIS}

Het is bekend dat ervaren artsen in staat zijn om snel accurate diagnoses te stellen en om kwalitatief goede verklaringen van patiëntsymptomen te geven. Dit komt doordat de kennisnetwerken van ervaren artsen zeer uitgebreid en coherent zijn, bestaande uit biomedische en klinische kennis. Biomedische kennis is de kennis die het normaal functioneren en disfunctioneren van het lichaam beschrijft, zoals anatomie, fysiologie, pathofysiologie etc. Er zijn twee soorten klinische kennis, namelijk, formele klinische kennis en informele klinische- ofwel ervaringskennis. Formele klinische kennis beschrijft het beloop, epidemiologie, symptomen en behandeling van ziektes en aandoeningen. Ervaringskennis behelst alle kennis over patiënten die ervaren artsen opdoen tijdens hun opleiding en in de praktijk. Door toenemende ervaringen met patiëntcontacten waarin de verschillende soorten kennis worden toegepast, wordt biomedische kennis geëncapsuleerd in hogere orde klinische concepten in de kennisnetwerken. De klinische concepten en hun onderlinge verbindingen worden in de loop van de tijd, door praktijkervaring, sterker dan de biomedische concepten en hun onderlinge verbindingen. Tijdens het diagnostisch redeneerproces worden de sterkste concepten en verbindingen geactiveerd.

Ervaren artsen lijken in hun dagelijks werk nauwelijks gebruik te maken van de biomedische kennis. Als zij geconfronteerd worden met niet-complexe en veel voorkomende patiëntproblemen dan worden automatisch en snel via een proces van patroonherkenning de relevante klinische concepten geactiveerd, het zgn. non-analytisch redeneren. Echter als het patiëntprobleem complex of zeldzaam is, dan zal de representatie van het patiëntprobleem niet meteen duidelijk zijn en wordt ook biomedische kennis geactiveerd, om het probleem te kunnen oplossen. Dit proces verloopt niet-automatisch, bewust en langzaam, en wordt analytisch redeneren genoemd.

De invoering van preklinische patiëntcontacten in PGO zou ertoe kunnen leiden dat de studenten alleen focussen op klinische kennis ten koste van biomedische kennis. Verder zou de invloed van de docenten tijdens groepsdiscussies hierdoor kunnen toenemen ten koste van de actieve participatie van de studenten. 
In hoofdstuk 5 wordt een observatiestudie beschreven waarin gekeken is in welke mate biomedische én klinische kennis aan bod komen tijdens de groepsdiscussies en in welke mate deze kennis wordt ingebracht door de studenten of de docenten. Verder is gekeken of er tijdens de discussies verbindingen worden gelegd tussen biomedische en klinische kennis. Zes voorbereidings- én rapportagefasen in het laatste preklinische jaar zijn hiertoe geobserveerd via beeldopnames. De transcripten van de opnames zijn vervolgens geanalyseerd.

De resultaten lieten zien dat zowel formeel klinische kennis als biomedische kennis tijdens de discussies aan bod kwamen. Tijdens de voorbereidingsfase werd $40.7 \%$ van de totale hoeveelheid kennis gewijd aan formele klinische kennis en $15.0 \%$ aan biomedische kennis. Tijdens de rapportagefase bedroegen deze percentages respectievelijk $34.8 \%$ en $28.0 \%$. Verder waren de tutoren tijdens de voorbereidingsfase verantwoordelijk voor de inbreng van $63.4 \%$ van de totale hoeveelheid kennis en tijdens de rapportagefase waren de studenten verantwoordelijk voor $80.1 \%$. Voorts bleek dat vrijwel alle biomedische kennis direct gerelateerd werd aan klinische kennis en dat biomedische kennis niet alleen gebruikt werd voor de verklaring van de patiëntsymptomen en de onderliggende mechanismen van de aandoeningen, maar ook ten aanzien van (aanvullende) diagnostiek, behandeling en complicaties.

Dus preklinische patiëntcontacten leiden ertoe dat zowel biomedische kennis als klinische kennis aan bod komen tijdens de groepsdiscussies en dat beiden aan elkaar gerelateerd worden, wat kan bijdragen aan de ontwikkeling van coherente en geïntegreerde kennisnetwerken. Tenslotte bleek dat de tutoren alleen de voorbereidingsfase domineerden, wat verklaard kan worden vanuit het feit dat de studenten weinig voorkennis hadden ten aanzien van de patiëntproblemen die aan bod kwamen en ze daarin dus gestuurd moesten worden door de docenten.

De observatiestudie uit hoofdstuk 5 liet niet zien of de verbindingen die de studenten legden tussen biomedische en klinische kennis ook daadwerkelijk leidden tot coherente en gestructureerde kennisnetwerken. De studie liet ook niet zien of er transfer van kennis optrad. Dus om de ontwikkeling van kennisnetwerken en de transfer van kennis te onderzoeken hebben we een pre - post interventiestudie gedaan, die beschreven wordt in hoofdstuk 6. De studenten werden aan het begin en aan het einde van een 10 weken durend 
PGO-blok, met preklinische patiëntcontacten, gevraagd om hardop denkend 4 typen patiënt problemen te diagnosticeren en vervolgens om het onderliggende pathofysiologisch mechanisme te verklaren. Met deze studie is onderzocht of het diagnostisch redeneerproces en het gebruik van biomedische en klinische kennis tijdens het diagnostisch redeneren veranderden na het volgen van het blok en of de kwaliteit van de pathofysiologische verklaringen toenam. Verder wilden we weten of er een verschil was tussen patiëntproblemen die de studenten in het blok aangeboden kregen (zgn. cursuscasussen) en problemen die niet tijdens het blok behandeld waren (zgn. transfercasussen). De verbale hardopdenkprotocollen en de schriftelijke verklaringen werden zowel kwalitatief als kwantitatief geanalyseerd.

De resultaten lieten zien dat de studenten na het volgen van het blok betere diagnoses stelden, dat minder tijd nodig hadden om tot de diagnose te komen en dat ze minder biomedische en klinische kennis gebruikten tijdens het diagnostisch redeneer proces. In de schriftelijke pathofysiologische verklaringen gebruikten de studenten meer concepten na het volgen van het blok, en met name meer biomedische concepten. Verder bleek dat de kwaliteit van de pathofysiologische verklaringen toenam: de studenten gebruikten meer concepten die ook in modelverklaringen voorkwamen, ze maakten meer links tussen deze modelconcepten en ze gebruikten minder onjuiste concepten en links. Het lijkt erop dat de studenten nieuwe kennis verwierven en in staat waren om deze kennis in de kennisnetwerken te integreren. Verder bleek dat het percentage modelconcepten en links in de verklaringen steeg, alhoewel het aandeel van de links niet zo groot was als dat van de modelconcepten. Hoewel de kwaliteit van de verklaringen toenam, waren de links tussen de concepten nog oppervlakkig waren en de ontwikkeling van de kennisnetwerken nog niet volledig. Verder lieten de resultaten zien dat de studenten er bij de transfercassussen langer over deden om tot een diagnose te komen dan bij de cursuscasussen. Ze gebruikten minder biomedische kennis in de transfercasussen, zowel tijdens het diagnostisch redeneren als in de verklaringen. Verder waren de verklaringen van de transfercasussen minder uitgebreid en nam de kwaliteit minder toe na het blok. Tenslotte waren er verschillen binnen de cursus- en transfercasussen onderling, wat duidt op casusspecificiteit van de kennis.

Dus de resultaten laten zien dat preklinische patiëntcontacten ertoe leiden 
dat studenten betere diagnoses stellen in kortere tijd en kwalitatief betere verklaringen geven, kenmerkend voor de ontwikkeling van medische expertise. Deze bevindingen komen overeen met de encapsulatietheorie. Door het herhaald toepassen van kennis en ervaring, worden biomedische concepten geëncapsuleerd in hogere orde klinische concepten die geactiveerd worden uit de kennisnetwerken tijdens het verklaren van de symptomen en verschijnselen van de patiënt. Tenslotte wijzen de resultaten erop dat transfer van kennis een langdurig en complex proces is en dat kennis casusspecifiek is.

Hoofdstuk 7 beschrijft de algemene discussie van de studies van dit proefschrift, aanbevelingen voor verder onderzoek en de implicaties voor medisch onderwijs. De belangrijkste conclusies die volgen uit de studies zijn dat preklinische patiëntcontacten in PGO een oplossing lijken te zijn voor de 'shock of practice' die studenten ervaren tijdens de overgang naar de klinische fase. Verder lijken de preklinische patiëntcontacten de ontwikkeling van de kennisnetwerken van de studenten en de integratie van biomedische en klinische kennis te ondersteunen. En tenslotte concluderen we dat transfer van kennis een langdurig, complex en casusspecifiek proces is.

De aanbevelingen voor verder onderzoek richten zich op onderzoek naar het effect van preklinische patiëntcontacten op het leren van studenten in curricula zonder PGO en op de transfer van kennis en naar de rol die de docent hierbij heeft.

Voor het medisch onderwijs betekenen de bevindingen van dit proefschrift dat preklinische patiëntcontacten geïmplementeerd kunnen worden in (probleem gestuurde) medische curricula op een manier dat ze een brug vormen tussen het leren van papieren- en simulatiepatiënten en het leren van echte patiënten. Op deze manier krijgen de studenten de mogelijkheden aangeboden om te leren in een leeromgeving met toenemende authenticiteit, complexiteit en eigen verantwoordelijkheid. Dit betekent dat de scholing van de docenten gericht moet zijn op informatie over het curriculum en over de ontwikkeling en transfer van kennis en redeneerprocessen. Verder moeten ze scholing krijgen in didactische vaardigheden die nodig zijn om de ontwikkeling van kennisnetwerken van studenten, klinisch redeneerprocessen en de transfer van kennis te kunnen stimuleren en faciliteren. 
Dankwoord (Acknowledgements) 
Dat dit proefschrift tot stand gekomen is tijdens nogal roerige jaren van mijn leven, kon ik bij de start ervan niet vermoeden. Het feit dat het 'boekje' hier nu ligt, heb ik te danken aan heel veel dierbare mensen om me heen, die op welke manier dan ook bijgedragen hebben.

Albert, Diana en Margje, jullie waren voor mij de perfecte begeleidingscommissie. Door jullie ben ik wetenschappelijk onderzoek leuk gaan vinden, merk ik wat het is om wetenschappelijk te denken en heb ik de basis mee gekregen om verder te kunnen in het onderzoek van medisch onderwijs. De begeleiding en feedback die ik van jullie kreeg was snel, doelgericht, verhelderend en leerzaam: als ik ook maar even dacht adem te kunnen halen als ik jullie een volgende versie van een artikel had gestuurd, lag het alweer in mijn mailbox voorzien van jullie kritische commentaren en suggesties.

Diana, jij liet me steeds terugkeren naar het doel van het onderzoek. Op die manier gaf je structuur en richting aan het denkproces en de artikelen. Als we met z'n allen weer eens aan het uitweiden waren, bracht je ons altijd weer terug naar de essentie. Ik heb bovenal veel geleerd van je helderheid van schrijven: onomwonden, rechttoe-rechtaan. Het doel is voor mij inmiddels verheven tot een soort mantra, niet alleen in onderzoek en onderwijs, maar (waar nodig) ook privé. Albert, jij hebt altijd de lange lijnen bewaakt. Waar kwamen we vandaan, waar gingen we naartoe. Het meest belangrijke voor mij was dat ik altijd 'mijn stem' kon laten horen, en waar ik de plank missloeg stuurde je bij. Doordat jij op de rem trapte op de juiste momenten lukte het mij om de vaart erin te houden. Daar heb ik veel van geleerd. Dat ik bovendien altijd met je kan sparren over keuzes die op mijn carrièrepad komen, waardeer ik enorm.

Margje, ik heb bewondering voor je eindeloze geduld, zorgvuldigheid en oog voor detail. Ik ben blij dat je halverwege m'n promotietraject ingestapt bent, zodat ik heb mogen profiteren van je kennis over de ontwikkeling van expertise en kennisnetwerken. Bovendien heb je ook nog eens veel tijd gestoken in het (mee-) coderen van de transcripten. Ik herinner me de 'codeer-sessie' bij jou thuis: heen en weer gingen we door de transcripten. Waar ik de neiging had om af te haken, hield jij vol en gaf me zo de basis voor het vervolg. 
Erik, in de loop van het proces heb je de begeleidingscommissie verlaten, maar je heldere blik en inbreng met een andere kijk op de zaken, maakten dat we scherp bleven ten aanzien van de inhoud.

Merijn, het was voor mij een leerzame ervaring om je te kunnen begeleiden bij je wetenschappelijke stage in je 6e jaar. Je hebt tijdens je stage het hele onderzoek van opzet tot artikel afgemaakt, wat niet niks is. Onze discussies waren scherp maar zeer waardevol. Het resultaat mag er zijn: het artikel gepubliceerd, waardoor ik het kon opnemen in mijn proefschrift.

Maarten, Marijke, Scheltus, Ameike en Frank, jullie kritische commentaren als co-auteurs hebben geholpen om iedere keer weer mijn artikelen te verbeteren waardoor dit proefschrift tot stand kon komen.

De studenten van de FHML Maastricht en de coaches van jaar 3 die meegewerkt hebben aan mijn studies wil ik bedanken voor hun enthousiaste deelname en kritische inbreng.

Aimee, als student-assistent heb je het merendeel van mijn laatste onderzoek uitgevoerd. Zowel de organisatie als het begeleiden van de studenten heb je perfect gedaan. Je zorgde ervoor dat we geen 'no-shows' hadden door de studenten desnoods nog zelf op te bellen en de gegevens heb je zeer zorgvuldig en compleet verzameld.

Mereke, wat jammer dat je er niet meer bij kunt zijn. Er is geen artikel gepubliceerd zonder dat een van de reviewers een compliment maakte over de Engelse taal: 'It's very clearly written' en 'The English spelling and grammar are immaculate'. Die waren voor jou. De manier waarop jij de teksten van mijn artikelen corrigeerde en perfectioneerde, is van onschatbare waarde geweest. Bovenal heb ik van je geleerd om 'nederig' te zijn in het schrijven.

De medewerkers van Science Vision: dank voor de hoge kwaliteit van de video-opnames, zowel in beeld als geluid. ledere ochtend waren jullie ogenschijnlijk geruisloos aanwezig tijdens de tutorgroep bijeenkomsten om de 
opnames zo perfect mogelijk te maken. Dat heeft het voor mij een stuk gemakkelijker gemaakt.

Maarten, Frank, Josca en Marjolein, jullie hebben mij als ‘bazen' altijd de ruimte, steun en vooral ook tijd gegeven om dit promotietraject aan te kunnen gaan en af te ronden. Daarin zijn jullie niet zomaar 'bazen', maar ‘bijzondere bazen'.

Collega's van het skillslab, ik mis jullie nog steeds en collega's van de huisartsopleiding, wat ben ik blij met jullie. Alhoewel jullie je bevinden in uitersten van het land, zijn jullie altijd dichtbij. Jullie hebben mij onvoorwaardelijk gesteund en waar nodig zelfs werk van me overgenomen. Dat was voor mij essentieel om verder te kunnen. Jullie bedenkelijke woorden ('wat doe je hier?') en afkeurende blikken als ik er weer eens in 'onderzoekstijd' was, hebben me geholpen om op rasse schreden naar het onderzoek terug te keren en mijn proefschrift af te ronden. Bovenal ervaar ik van en met jullie plezier, waardering, respect, empathie en bevlogenheid en kan ik enorm met jullie lachen.

Emer, het proefschrift 'op afstand' afmaken, had niet gekund en was niet zo leuk geweest als ik niet gebruik had mogen maken van jouw 'bed \& breakfast' tijdens mijn bezoekjes aan Maastricht. Het was meer dan dat. Dat het proefschrift nu af is, is geen reden om niet meer naar Maastricht af te reizen. Dus 'reserveer' ik hierbij alvast.

Marleen, het proefschrift is prachtig geworden.

Alle lieve vrienden, die er altijd waren en er altijd zullen zijn.

En iedereen die niet genoemd wordt, maar even zo goed belangrijk is (geweest).

Mijn paranimfen en ceremoniemeester.

Jan, (skillslab-) collega en vriend. Ik vertrek nooit uit Maastricht zonder een etentje met jou. Bomen over lief en leed, kinderen, werk, voetbal, en alles wat verder nog voorbij komt en vooral veel lachen. Om dat alles, maar zeker ook vanwege je expertise op het gebeid van onderzoek en medisch onderwijs ben ik blij dat je mijn paranimf wilt zijn. 
Arnoud en Jojanneke, we hebben er even over gedebatteerd onder een etentje als broer en zussen: wie wordt er ceremoniemeester en wie paranimf. Ik kon werkelijk niet kiezen, jullie zijn me even dierbaar. Maar een keuze moest er gemaakt worden en die lag er voor we aan het dessert toe waren. Arnoud, er zijn tijden geweest dat we vochten als kat en hond (lees: broer en zus), maar jouw wekelijkse telefoontjes, jij in de auto en ik op de fiets, hebben ons dichter bij elkaar gebracht. In tijden van verdriet altijd een grap, en in goede tijden ruimte voor een traan.

Jojanneke, m'n kleine zusje, maar steeds vaker m'n grote zus. Eerlijk en recht door zee. We lijken op elkaar, maar veel van wat ik nog moet leren, kan jij al.

Dat etentje houden we er overigens in.

Lieve Mamma (en natuurlijk ook Tom), Arnoud en Jojanneke, jullie zijn voor mij de basis waarop ik altijd terug kan vallen. Meer heb ik niet nodig. Onvoorwaardelijk hebben jullie mij gesteund en liepen jullie met me mee op mijn pad, ook al waren jullie het misschien niet eens met de richting die ik op ging. Ik had niets geleerd en was nooit tot hier gekomen als ik die ruimte niet had gehad.

Lieve Youri, lieve Tim, wat ben ik trots op jullie en wat hou ik van jullie. Van hier naar de maan, de zon en weer terug, en nog een beetje...en dat oneindig vaak. 
Curriculum Vitae 
Agnes Diemers is geboren op 11 mei 1966 in Hoogeveen. Nadat ze het Gymnasium B op het Ichthus College te Drachten succesvol had afgerond in 1984, studeerde ze Geneeskunde aan de Rijks Universiteit Groningen. Na haar afstuderen in 1993 heeft ze ervaring opgedaan als poortarts in het Wilhelmina Ziekenhuis Assen. In 1994 startte zij met de huisartsopleiding waarna zij van 1997 tot 2000 als huisarts in loondienst in een praktijk in Gieten werkte. Zij combineerde in die tijd het huisartsenvak met een baan als docent vaardigheidsonderwijs aan de basisopleiding Geneeskunde en werd coördinator van de toenmalige introductiecursus (ALCO-schap). Later werd zij hoofd vaardigheidsonderwijs. In 2000 besloot zij tijdelijk te stoppen als huisarts maar bleef werkzaam in de patiëntenzorg als consultatiebureauarts en (waarnemend) poortarts.

In 2001 verhuisde zij naar Maastricht en werkte tot 2007 als docent en coördinator vaardigheidsonderwijs jaar 1-3 bij het skillslab van de medische faculteit. Ze trad daarnaast ook op als docent in het Teach the Teacher programma van de UM; didactische scholing voor medisch specialisten en assistenten in opleiding tot medisch specialist.

In die tijd nam ze de beslissing om definitief te stoppen als huisarts en zich om te scholen richting het medisch onderwijs. Daartoe volgde zij van 2003-2005 de Master of Health Professions Education in Maastricht. Het afstudeerproject van de MHPE was tevens de start van het promotietraject: de MHPE thesis werd haar eerste artikel.

In 2007 verhuisde zij terug naar Groningen en ging werken aan de huisartsopleiding, eerst als onderwijscoördinator en sinds 2014 als hoofd Onderzoek en Onderwijs. In die functie is ze verantwoordelijk voor de didactische kwaliteit van het aios curriculum, de scholing van huisartsopleiders en docenten en de ontwikkeling en implementatie van een onderzoekslijn 'medisch onderwijs'. Ook in het Noorden treedt zij op als docent in het Teach the Teacher programma van het UMCG en ontwikkelt en verzorgt ze regelmatig didactische scholingen voor huisartsen (in scholingscommissies).

In haar vrije tijd is ze veelvuldig te zien, zowel als toeschouwer als actief sporter, op het hockeyveld. Ze woont met haar 2 zoons, Youri en Tim, in Haren. 
SHE dissertations series 
The SHE Dissertation Series publishes dissertations of PhD candidates from the School of Health Professions Education (SHE) who defended their PhD theses at Maastricht University. The most recent ones are listed below. For more information go to: www.maastrichtuniversity.nl/she.

Berkenbosch, L. (30-06-2014) Management and leadership education for medical residents

Bergman, E.M. (30-06-2014) Dissecting anatomy education in the medical curriculum Dijkstra, J. (25-06-2014) Guidelines for designing programmes of assessment Van Loon, M.H. (08-05-2014) Fostering monitoring and regulation of learning Frambach, J.M. (26-03-2014) The cultural complexity of problem-based learning across the world

Hommes, J.E. (26-02-2014) How relations, time \& size matter in medical education Van der Zwet, J. (30-01-2014) Identity, Interaction and Power. Explaining the affordances of doctor-student interaction during clerkships

Watling, C.J. (22-01-2014) Cognition, Culture, and Credibility. Deconstructing Feedback in Medical Education

Winston, K. (12-12-2013) Remediation Theory and Practice: Transforming At-Risk Medical Students

Kamp, R.J.A. (28-11-2013) Peer Feedback to Enhance Learning in Problem-Based

Tutorial Groups

Junod Perron, N. (24-10-2013) Towards a learner-centered approach to postgraduate communications skills teaching

Pratidina Susilo, A. (24-10-2013) Learning to be the Patient Advocate

The Development of a Communication Skills Course to Enhance Nurses' Contribution to the Informed Consent Process

Alves de Lima, A. (23-10-2013) Assessment of clinical competence: Reliability, Validity, Feasibility and Educational Impact of the mini-CEX

Sibbald, M. (09-10-2013) Is that your final answer? How doctors should check decisions Ladhani, Z. (05-07-2013) Competency based education and professional competencies: a study of institutional structures, perspectives and practices in Pakistan Jippes, M. (01-02-2013) Culture matters in medical schools: How values shape a successful curriculum change

Duvivier, R. J. (12-12-2012) Teaching and Learning Clinical Skills. Mastering the Art of Medicine

De Feijter, J.M. (09-11-2012) Learning from error to improve patient safety

Prescott, L. (09-11-2012) Ensuring the Competence of Dental Practitioners through the Development of a Workplace-Based System of Assessment 
Cilliers, F.J. (05-09-2012) The Pre-assessment Learning Effects of Consequential Assessment: Modelling how the Examination Game is Played

Spanjers, I. A.E. (05-07-2012) Segmentation of Animations: Explaining the Effects on the Learning Process and Learning Outcomes

Al-Kadri, H.M.F. (28-06-2012) Does Assessment Drive Students' Learning?

Leppink, J. (20-06-2012) Propositional manipulation for conceptual understanding of statistics

Van Zundert, M.J. (04-05-2012) Conditions of Peer Assessment for Complex Learning

Claramita, M. (30-03-2012) Doctor-patient communication in a culturally hierarchical context of Southeast Asia: A partnership approach

Kleijnen, J.C.B.M. (21-03-2012) Internal quality management and organizational values in higher education

Persoon, M.C. (19-01-2012) Learning in Urology; The influence of simulators and human factors

Pawlikowska, T.R.B. (21-12-2011) Patient Enablement; A Living Dialogue

Sok Ying Liaw, (14-12-2011) Rescuing A Patient In Deteriorating Situations (RAPIDS):

A programmatic approach in developing and evaluating a simulation-based educational program

Singaram, V.S. (7-12-2011) Exploring the Impact of Diversity Factors on Problem-Based Collaborative Learning

Balslev, T. (24-11-2011) Learning to diagnose using patient video cases in paediatrics:

Perceptive and cognitive processes

Widyandana, D. (19-10-2011) Integrating Pre-clinical skills training in skills laboratory and primary health care centers to prepare medical students for their clerkships

Durning, S.J. (09-09-2011) Exploring the Influence of Contextual Factors of the Clinical

Encounter on Clinical Reasoning Success (Unraveling context specificity)

Govaerts, M.J.B. (08-09-2011) Climbing the Pyramid;Towards Understanding

Performance Assessment

Stalmeijer, R. E. (07-07-2011) Evaluating Clinical Teaching through Cognitive

Apprenticeship

Malling, B.V.G. (01-07-2011) Managing word-based postgraduate medical education in clinical departments

Veldhuijzen, J.W. (17-06-2011) Challenging the patient-centred paradigm: designing feasible guidelines for doctor patient communication

Van Blankenstein, F. (18-05-2011) Elaboration during problem-based, small group discussion: A new approach to study collaborative learning

Van Mook, W. (13-05-2011) Teaching and assessment of professional behavior: Rhetoric and reality 
De Leng, B. (8-12-2009). Wired for learning. How computers can support interaction in small group learning in higher education

Maiorova, T. (29-05-2009). The role of gender in medical specialty choice and general practice preferences

Bokken, L. (04-03-2009). Innovative use of simulated patients for educational purposes Wagenaar, A. (18-09-2008). Learning in internships. What and how students learn from experience

Driessen, E. (25-06-2008). Educating the self-critical doctor. Using portfolio to stimulate and assess medical students' reflection

Derkx, H. (18-06-2008). For your ears only. Quality of telephone triage at out-of-hours centres in the Netherlands

Niessen, Th. (30-11-2007). Emerging epistemologies: making sense of teaching practice Budé, L. (05-10-2007). On the improvement of students' conceptual understanding in statistics education

Niemantsverdriet, S. (26-07-2007). Learning from international internships: A reconstruction in the medical domain

Marambe, K. (20-06-2007). Patterns of student learning in medical education - A Sri Lankan study in traditional curriculum

Pleijers, A. (19-01-2007). Tutorial group discussion in problem-based learning

Sargeant, J. (21-09-2006). Multi-source feedback for physician learning and change

Dornan, T. (12-06-2006). Experience-based learning

Wass, V. (12-05-2006). The assessment of clinical competence in high stakes examinations

Prince, K. (21-04-2006). Problem-based learning as a preparation for professional practice 